\title{
California Urban Agriculture Food Safety Guide: Laws and Standard Operating Procedures for Farming Safely in the City
}

Produced by UC Berkeley, UC Cooperative Extension, and the Sustainable Economies Law Center

JENNIFER SOWERWINE, University of California, Berkeley, University of California Cooperative Extension, Metropolitan Agriculture and Food Systems Specialist;

CHRISTINA OATFIELD, Sustainable Economies Law Center, Policy Director;

ROB BENNATON, University of California Cooperative Extension, County Director for Alameda and Contra Costa Counties and Bay Area Urban Agriculture Advisor;

ALDA PIRES, University of California, Davis School of Veterinary Medicine, University of California Cooperative Extension, Urban Agriculture and Food Safety Specialist

RACHEL SURLS, University of California Cooperative Extension, Sustainable Food Systems Advisor;

VALERIE BOREL, University of California Cooperative Extension, Program Representative; and

ANDRE BISCARO, University of California Cooperative Extension, Agriculture and Environmental Issues Advisor

\section{Section I. Food Safety Considerations for Urban Agriculture}

\section{INTRODUCTION}

rban agriculture is proliferating across the state of California on both public and private lands, taking the form of school, community, church, and backyard farms and gardens, vertical and rooftop farms, for profit and nonprofit farms, as well as a whole suite of indoor and outdoor greenhouse growing. According to recent UC Cooperative Extension efforts to map regional food growing sites, there are approximately 160 East and South San Francisco Bay Area urban and community farms and gardens. These urban farms are transforming the landscape of food production, helping to address urban food insecurity, creating opportunities for micro-enterprise development, and educating our youth and the public about the value of growing and eating healthy foods.

The value of urban farming is indisputable, as studies provide mounting evidence of the myriad social, economic, ecological, recreational, therapeutic, and nutritional benefits of urban agriculture (Santo et al. 2016). Urban farmers grow a wide variety of fruit, vegetables, herbs, chickens (for both eggs and meat), and small livestock. Some are growing for home consumption, others are processing, sharing, selling, or exchanging their urban-produced foods through both formal and informal arrangements. Regardless of the nature or scale of operation, it is important that everyone involved in the production and exchange of urban-produced foods follows general food safety guidelines to ensure the health and safety of their family, their workers, and others who may consume the foods they produce. Following food safety guidelines not only helps minimize the risk of contamination and illness, it helps to protect the reputation of urban farms and ensures compliance with California laws.

The purpose of this guide is to provide urban food producers in California with an overview of food safety laws and regulations that may impact their operations, as well as guidelines for best practices, or Good Agricultural 
Practices (GAPs), that can help minimize the risk of contamination in the production and exchange of urban-produced foods. This guide will cover best practices for fresh produce safety, urban soils safety, as well as food safety in the context of small animal husbandry (poultry and small livestock) in the urban environment.

\section{NEW OPPORTUNITIES FOR URBAN AGRICULTURE IN CALIFORNIA}

This is an exciting time with expanding opportunities for urban farmers in California. The California Legislature recently passed several laws creating incentives and opportunities for increased production and exchange of urban-produced foods. In 2012, the California Legislature passed the California Homemade Food Act (AB 1616), commonly known as the "Cottage Food Law," which allows for small-scale commercial food processing in a home kitchen so long as foods produced for sale are "not potentially hazardous," which includes low-risk food products such as breads, pies, tortillas, jams, and numerous dried goods including dried fruits, dried vegetables, and other dried foods like herbs, spices, teas, and so on. In 2013, the California Legislature passed the Urban Agriculture Incentive Zones Act (AB 551) to allow city and county governments to choose to create tax incentives for urban land dedicated to urban agriculture for five or more years. The law was renewed in 2017 (now renamed AB 465). Several local governments have used this law to create tax incentives for urban agriculture, so there are now opportunities for reduced property tax bills available to property owners in San Francisco, Sacramento City and County, Santa Clara County, and the cities of San Jose, Los Angeles, San Diego, and Long Beach. Additional local governments are considering adopting tax incentives under this law.

In 2014 and 2015, the Legislature passed a series of bills (AB 1990 and AB 234, respectively) that set clear, statewide legal standards for "food safety for urban farms," community gardens, school gardens, culinary gardens, backyard gardeners, and gleaners who sell or donate food to the public. Previously, there was confusion around what food safety laws applied to such farms and gardens, if any, which caused uncertainty around whether produce grown at these farms and gardens was eligible to be sold to cottage food operations, stores, and restaurants. As a result of AB 1990, these types of very small-scale California farmers are now legally called "community food producers," and they do not need to register with a regulatory agency in most cases but do need to follow a set of Good Agricultural Practices (GAPs) as outlined in the California Department of Food and Agriculture (CDFA) Small Farm Food Safety Guidelines.

In 2016, the Legislature passed the Seed Exchange Democracy Act (AB 1810) to exempt casual seed swaps from costly regulations designed for large industrial seed producers, so small-scale farmers and gardeners can now freely give away and trade seeds. The legality of seed libraries was clearly established by the law, which perhaps played a part in the spread of seed libraries across many parts of California. As recently as 2017, the Farmer Equity Act (AB 1348) was signed into law, directing the CDFA to take additional steps to make sure that its resources, policies, and programs are more inclusive of "socially disadvantaged farmers," including farmers of color, Native American farmers, and urban farmers.

These new laws have created opportunities for urban food producers to expand and to distribute food in a greater variety of ways legally, provided that the restrictions and requirements of these laws are followed, paving the way for even more availability of local produce.

Additionally, over the past decade, many city governments in California have revised local zoning laws to legalize and recognize urban agriculture in residential and other zones. Among the trailblazers in recent efforts to promote urban agriculture in local land use laws are the cities of San Francisco, San Diego, Hayward, and Sacramento. Many other cities have since followed with progressive urban agriculture zoning laws.

\section{WHAT IS FOOD SAFETY AND WHY IS IT IMPORTANT?}

About 48 million people ( 1 in 6 Americans) get sick each year, 128,000 are hospitalized, and 3,000 die from foodborne diseases (CDC 2016a). Salmonella, E. coli O157:H7, and Campylobacter are major causes of foodborne diseases in the United States. While most foodborne illnesses are caused by biological pathogens (such as viruses or bacteria), chemical 
contaminants found in some urban soils can also cause illness.

To minimize the risk of biological or chemical contamination, it is important to identify the potential sources or pathways of on-farm contamination, and then develop steps or strategies to minimize the risk of contamination in production, harvesting, processing, storage, and distribution. Consumers should always take precautionary measures and wash any produce before consuming it, regardless of its origin. However, this guide focuses on minimizing the risk of contamination at the urban farm level.

Urban farms are somewhat unique with respect to potential risks of contamination. In some cases, urban farming may pose a lower risk of contamination. For example, there may be a lower risk of microbial contamination from water, as most urban farms rely on municipal water as a primary source of irrigation, which is required to meet state or federal drinking water standards. In other cases, there may be an elevated risk. For example, urban soils may have a higher risk of containing pollutants. There may also be an elevated risk of pathogen exposure associated with raising chickens and livestock in urban environments. For example, human Salmonella outbreaks linked to contact with live poultry have increased in recent years as more people keep backyard flocks (CDC 2016b). It is important to understand the risk of exposure to pathogens carried by poultry or livestock, particularly in dense urban spaces where animals are often raised in close proximity to humans and vegetable crops. Because of the diversity of urban agriculture activities (backyard, educational, farm to school, or foodbank) vulnerable populations such as the young and elderly may be at higher risk of illness through exposure.

Each farm has its own unique land use history, participant demographic, type of production, and associated risks. As such, it is important to assess and develop a food safety program that best fits your own operation.

In 2016, the CDFA issued a set of food safety guidelines for small farms, which all farmers are expected to follow. This publication draws on best practices outlined in the CDFA food safety guidelines, tailored to farming in an urban environment. Additional materials are included regarding food safety guidelines for safe soils, safe chicken and livestock raising, and egg handling. In addition to helping identify potential sources of contamination on the farm, this guide provides detailed information, templates, and resources for developing customized food safety policies and a set of standard operating procedures (SOPs) to minimize the risks of contamination identified for your operation. It also provides guidelines for worker and volunteer training, as well as a set of record-keeping sheets to assist with tracking and monitoring your food safety program.

\section{REFERENCES}

Santo, R., A. Palmer, and B. Kim. 2016. A review of the benefits and limitations of urban agriculture. Johns Hopkins Center for a Livable Future.

Center for Disease Control and Prevention (CDC). 2016a. Annual report to the Secretary, Department of Health and Human Services. CDC website, www.cdc. gov/oid/docs/BSC_OID_FSMA_Surv_WG_2016_ Annual_Report.pdf.

\footnotetext{
. 2016b. Eight multistate outbreaks of human Salmonella infections linked to live poultry in backyard flocks (final update). CDC website, https:// www.cdc.gov/salmonella/live-poultry-05-16/.
} 


\section{Section II. Food Safety Laws for Urban Agriculture}

\section{ARE URBAN FARMS SUBJECT TO THE FOOD SAFETY MODERNIZATION ACT?}

\section{About the Food Safety Modernization Act}

The Food Safety Modernization Act (FSMA) was passed by the U.S. Congress in 2011. The law has received a great deal of attention from the press, farmers, food safety advocates, organizations that support small-scale farmers, and others because it represents landmark changes in federal law pertaining to food safety, especially for growers, packers, and distributors of fresh fruits, vegetables, nuts, and herbs. However, many very small farms, such as community gardens and urban farms, are exempt from certain components of FSMA or are entirely exempt. Below are explanations of exemptions that are likely to apply to many of these farms and gardens. This publication will not cover all the FSMA requirements, as there are other guides and training programs that do so. Those other sources include the Food and Drug Administration (FDA), the agency that implements FSMA, as well as nongovernmental organizations listed in the Resources section at the end of this publication.

FSMA contains two main parts that apply to small produce farms: the Produce Safety Rule and the Preventive Controls Rule. The Produce Safety Rule is more directly relevant to farms because it regulates the growing, harvesting, and packing of produce. The Preventive Controls Rule is generally designed for food manufacturing and for facilities that pack and hold produce; farms are expressly exempt from this rule (21 CFR $\$ 117.5(\mathrm{k})(1))$. As far as FSMA is concerned, a farm is in "one general (but not necessarily contiguous) physical location devoted to the growing of crops, the harvesting of crops, the raising of animals (including seafood), or any combination of these activities," and it may include space devoted to packing or holding agricultural products, among other related activities (21 CFR $\$ 1.227$ ).

\section{Exemptions from FSMA Produce Rule}

There are two main categories of exemptions for farms under FSMA: fully exempt and qualified exempt (or partially exempt).

\section{Full Exemptions}

Produce that is produced by an individual for personal consumption or produced for consumption on the farm of origin or another farm under the same management is exempt-no matter what crops you grow or how much you grow of those crops (CFR Title $21 \S 112.2(\mathrm{a})(2))$.

Produce that is rarely consumed raw: The FDA has developed a list of produce that is rarely consumed raw, which is entirely exempt from FSMA's produce rule, so a farm that produces only the following produce is entirely exempt (CFR Title 21 $\$ 112.2(\mathrm{a})(1))$. It doesn't matter how much you grow of these crops; if you only grow crops on this list, you are exempt.

- asparagus

- beans (black, great northern, kidney, lima, navy, pinto)

- beets, garden (roots and tops)

- beets, sugar

- cashews

- cherries, sour

- chickpeas

- cocoa beans

- coffee beans

- collards

- corn, sweet

- cranberries

- dates

- dill (seeds and weed)

- eggplants

- figs

- ginger

- hazelnuts

- horseradish

- lentils

- okra

- peanuts

- pecans

- peppermint 
- potatoes

- pumpkins

- squash, winter

- sweet potatoes

- water chestnuts

Farms with $\$ 25,000$ or less annual sales of produce averaged over the past 3 years, adjusted for inflation using 2011 as the baseline year for calculating the adjustment, are exempt. This means that a farm could have greater than $\$ 25,000$ in sales of produce one year, but if the 3-year average of produce sales from that farm average no more than $\$ 25,000$ adjusted for inflation, then the farm is exempt (CFR Title $21 \S 112.4)$. Because this rule adjusts the dollar amount limit based on inflation, in 2016 the exemption was for up to $\$ 26,956$, and the FDA provides useful tables showing inflation-adjusted figures at the FDA's FSMA Inflation Adjusted Cut Offs website, https://www.fda.gov/Food/GuidanceRegulation/ FSMA/ucm554484.htm.

\section{Qualified Exemptions}

Farms with $\$ 500,000$ or less annual sales of produce, with a majority of sales to "qualified end-users" (such as end consumers, restaurants, grocery stores [not including grocery store chain distribution centers], and other retail food establishments) are eligible for a "qualified exemption," meaning the farm is exempt from some, but not all, FSMA requirements (CFR Title $21 \S 112.5$; also see $\$ 112.6$ and $\$ 112.7)$. The requirements for farmers using the "qualified exemption" include basic record-keeping requirements and labeling requirements, described in more detail below.

Qualified end-user means the consumer of the food (where the term consumer does not include a business) or a restaurant or retail food establishment (where a retail food establishment is any enterprise that sells food primarily to end consumers (CFR Title $21 \$ 1.227)$ ) that is located 1) in the same state or the same Indian reservation as the farm that produced the food or 2) not more than 275 miles from the farm that produced the food (CFR Title $21 \$ 112.3$ ).

Note that the FDA has the right to withdraw a farm's exemption in the event of an active investigation of a foodborne illness outbreak that is directly linked to the farm, or if the FDA determines that withdrawal is necessary to prevent or mitigate a foodborne illness outbreak based on conduct or conditions associated with the farm that are material to the safety of the food (CFR Title $21 \$ 112.201$ ).

Caution about relying on exemptions from the FSMA Produce Rule: If your farm currently meets the criteria for the $\$ 25,000$ exemption or the qualified exemption, be aware that it could hinder your ability to sell to a produce distributor or wholesaler in the future, because under the Preventive Control Rule, distributors must source all their raw materials and ingredients from approved suppliers, which are suppliers (i.e., farmers, among other food producers) who engage in food safety practices such as having on-site audits, testing, maintaining food safety plans and records, and other practices, which your farm may or may not fulfill if you are relying on an exemption. FDA rules on this matter do not necessarily prohibit a distributor regulated by FSMA from purchasing produce from an exempt or qualified exempt farm, but the rules require the buyer to consider the farm's history of compliance and use of good agricultural practices (CFR Title $21 \S 117.410$ ).

Therefore, exempt and qualified exempt farms may still be able to sell to a larger produce distributor or other wholesaler. In these cases, it will be especially important for the farm to have thorough documentation about its robust food safety practices, compliance with the terms of FSMA exemptions, compliance with other applicable food safety laws, and implementation of good agricultural practices. Under FSMA, farmers would provide a letter to the buyer with these assurances.

\section{Record-Keeping Requirements for "Qualified Exempt" Farms}

If relying on the "qualified exemption," farms must keep records to show they are eligible to use that exemption, including a written record reflecting annual review and verification of the farm's continued eligibility (CFR Title $21 \S 112.7$ ). Records should generally be retained for 3 years to show eligibility for the "qualified exemption" (CFR Title 21 $\$ 112.164)$.

Records should be created at the time of the activity recorded and should include the following:

- the name and location of your farm

- actual values and observations obtained during monitoring

- a description of produce applicable to the record

- the location of a growing area (e.g., a specific field) 
or other area (e.g., a specific packing shed) applicable to the record

- the date and time of the activity documented (CFR Title $21 \$ 112.161)$

\section{Labeling and Signage}

Farmers relying on the qualified exemption must prominently and conspicuously display, at the point of purchase, the name and complete business address (including street address or P.O. Box, city, state, and zip code) of the farm where the produce was grown. This information can be presented on a label, poster, sign, placard, or documents delivered contemporaneously with the produce in the normal course of business, or, in the case of Internet sales, in an electronic notice (such as an email) (CFR Title $21 \$ 112.6)$. These labeling requirements are similar to those required of California farmers in various scenarios described in the section on California law. Farmers who comply with the more nuanced California labeling requirements will simultaneously satisfy the federal FSMA labeling requirements. Note, however, that record-keeping requirements vary between FSMA qualified exempt farms and California food safety laws for small farms.

\section{EXEMPTION FROM FSMA BUT SUBJECT TO BUYER REQUIREMENTS}

California urban farmers may be entirely exempt from FSMA, or partially exempt per the qualified exemption, but they are still required to follow GAPs. Furthermore, some buyers may also have their own internal food safety requirements. It is recommended that urban food and agricultural producers who are interested in selling to specific retail outlets, wholesalers, schools, or other institutional buyers contact those buyers directly to ask what specific food safety requirements they may have. They may request evidence of a food safety plan, having participated in a food safety training (such as a Produce Safety Alliance training), or even having a third-party audit. For more information on food safety training opportunities and obtaining a third-party audit, please contact the University of California Cooperative Extension or the Community Alliance with Family Farmers (CAFF).

\section{OVERVIEW OF CALIFORNIA LAWS THAT APPLY TO URBAN FARMS}

Multiple sources of California law apply to urban farms. Some of these laws apply to small-scale farming generally, some to urban agriculture specifically, and others are more generally applicable to agriculture, food safety, and commerce more broadly. This publication focuses on food safety laws applicable to urban farms and does not cover all general business regulations that likely apply to a commercial urban farm. One major body of law is the California Food and Agricultural Code (statutes that are controlled by the state legislature), where general laws applicable to selling produce are found. Another body of law is Title 3 of the California Code of Regulations (abbreviated as "CCR" in this publication), which contains rules controlled by a state agency. Title 3 of the CCR includes standard container rules, farmers' market rules, and other agricultural matters. Finally, the Health and Safety Code (statutes that are controlled by the state legislature) contains all of California's food safety laws that apply to commercial kitchens, restaurants, cafes, grocery stores, and food manufacturing facilities.

The new law that defines and regulates "community food producers" discussed in the introduction and described in more detail in this section is located in the Health and Safety Code, even though agricultural matters are otherwise generally in the Food and Agricultural Code or in Title 3 of the CCR. Matters related to preparing or processing food are generally covered in the Health and Safety Code. The community food producer law is a unique example of specific agricultural laws appearing in the Health and Safety Code.

Finally, this publication will refer to the Small Farm Food Safety Guidelines, which are neither statutes nor rules, but they are distributed by the CDFA as guidelines for best practices that farmers selling at farmers' markets and community food producers are required to follow.

California statutes can be found online at the California Legislative Information website, http://leginfo. legislature.ca.gov/ (click on "California Law" in the menu bar at the top of the page).

The regulations (referred to as CCR in this publication) can be found at the California Office of Administrative Law website, http://ccr.oal.ca.gov/. 


\section{California Department of Food and Agriculture's Small Farm Food Safety Guidelines}

The CDFA has published a set of guidelines for farmers on how to safely grow, harvest, and handle fresh produce. The practices described in the guidelines are now required practices for most small farms in California, including all "community food producers" (which includes most urban farms, as described below), all farmers selling at certified farmers' markets, farms with CSA (Community Supported Agriculture) programs, and gleaners. Additionally, in most cases, urban farms selling produce directly to a restaurant, grocery store, or other retail store must follow GAPs as outlined in these guidelines. Even some transactions where no money is exchanged may be subject to these guidelines. For example, gleaning organizations and donors who provide produce to food banks and other charities must follow best practices as described in the guidelines.

Generally, any farm or organization in California that grows or distributes produce offered for "public

\section{California Small Farm Food Safety Guidelines}

Fruit and vegetable consumption has grown significantly in the past two decades as the health benefits of these crops have been emphasized. Unfortunately, the incidence of foodborne illnesses has also increased. In some cases, the financial impact on the growers of the crops associated with these incidents has been devastating. This means that it is important for all growers to be aware of food safety practices that minimize contamination of their crops with human pathogens. The most important disease organisms are Salmonella, E. coli O157:H7, Listeria, Shigella, and Bacillus cereus. The primary pathways for these pathogens to enter the field or packing shed are:

- contaminated irrigation or processing water

- poor worker health and hygiene

- improperly aged or treated organic soil amendments (manure, etc.)

- domestic or wild animals entering the field

- contaminated harvest equipment

- inadequate or unsanitary processing and storage conditions

- improper transportation

The following checklist of recommendations should be considered during crop production, harvest, processing, and transport. consumption" is subject to these guidelines. Therefore, urban farmers, community gardens, and backyard gardeners should all read and implement the practices outlined in these guidelines before offering food for public consumption, whether by sale or by donation. Make sure that all people involved in planting, harvesting, or handling food at your farm, garden, or gleaning organization are familiar with these guidelines. If you are growing produce exclusively for personal consumption, then following the guidelines is not required; however, it is generally advisable that even casual backyard gardeners follow these guidelines in order to minimize the risk of illness.

The Small Farm Food Safety Guidelines are included below and are also available in several different languages at the CDFA website, http://www. cdfa.ca.gov/is/i_\&_c/sffsg.html. To assist the urban grower with implementation, we provide supplemental information on specific practices and standard operating procedures in the guidelines below.

\section{Prior to Planting}

- Keep records of all farm activity, especially food safety practices.

- If manure will be used as a fertilizer, apply untreated manure in the fallow period after the last harvest and incorporate it as soon as possible. Apply it at least 120 days before harvest of a crop that touches the ground (lettuce, carrots) and at least 90 days before harvest for a crop that does not touch the ground (tomato, broccoli).

- Be sure that there is a buffer between the production field and any source of contamination, including, but not limited to, the following: manure and compost storage, concentrated animal feeding operations, grazing or open range areas, surface water, sanitary facilities, dump sites, and composting operations. Appropriate distance should take topography and climate into consideration (i.e., slope, wind direction, rainfall, and runoff patterns).

- Obtain municipal water test results if farming on city water, or test irrigation water for generic $E$. coli, and, if contaminated, find the source and fix it, or request that your water supplier do so.

- Train your employees about hygiene (hand- 
washing, etc.), proper sanitation practices, what to do if bodily injury occurs, and other aspects of foor safety that apply to them. Do follow-up training during the growing season.

- Evaluate fields for evidence of animal entry (domestic or wild). If you see animal signs, use mitigation procedures (fences, noisemakers, etc.) Avoid harvest if crops have been contaminated (feces on crop, significant animal damage to crop, such as bites out of crop, plants trampled by animals, etc.).

- Assess adjacent lands for possible sources of field contamination (e.g., landfills, concentrated animal feeding operations), and take corrective actions if needed.

\section{During the Growing Season}

- Provide proper sanitation and hand-washing facilities in an area outside of the field. Provide an area outside of the field for eating, breaks, smoking, and storage of personal items.

- Do not allow pets or other domestic animals to wander onto the field, and continue to look for signs of wild animals. Minimize standing water in the field because it attracts wildlife.

- If you side dress with composted manure, try to minimize manure contact with the crop and incorporate it, if possible.

- Clean and sanitize tractors and other implements that were used in manure application and incorporation prior to entering the field.

- Test irrigation water as close to point-of-use as possible at least once during the growing season, and more often if you use surface water.

- Ensure that water used for spray applications of pesticides and fertilizers is not contaminated.

- Consider using drip irrigation wherever possible. It minimizes the risk of contamination because above-ground plant parts are not directly wetted.

- Sick employees should not have direct contact with produce. Assign them other duties while they are sick or send them home. Employees who cut themselves should wear gloves and use bandages until the wound is healed.

\section{Harvest}

- Continue to emphasize worker hygiene, and monitor employees for symptoms of illness and for wounds.

- Clean and sanitize harvesting equipment at least once a day or more often, if needed. Scrub all harvest crates and buckets with a firm bristle brush and soap when they are dirty, prior to rinsing and sanitizing.

- Cover clean bins to avoid contamination.

- Do not allow workers to stand or place personal items in bins.

- Remove field soil from the outside of bins prior to moving them into packing areas. Emphasize hygiene to U-Pick customers.

- Use clean water and ice made from clean water during field processing.

- Remove or prevent the harvest of any potentially contaminated produce if signs of animal intrusion are detected.

\section{Postharvest Processing and Storage}

- Clean facilities, equipment, and food contact surfaces thoroughly, and then sanitize just before the first use and then once a day during use or more often, if needed.

- Provide sanitary and hygiene facilities and an area for smoking, meals, breaks, and personal item storage for employees away from processing and storage areas. Continue to monitor use.

- Use a potable water source for processing, and use ice made from potable water. Wash, rinse, and sanitize storage facilities.

- Fix or fill in any cracks or defects in the processing and storage building to keep out pests. Establish an ongoing pest control program (rodents, birds, etc.).

- Ensure that refrigeration equipment is working properly. Measure and record temperatures at least once daily.

- If employees are working with animals, change coveralls and boots before working with crops and entering the packing area to minimize crosscontamination.

- Use chlorinated water and other labeled disinfectants to wash produce; make sure to read the label of the product and determine if it is allowed to be used on produce and that it is being used correctly.

- Store packaging materials in a clean, covered area.

- Do not load refrigeration rooms beyond their cooling capacity.

\section{Transportation}

- Ensure that transport vehicles are clean and sanitary.

- Be sure that vehicles that have carried live animals or harmful substances (pesticides, etc.) are thoroughly washed, rinsed, and sanitized before shipping produce. 
- Use refrigerated trucks when possible.

- Be sure that each package leaving the packing area can be traced to the field of origin and date of packing.

\section{Record Keeping}

This is very important in documenting the steps you take to ensure that you have complied with food safety recommendations. Some of the important things that need to be recorded are

- planting date(s)—varieties, suppliers, etc.

- applications of fertilizer, pesticides, or any other inputs; water testing dates and results

- employee training - type of training (general safety, food safety, etc.), dates, who was trained, follow-up training

- animal entry-dates when checked or observed, type(s) of animal signs, what action(s) you took to try to solve or mitigate the problem

- equipment maintenance-dates, type of maintenance, which piece of equipment, cleaning

- harvest date(s) - sanitation of harvest implements and harvest containers

- cleaning schedule for processing and storage facilities

- pest control program in processing and storage facilities-who does the program, treatment, and trapping dates

- maintenance of refrigeration equipment and temperature of storage rooms

- dates of farmers' markets or other marketing options

- package identification

\section{Hygiene}

To prevent field and packing shed workers from contaminating crops, make sure these rules are followed:

- Workers should be trained in hand-washing-use plenty of liquid soap and water, wash for at least 20 seconds, clean under fingernails and between fingers, rinse under clean water, and dry hands with a single-use towel. Wash hands before starting to work, after each break, after handling unsanitary items such as animals, manure, etc., and after usins the toilet.

- Workers should not eat, chew gum, use tobacco, spit, urinate, or defecate while in growing or processing areas.

- Workers should use the toilet and hand-washing facilities, and use them properly.
- Workers who show signs of diarrhea, vomiting fever, jaundice, or infected wounds should not handle fresh produce.

Workers should use single-use cups, their own reusable water bottle, or fountains for drinking water.

The grower, packer, or labor contractor should also provide signs that reinforce good hygiene, both in the field and in the packing shed.

\section{Water Testing}

Water needs to be tested to know whether it is contaminated with unacceptable levels of bacteria. If using municipal water, request a copy of their water test for your files. One can still test the water if desired. While there is no standard for food safety testing levels, a number of commodity groups have used the recreational water standard as a safe level. Water should be tested as near to the point-of-use as possible. All of the water used to produce and process crops should be tested (pesticide spray water, water used in processing, etc.).

\section{Manure}

Unprocessed manure is a perfect medium to support bacterial growth. Many food safety programs do not allow the use of unprocessed manure. Only properly composted or aged manure can be used. They also require that root crops not be grown for one year after manure application. If untreated manure must be applied shortly before planting, apply and incorporate at least 2 weeks before planting, and do not harvest the crop for 120 days after application. If the 120-day waiting period is not feasible, apply only properly composted or aged (at least 1 year) manure. (See Section VI for detailed discussion of how to properly compost, including time and temperature requirements.)

\section{References}

Food and Drug Administration. 2009. Draft guidance for industry: Guide to minimize microbial food safety hazards of tomatoes. Washington D.C.: Food and Drug Administration, HHS.

California Leafy Green Products Handler Marketing Agreement (LGMA). 12012. Commodity specific food safety guidelines for the production and harvest of lettuce and leafy greens.

Sacramento, CA: California Leafy Green Handler Marketing Board. Rangarajan, A. 2000. Food safety begins on the farm: A grower's Guide. Ithaca, NY: Cornell University Press. 


\section{Community Food Producers}

A new law that applies to mostly urban (and some rural) producers of fresh fruits, vegetables, and eggs in California went into effect in 2015. It defines anyone growing such produce on land that is not zoned as agricultural as a "community food producer" and requires these producers to follow the Small Farm Food Safety Guidelines and certain labeling requirements (Health and Safety Code $\$ 114376$ ). Though the law initially allowed local environmental health departments to require these producers to register with the department in certain situations, since the beginning of 2016 numerous exemptions from registration have been in place. However, food safety and labeling requirements still apply to all community food producers (Health and Safety Code $\$ 114376(c))$.

All community food producers, whether exempt from registration or not, must follow the California Small Farm Food Safety Guidelines. Additionally, all community food producers must follow basic labeling requirements when selling or giving away produce. At a farm stand where the food is grown, community food producers must have a sign with their name and address displayed on-site. When selling or donating produce elsewhere, they must label produce with their name and address if the produce is sold in a package. When selling directly to the public (rather than through a food facility, such as a store or restaurant), community food producers and gleaners must keep records of the type of food sold and the date. These records must be kept for 30 days. For example, if your farm operates a produce stand once per week, you must keep a list of the products you sold at the farm stand for each date you operated the farm stand.

\section{Gleaners}

A gleaner is defined as "a person who legally gathers remnants of an agricultural crop or harvests part of, or all of, an agricultural crop made available by the owner of the agricultural crop" (Health and Safety Code $\$ 113796)$. Gleaners often gather fruits and vegetables from residential areas, community gardens, and small farms in order to access low-cost food or prevent waste. Many gleaning organizations in California collect fresh produce to deliver to charitable organizations, such as food pantries. These organizations and other gleaners should be aware of the new requirements regarding community food producers described above. Generally, gleaners are subject to the safe food handling, labeling, and record-keeping requirements, just as are community food producers. When working with community food producers or any farmers, gleaners should make sure their sources of produce comply with applicable food safety laws.

\section{Donating Gleaned Produce}

As of 2016, new provisions of the California Health and Safety Code clarify that gleaners may collect whole, uncut fruits and vegetables to donate to a food bank or food kitchen. In this scenario, a gleaning organization does not need to register with the local department of environmental health. Additionally, community food producers are exempt from registration when their agricultural products are donated to a food bank or food kitchen that provides food at no cost to consumers. This means that gleaners can aggregate whole, uncut fruits and vegetables from community food producers to donate to a food bank, and both the community food producer and gleaner do not need to file paperwork with the health department or pay associated fees (Health and Safety Code $\$ 114376)$. But remember that the food safety guidelines, labeling, and record-keeping requirements still apply to both gleaners and community food producers.

\section{Registration Generally Not Required for Community Food Producers and Gleaners}

The following situations illustrate some instances when community food producers and gleaners are exempt from registration requirements:

- A gleaner sells or donates produce from a community food producer to consumers, and the producer or gleaner keeps records for 30 days of the type of food sold or donated and the date.

- A gleaner donates produce of a community food producer to a food bank or food kitchen, and the producer or gleaner keeps records for 30 days of the type of food donated (or sold) and the date it was donated.

- A community food producer or gleaner provides produce directly to the public at their farm, garden, or some other premises controlled by the community food producer.

- A community food producer donates produce to a food bank or food kitchen that provides food at no cost to consumers. 
- A community food producer sells produce directly to a food facility that is permitted by a health regulatory agency, such as a corner store or grocery store that has a perm to operate from the local Department of Environmental Health (Health and Safety Code $\$ 114376)$.

\section{When Are Community Food Producers and Gleaners Required to Register with an Agency?}

Because so many transactions are exempt from registration (i.e., all of those listed in the prior paragraph) under state law, there are very few situations in which a community food producer or gleaner would need to register with an environmental health department. One type of transaction that is not exempt from registration is where a community food producer has a produce stand at a festival, other temporary event, or other site that is not at the farm or garden where produce is grown. This could be done lawfully if the community food producer obtains a Temporary Food Facility permit from the local Department of Environmental Health. Contact your local department for information on fees and the application process.

\section{OTHER REQUIREMENTS THAT MAY APPLY TO URBAN FARMS}

\section{Certified Producer's Certificate}

The Certified Producer's Certificate was developed to ensure that farmers selling at certified farmers' markets are in fact selling produce that they grew and not someone else's agricultural products (unless the producer of the other agricultural products is also a certified producer and is identified on that seller's certified producer's certificate and properly labeled at the farmers' market booth). This certificate is required of any farm seeking to sell at a certified farmers' market in California. The application for a Certified Producer's Certificate includes a declaration by producers that their produce is grown, harvested, and handled in accordance with the Small Farm Food Safety Guidelines (Food and Agricultural Code $\$ 47020(\mathrm{c}))$. There are numerous other requirements for selling at a certified farmers' market that are not covered in this guide, so check with other resources or the farmers' market manager for more details if you plan to sell at a certified farmers' market.
Farmers seeking a Certified Producer's Certificate may apply online at the CDFA website, https://www. cdfa.ca.gov/egov/farmersmarket/.

\section{Community Supported Agriculture (CSA)}

Anyone seeking to sell produce advertised as a Community Supported Agriculture (CSA) share or subscription is required to register with the CDFA. The registration includes a declaration by producers that they will follow the Small Farm Food Safety Guidelines (Food and Agricultural Code $\$ 47060$ to 47062). The fee for registering a CSA operation is currently $\$ 75$ annually. Each amendment to the registration requires an additional $\$ 25$ fee.

The CSA registration form is available at the CDFA website, http://www.cdfa.ca.gov/is/i_\&_c/pdfs/ CSAProducerRegistrationRemittanceForm.pdf.

\section{Standard Container Requirements for Farmers Selling Fresh Produce}

Fresh fruits and vegetables must generally be sold in containers of standard dimensions. The specifications for standard containers are detailed in Title 3 CCR $\$ 1380.19$. These so-called "standard pack" requirements are designed for produce that is sold through large distribution supply chains and are not generally convenient or practical for a small farmer selling to a store or restaurant, but they still apply in some circumstances.

However, certain sales known as "direct marketing" in California law are exempt from these "standard pack" requirements, including

- sales at certified farmers' markets (Title 3 CCR $\$$ 1392.1(d))

- sales at or near the site of the farm (Title 3 CCR $\$$ 1392.1(d))

- sales or donations to a charitable organization within the state for charitable purposes (Title 3 CCR $\$ 1390(f)$ )

Certain types of fresh fruits and vegetables do not have standard pack requirements, regardless of the type of sale or delivery involved (i.e., if the produce you are selling is not on the list of fruits and vegetables with standard container rules listed below, then no standard container rules apply).

Individual consumers, grocery stores, and restaurants can purchase fresh produce from farmers at the site of a farmers market, at a farm, or at a roadside stand near a farm without the farmer having to sell 
the produce in standard container sizes. A farmer delivering to a restaurant or store, however, must still comply with standard pack rules (Food and Agricultural Code $\$ 47002$ and Title 3 CCR $\$ 1392.19$ ).

The following fruits and vegetables must be packed and sold in containers of specific dimensions:

- apples

- apricots

- $\operatorname{artichokes}$

- avocados

- baskets of fruits

- cabbage

- cantaloupe

- cauliflower

- celery

- cherries

- citrus fruits

- grapes

- lettuce

- melons (and honeyball melons)

- nectarines

- peaches

- plums and fresh prunes

- sweet potatoes

- tomatoes

The regulations describing the container dimensions are in Title 3 CCR, $\$ 1380.19$. Other produce not listed above does not need to be sold in containers of specific dimensions, regardless of the method and location of the sale.

\section{Labeling and Record-Keeping Requirements for Community Food Producers}

\section{Selling or Donating Produce to a Retail Food Facility}

Farmers providing produce to a retail food facility such as a restaurant or grocery store must ensure that the produce containers have the following information:

- name, address, and zip code of the producer

- name of the produce in the package

- quantity of the produce in the package (California Food and Agricultural Code $\$ 47002(\mathrm{c})$ )
Additionally, the farmer must provide the food facility with a receipt that contains the information above and the date (California Food and Agricultural Code $\$ 47002(\mathrm{e})$ and Title 3 CCR $\$ 1392.4)$.

\section{Selling or Donating Produce Directly to Consumers}

When selling directly to end consumers, for example at a farm stand or farmers' market booth, community food producers selling agricultural products in any packaging must adhere to the labeling requirements listed in the section above. For agricultural products sold with or without packaging directly to consumers, conspicuous signage must include the name and address of the community food producer (California Health and Safety Code $\$ 114376(a)$ ).

\section{Additional Notes on Signage and Record-Keeping}

California law directs community food producers to keep records for 30 days after the sale when selling directly to consumers (California Health and Safety Code Section 114376(d). However, if your farm or garden is "qualified exempt" under FSMA, you are required to keep records for 3 years to prove your "qualified exempt" status.

Additional signage requirements apply to farmers selling at a certified farmers' market, and the market manager can provide more detailed information, or you can read more in the California Code of Regulations (e.g., Title 3 CCR $\$ 1392.4$ and California Food and Agricultural Code $\$ 47004$ ).

Though not required by California law, it is advisable to note prices in these records for accounting purposes and for demonstrating compliance with FSMA exemptions.

\section{Produce Dealers Need to Register with the CDFA}

Does your business intend to purchase produce that was grown by a separate enterprise and then resell that produce to a retail store or to another food business? If you are acting as an intermediary in this way, then you are considered a "dealer" by the California Produce Dealers Act, and you must register as such with the CDFA. If your business is a corner store, grocery store, or other retail business with a fixed location and it only sells directly to consumers (not to other businesses), then this registration requirement does not apply to you; this registration requirement only applies to businesses that sell produce at wholesale. For example, you would need a Produce Dealer registration if you started a business that 
collected produce from several different urban farms and sold the produce to grocery stores, where the produce is then sold to consumers. An urban farm that sells produce from its own farm and produce from a few other farms or community gardens at a produce stand where consumers shop for produce would not need this Produce Dealer registration.

The annual registration fee for Produce Dealers through the CDFA's Market Enforcement Branch as of this writing is $\$ 136$ to $\$ 400$, depending on the volume of sales of your business.

Find the registration instructions and application online at the CDFA website, http://www.cdfa.ca.gov/ $\mathrm{mkt} / \mathrm{meb} /$ forms.html.

Note: A farm, store, or other retail food facility may be able to act as a pick-up and drop-off site for farm products without registering with the CDFA as a produce "dealer" if the retail store does not actually sell the produce or otherwise collect any money from acting as a pick-up and drop-off site. For example, a store or restaurant acting as a CSA drop-off and pickup site may be exempt if the store or restaurant is not a seller of the produce.

\section{Farms Using Pesticides Must Obtain Permits}

We generally recommend that community gardens and urban farms limit the use of pesticides as much as possible because of their close proximity to homes, schools, businesses, etc., and because many urban farms and gardens are routinely visited by many people. However, any farms (including home gardens) that provide or sell food to the public and that are planning to use pesticides, including herbicides, regardless of the size of the production area, must either register or have permission to do so by the County Agricultural Commissioner, and the farm must keep detailed records of pesticide use (CDPR 2019). Even some organic pesticides fall under these regulatory requirements.

In California there are three levels of pesticide regulation depending on the category of pesticides you are applying: "non-restricted," "restricted," and "exempt" materials. All three categories of pesticides require the farmer to obtain an Operator Identification Number (OIN), which entails registering with the County Agricultural Commissioner in the county where the farm is located. For less hazardous substances known as "non-restricted materials," once an operator ID is obtained, the farm must submit monthly "pesticide use reports" to the Agricultural
Commissioner, detailing pesticide use for the month, including the name of the product used, the date of application, and the quantity of the substance applied. Use of any pesticide, herbicide, or other such substance that has an EPA number on the label is subject to these requirements. This includes organic pesticides and even some of those pesticides commonly used by home gardeners.

Urban farmers should be aware that many substances available in nurseries and home improvement stores, and even in some organic pesticides, require monthly reporting requirements and, in some cases, may not be legally used for commercial agriculture production. Be sure to read the label carefully. For example, Bonide Citrus Fruit and Nut Orchard Spray Concentrate specifically states on the label "For use only on residential lawns and gardens. Not for use on agricultural establishments growing agricultural crops or commodities for resale."

A second type of pesticide regulation applies to the use of more hazardous substances known in the law as "restricted materials," which require obtaining a restricted-materials permit from the Agriculture Commissioner's office and can only be applied by a trained and licensed individual. Application of restricted materials requires approval from the Agricultural Commissioner prior to each application and submission of monthly pesticide use reports. It is highly unlikely that urban farms will need to use restricted materials. Per the California Department of Pesticide Regulation, "restricted materials are pesticides deemed to have a higher potential to cause harm to public health, farm workers, domestic animals, honeybees, the environment, wildlife, or other crops compared to other pesticides. With certain exceptions, restricted materials may be purchased and used only by or under the supervision of a certified commercial or private applicator under a permit issued by the County Agricultural Commissioner." An example of a restricted use pesticide (RUP) is Lesco Sevin SL Carbaryl Insecticide (43\% carbaryl).

A third type of pesticide, known as 25(b) materials, are minimum-risk pesticide products that are exempt from registration, provided the product meets certain criteria. Because these products are still pesticides, however, the applicator still needs to obtain an operator ID but does not need an applicator certificate or license, and the pesticides do not need to be included on the monthly pesticide use reporting form. Users required to maintain use 
records per Title 3 CCR, $\$ 6624$, must still maintain pesticide use records detailing the use of these exempt pesticide products. To determine if your product qualifies for a minimum-risk pesticide exemption in California, see the following flowchart available online at the California Department of Pesticide Regulation website, https://www.cdpr.ca.gov/ docs/registration/sec25/minimum_risk_flowchart. pdf.

\section{Food Safety Laws for Egg Producers in California}

An "egg handler" refers to a person engaged in the business of producing, grading, packing, or otherwise preparing shell eggs for market. This definition also applies to people who sell eggs that they have acquired from another producer. Generally, however, it does not apply to any retail purchaser, such as a grocery store (CA Food and Agricultural Code $₫$ 27510).

\section{Registration Requirements}

All egg handlers must register with the CDFA. A new registration form (with fee) needs to be submitted within 30 days if any registration information changes. As of this writing, the initial annual registration fee for egg handling is $\$ 75$, and the annual registration fee thereafter is $\$ 50$ (Title 3 CCR $\$ 1358.3$ ).

The registration form for egg handlers can be found online at the CDFA website, https://www.cdfa. ca.gov/ahfss/mpes/pdfs/EggHandlersRegistrationApplication.pdf.

\section{Storage and Handling Requirements}

Generally, in order to produce and sell eggs, the eggs must be kept at a temperature of $45^{\circ} \mathrm{F}$ or lower, including during transportation. Transport vehicles may exceed the $45^{\circ} \mathrm{F}$ maximum temperature required when eggs are being loaded or unloaded from the vehicle (Title 3 CCR $\$ 1358.5$ ). However, raw shell eggs may be stored and displayed without refrigeration at a certified farmers' market if all of the following conditions are met (CA Health and Safety Code $\$$ 114373):

1. The eggs were produced from poultry owned by the seller and collected on the seller's property.

2. The eggs are not placed in direct sunlight during storage or display.

3. Retail egg containers are prominently labeled "refrigerate after purchase," or the seller posts a conspicuous sign advising consumers that the eggs should be refrigerated as soon as practical after purchase.

4. Retail egg containers are conspicuously identified as to the date of the pack.

5. The eggs have been cleaned and sanitized.

6. The eggs are not checked, cracked, or broken.

7. Any eggs that are stored and displayed at temperatures of $90^{\circ} \mathrm{F}$ or below and that are unsold after 4 days from the date of packing shall be stored and displayed at an ambient temperature of $45^{\circ} \mathrm{F}$ or below, diverted to pasteurization, or destroyed in a manner approved by the enforcement agency.

8. Any eggs that are stored and displayed at temperatures above $90^{\circ} \mathrm{F}$ that are unsold after 4 days from the date of packing shall be diverted to pasteurization or destroyed in a manner approved by the enforcement agency.

Additionally, farmers and community food producers may sell unrefrigerated eggs at an outlet or location they control, such as a farm stand at or near the site of the farm (CA Health and Safety Code $\$$ 114375(c)(1) and 114376(a)). Note: Community food producers are limited to selling 15 dozen eggs per month (CA Health and Safety Code $\$ 114376(a)(5)$ ).

\section{Inspection}

Eggs are subject to inspection at any time at production plants, wholesale warehouses, retail facilities, and farmers' markets. Inspectors from the CDFA can seize varying numbers of eggs from a producer to test for food safety. Title 3 CCR $\$ 1350$ provides a chart of designated sampling size requirements for inspection.

\section{Labeling Requirements}

Consumer packages or containers of eggs must state all of the following (Title 3 CCR $\$ 1354$ ):

- name of the farm

- address and zip code of the farm

- quantity of eggs

- California state handler code number

- [if applicable, see exemptions] egg size as described in table 1 (egg size must appear plainly marked in a font size $1 / 4$-inch tall minimum)

- [if applicable, see exemption] egg grade (i.e., AA, A, B). The larger the air-cell is, the lower the grade of the egg. The outside appearance also factors into the grade of an egg. Eggs with moderate staining 
Table 1. California egg size standards

\begin{tabular}{|l|c|c|}
$\begin{array}{l}\text { CA egg size } \\
\text { standards }\end{array}$ & Grams (min) & Ounces (min) \\
\hline jumbo & 68.51 & $2 \frac{5}{12}$ \\
\hline extra large & 61.42 & $2 \frac{1}{6}$ \\
\hline large & 54.34 & $1 \frac{11 / 12}{12 / 3}$ \\
\hline medium & 47.25 & $1 \frac{5}{12}$ \\
\hline small & 40.16 & N/A \\
\hline peewee & N/A & \\
\hline
\end{tabular}

Source: Title 3 CCR $\S 1353.4$.

Table 2. Minimum space requirements for bird enclosures

\begin{tabular}{|c|c|}
\hline $\begin{array}{c}\text { Number of birds } \\
1\end{array}$ & $\begin{array}{c}\text { Minimum square inches } \\
\text { per bird }\end{array}$ \\
\hline 2 & 332 \\
\hline 3 & 205 \\
\hline 4 & 166 \\
\hline 5 & 146 \\
\hline 6 & 135 \\
\hline 7 & 127 \\
\hline 8 & 121 \\
\hline 9 or more & 117 \\
\hline
\end{tabular}

Source: Title 3 CCR $\S 1350$.

(but not adhering dirt) can be sold as grade B. But $\mathrm{AA}$ and $\mathrm{A}$ grades require a clean, unblemished shell. Dirty eggs cannot be sold to consumers (egg grade must appear plainly marked in a font size $1 / 4$-inch tall minimum).

- the words "California Shell Egg Food Safety Compliant" or "CA SEFS Compliant." (This must appear plainly marked on the principal display panel in font size $1 / 4$-inch tall minimum.)

\section{Exemptions from Certain Labeling Requirements}

Size, grade, name, and address markings are not required on containers of eggs when sold by the producer directly to household consumers, without advertising by the producer on the premises where it was produced, so long as it was produced from a flock of 500 hens or fewer (Title 3 CCR $\$ 1354.2(a)$ ).

Eggs classified as "restricted eggs" are exempt from the size and quality (e.g., grade AA, A, B) standards for consumer grade eggs. "Restricted eggs" may be sold directly to consumers only as follows: by egg producers from their own flock's production, at the site of production or segregation, or at secondary locations operated by the producer, such as a farmers' market booth or farm stand (Title 3 CCR $\S 1356.2)$.

\section{California Shell Egg Food Safety Compliance}

All egg producers (regardless of any exemptions from certain labeling or refrigeration requirements) are subject to bird enclosure space requirements detailed in table 2 .

California has rules to reduce the growth of salmonella, including testing and vaccination requirements; however, these rules apply only to egg producers with 3,000 or more laying hens. These Salmonella testing and vaccination programs, among other requirements, are detailed in Title 3 CCR $\$ 1350$.

\section{Record-Keeping Requirements}

All egg handlers must maintain business records for egg transactions for 3 years, subject to audit by the CDFA. The records should include the pack date, egg quality, quantity, and identity of purchaser and seller. The name of purchaser is not required for eggs sold directly to end consumers. 


\section{Section III. Developing a Food Safety Program for Your Urban Farm}

This section provides step-by-step guidelines for developing a food safety program for your urban farm. As noted in the previous section, the CDFA Small Farm Food Safety Guidelines provide a checklist of recommendations that should be followed during crop production, harvest processing, and transport. This section provides a systematic approach and a bit more information to help you determine how to assess risks on your farm and how to develop standard operating procedures (SOPs) that, when implemented effectively, can help minimize food safety risks on your farm. We will cover eight basic steps to develop your own personalized food safety program for your farm.

\section{Steps to Develop a Food Safety Program for Your Farm}

1. Talk to your buyers.

2. Assess food safety risks on your farm (WASSH is an acronym for the five potential sources of contamination).

3. Develop SOPs and GAPs to minimize the risk of on-farm contamination.

4. Develop a food safety plan outlining your policies and procedures.

5. Train your workers (helpers, volunteers, family).

6. Post signage reinforcing GAPs (hand-washing, SOPs).

7. Keep records.

8. Implement, review, correct.

\section{Step 1: Talk to Your Buyers}

Find out what food safety requirements your buyers have, beyond complying with the CDFA and FSMA guidelines. Do they want to see your food safety plan? Do they want to visit your operations and observe your food safety practices? Do they want you to obtain a third-party audit? Be clear about the expectations of your buyers so that you can tailor your program to address their needs or seek other markets. If you are donating to a food bank or homeless shelter, ask if they have any particular guidelines as well

\section{Step 2: Assess Food Safety Risks on Your Farm}

Each farm is unique in terms of its land use history, adjacent land use, materials and supplies used, and workers or participants at the farm. As such, it is important to conduct an on-farm risk assessment for your own operation.

In general, there are five potential sources of contamination on the farm, and they correspond with an acronym that is easy to remember: WASSH (as shown in table 3 ).

Table 3. Examples of the top five potential sources of contamination on the farm (WASSH)

\begin{tabular}{|c|c|}
\hline $\begin{array}{l}\text { Possible } \\
\text { sources of } \\
\text { contamination }\end{array}$ & Examples \\
\hline water & $\begin{array}{l}\text { Sources of dirty water may include } \\
\text { contaminated irrigation water, hand- } \\
\text { washing water, produce wash water, } \\
\text { water runoff from adjacent property or } \\
\text { street during heavy rains, and standing } \\
\text { water that may attract wildlife. }\end{array}$ \\
\hline animals & $\begin{array}{l}\text { Contamination may occur from } \\
\text { domestic and wild animal intrusion and } \\
\text { other pests. }\end{array}$ \\
\hline soils & $\begin{array}{l}\text { Contamination of soils may be } \\
\text { associated with site history (former } \\
\text { dump site, old houses with flaking paint, } \\
\text { railway ties, etc.), improperly treated } \\
\text { compost, raw manure, improper storage } \\
\text { of manure and compost, risk of drift } \\
\text { from adjacent or industrial land use. }\end{array}$ \\
\hline surfaces & $\begin{array}{l}\text { Dirty surfaces may include equipment, } \\
\text { tools, harvest buckets, boxes, hoses } \\
\text { on the ground, packing tables, sinks, } \\
\text { wash basins, toilets, and transportation } \\
\text { that are not washed and sanitized on a } \\
\text { regular basis. }\end{array}$ \\
\hline $\begin{array}{l}\text { health and } \\
\text { hygiene }\end{array}$ & $\begin{array}{l}\text { Contamination can be associated with } \\
\text { people handling produce who are } \\
\text { sick or fail to follow proper hygiene } \\
\text { practices or use poorly maintained } \\
\text { sanitary facilities. For example: cross- } \\
\text { contamination from not washing hands } \\
\text { after handling money, food, smoking, } \\
\text { using the toilet or poorly maintained } \\
\text { toilets and no hand-washing stations, } \\
\text { etc. }\end{array}$ \\
\hline
\end{tabular}


It is important to first assess your farm for any potential sources of contamination. Using the On-Farm Food Safety Assessment for California Urban Farms provided (appendix 1), walk around the farm, evaluate each of the possible sources of contamination listed above, observe current practices, and record any potential risks that you may need to address

\section{Step 3: Develop Standard Operating Procedures (SOPs) Implementing Good Agricultural Practices (GAPs) to Minimize Risk of On-Farm Contamination}

Once you have assessed and identified any potential risks, then consider developing a set of corrective actions to minimize the risk of contamination on the farm. Each farm is unique, so you may need to develop your own set of SOPs to effectively address a risk. The Resources section has materials on SOPs needed for GAPs and how to write them. Common examples of corrective actions that may be required are listed in table 4.

\section{Standard Operating Procedures}

The CDFA Small Farm Food Safety Guidelines provide a checklist of recommendations that should be considered during crop production, harvest, processing, and transport in order to minimize the risk of on-farm contamination. In the section below, we provide some examples of SOPs for good agricultural practices that you may consider for your operation.

\section{Water Testing}

It is recommended that all water sources be tested for the presence of an indicator organism (e.g., generic $E$. coli) at least once a year prior to harvest season. The presence of indicator organisms can predict undesirable conditions (e.g., ineffective treatment, presence of fecal material, etc.).

Municipal water districts conduct their own annual tests and are accepted as evidence of safe water; obtain a record for your file. If using water from other sources (e.g., well) for wash water, ice, or hand-washing, it must be potable. If there is evidence of risk of contamination, take corrective action to address the source of contamination (FDA 2019).

Table 4. Common examples of corrective actions to minimize or mitigate risk of on-farm contamination

\begin{tabular}{|c|c|}
\hline $\begin{array}{l}\text { Possible sources of } \\
\text { contamination }\end{array}$ & Corrective actions \\
\hline water & $\begin{array}{l}\text { Water source: If using a municipal water source, obtain annual records from water district. If using a } \\
\text { well or other source of water, test water for generic E. coli (see SOP below for water sampling method) } \\
\text { and treat if necessary, following industry standards. } \\
\text { Produce wash water: Use potable, chlorinated water or other labeled disinfectants to wash produce. } \\
\text { Water runoff: Mitigate risk of flooding by building berm or digging ditch to divert runoff. Minimize } \\
\text { standing water that attracts wildlife. }\end{array}$ \\
\hline animals & $\begin{array}{l}\text { Develop and implement a pest management program. Monitor and record intrusion of animals, use } \\
\text { mitigation measures (fences, traps, noisemakers) to minimize intrusion and predation, and record } \\
\text { all actions taken and follow-up observations. Remove dead animals and traps in a timely manner, } \\
\text { keep all domestic animals out of active harvest area, separate chickens from produce area, and avoid } \\
\text { harvesting produce with evidence of bird, rodent, or other animal feces present. (More information on } \\
\text { animals in Section V.) }\end{array}$ \\
\hline soils & $\begin{array}{l}\text { Evaluate site history, test your soil if potential for risk, procure OMRI-certified compost and clean } \\
\text { soils or follow best practices (see resources page), create wind barriers to minimize drift, use best soil } \\
\text { management practices (subsurface irrigation, raised bed, maintain soil pH, soil barrier cloths, etc.). See } \\
\text { Section IV for more information on soils. }\end{array}$ \\
\hline surfaces & $\begin{array}{l}\text { Clean and sanitize all surfaces on a regular basis, including tools, equipment, harvest buckets, packing } \\
\text { areas, storage bins, and transportation. All transportation should be covered. }\end{array}$ \\
\hline health and hygiene & $\begin{array}{l}\text { Provide illness and accident prevention, as well as good health and hygiene training to all workers, } \\
\text { volunteers, and staff. Create SOPs that your workers follow. Avoid work when sick, wash hands, } \\
\text { practice good hygiene, install fully equipped hand-washing stations (liquid soap, paper towel, } \\
\text { garbage can) adjacent to all toilets. }\end{array}$ \\
\hline
\end{tabular}


Farmers on small or medium-sized urban farms are unlikely to be subject to FSMA's water rule and microbiological testing requirements. In any case, compliance dates for all provisions dealing with agricultural water have been extended to 2022 to 2024 (Stoeckel et. al. 2018). As of 2018, the Cornell Produce Safety Alliance advises that growers should not make significant changes to their current water testing practices, as far as compliance with the Produce Safety Rule goes, until more is known about potential changes to regulatory requirements. Visit the Produce Safety Alliance website (in the Resources section) for regulatory updates.

Contact a local laboratory or cooperative extension advisor for more detailed guidance on water collection, testing and corrective actions.

\section{Reducing Cross-Contamination in Produce Wash Water}

If washing produce at the farm, it is important to follow SOPs to minimize cross-contamination in the produce wash water. When using chlorine in produce wash water or as a sanitizer on food contact surfaces, be sure that the product is registered with the EPA and is labeled for use with produce. Examples include Chlorox Regular Bleach (6\% sodium hypochlorite) EPA\# 5813-50 or Chlorox Germicidal Bleach (8.25\% sodium hypochlorite) EPA\#5813-100 (Lawton et al. 2015). Suslow (1997) provides details on chlorine wash water concentrations, and Lawton et al. (2015) provide a list of additional approved produce wash sanitizers. Common SOPs to minimize contamination in produce wash water include the following:

- Clean and sanitize the produce wash bin on a daily basis and let air dry (see surface sanitizing SOP below).

- Make sure that all water that comes in contact with produce for washing is tested and is safe to drink.

- If using chlorine (sodium hypochlorite), water should contain between 5 and 10 parts per million (ppm) total chlorine. (Use $1 / 2$ teaspoon pure unscented bleach $(6 \%)$ in 6 gallons of water $=5$ $\mathrm{ppm}$.) Use chlorine test strips to determine chlorine content.

- For chlorine to be effective, water should have a $\mathrm{pH}$ of between 6 and 7.5, with minimal organic matter (soil) in the water. Use $\mathrm{pH}$ test strips to determine $\mathrm{pH}$.
- Make sure that water is changed in the dump tanks daily or when $\mathrm{pH}$, chlorine content, or organic matter makes chlorine ineffective. Root crops will require more frequent change of water.

- Wash root crops after leafy greens or other produce.

- To minimize chlorine residue, rinse produce with potable water (do not submerge in a dump tank) only prior to packaging.

\section{Mitigating Water Runoff onto Farm}

In the event that your farm is at risk of flooding during heavy rain and the adjacent land use may pose a risk of contamination (e.g., railroad ties, industrial site, abandoned lot), take the following measures:

- Before planting, observe farm during heavy rains, noting volume, timing, frequency, directionality, and extent of runoff.

- When dry, dig a diversion ditch for water to run away from the intended crop production area, or build a berm to prevent water runoff onto farm.

- Monitor and take measures to prevent any standing pools of water (level the surface, divert the runoff).

- After planting, monitor and record actions taken and their effects in record-keeping sheet.

\section{Rodent Control in Farm Stand, Packing Shed, and Storage Area}

It is important to take measures to prevent rodents from entering farm stand, packing, and storage areas. Effective measures include the following:

- Remove all potential food sources and nesting sites from inside and around the storage area and farm stand. Keep all garbage receptacles emptied on a regular basis.

- Seal off entry points with screens, barriers.

- Store empty boxes off the ground, away from moisture, and covered or enclosed in plastic wrapping.

- Best to trap rodents between winter and springbut make sure to monitor for them whenever the farm is in use.

- Monitor for rodent presence (droppings, sightings); keep records.

- Place mechanical (snap) or sticky traps inside where there is evidence of rodents. Do not use bait 
traps inside farm stand or packing shed.

- Monitor traps regularly, and record effects.

- Dispose of trapped animal immediately, and document effects.

- Maintain a pest control log that includes inspection dates, inspection reports, and procedures implemented to eliminate any problems.

- Frequently monitor affected and treated areas to determine the effectiveness of the treatment applied.

- Generally, all traps are marked and flagged by numbers or some type of coding system. There should also be a map of the premises that shows the location of such traps.

\section{Cleaning Harvest Tools}

- Workers must put on proper protective gear (waterproof aprons, thick rubber gloves, goggles).

- Clean and sanitize surface for drying harvest tools and equipment (e.g., plastic table, plastic tarp, stainless steel wire mesh table), using spray nozzle cleaner and sanitizing solution as described below. Avoid using wood or plywood surfaces for packing as they cannot be sanitized.

- For sanitizing tools and buckets: Set up four wash bins labeled 1) Pre-rinse, 2) Wash, 3) Rinse, and 4) Sanitize.

- Fill all wash bins with water to fill line and put dishwashing detergent in "Wash" bin, and create sanitizing solution in "Sanitize" bin.

- To create sanitizing solution: mix 1 tablespoon pure unscented bleach (6\%) to 1 gallon water (= $150 \mathrm{ppm}$ ) and pour into sanitation tub (see Suslow 1997 and Lawton 2015 for a list of registered products).

- Bin 1: Pre-rinse all tools and buckets, using scraping, brushing, and hosing to remove any visible soil.

- Bin 2: Tools and buckets are scrubbed with detergent in "Wash" bin.

- Bin 3: Tools and buckets are rinsed in "Rinse" bin.

- Bin 4: Buckets are dipped in sanitizer, then airdried and stacked in sanitary storage.

- Check water for free chlorine with chlorine test strips to determine when to change water, as turbidity in the water can result in chlorine binding with soil particulates, limiting its efficacy. Free chlorine should be kept at $150 \mathrm{ppm}$. Chlorine will evaporate over time.

- Dispose of wastewater daily, away from production area, with proper drainage.

- All brushes and tubs are labeled for "Harvest Equipment Only" and stored separately.

\section{Toilet and Hand-Washing Facilities}

The CDFA guidelines instruct that proper sanitation and hand-washing facilities be provided in an area outside the field. Unless service is provided by a portable toilet company, it is important to come up with a standard operating procedure for ensuring clean, supplied toilet and hand-washing stations. To learn how to make an inexpensive hand-washing station, watch the UCCE video here: https://www.youtube. $\mathrm{com} /$ watch?v=0XCXVcTVQMc.

\section{Cleaning Hand-Washing Facilities}

- Hand-washing facility is located in close proximity of toilet.

- All hand-washing facilities are clean and water source is covered. They are supplied with single-use towels, liquid hand soap, and potable water for hand-washing. Trash can with lid is located in vicinity and emptied regularly.

- When using outdoor hand-washing facilities, place a bucket beneath the spigot to capture wastewater as necessary, and dispose of wastewater away from crops in a manner that does not cause unsanitary conditions, nuisance, or contamination.

- Hand-washing container is thoroughly cleaned and sanitized on a weekly basis by scrubbing with a clearly labeled brush that is stored separately.

- Cleaning and resupply records are maintained.

\section{Cleaning Restroom Facilities}

- Toilet facilities are located within $1 / 4$ mile or 5 -minute walk of workers.

- When using portable toilets, they are properly screened to keep animals and insects out. They are ventilated and provided with self-closing doors, lockable from the inside.

- Daily spot checks are conducted for cleanliness, spot cleaning, and trash pickup.

- Weekly thorough cleaning (toilet, walls, floors) and sanitizing (toilets and urinals, doorknobs, and 
any other surface) are carried out. Rinse with hose in outdoor facility as necessary.

- Fill paper products and soap dispensers.

- Provide covered trash bin, and remove trash to dumpster as needed.

- Maintain a cleaning and product resupply log with date and initials upon completion.

- Store all restroom cleaning equipment in bucket labeled "Restroom Cleaning Only."

\section{Cleaning Farm Stand, Packing Shed, and Storage Facility}

- Storage facilities are cleaned regularly, prior to loading with product, and records are maintained. (Determine your cleaning schedule based on your own operation routine.)

- Materials used for cleaning include a broom, dustpan, and trigger spray bottle with clean rags.

- Cleaning includes removal of all spider webs, bird nests from rafters, dust and debris from the floor, shelves, and ledges. All potential nest sites or food sources for rodents are removed.

- Hang fly strips as necessary, and monitor and replace as needed.

- Spot cleaning is conducted as needed. Trash cans are emptied on a regular basis as needed.

- All cleaning supplies are labeled and stored separately.

\section{Step 4: Develop a Food Safety Plan}

While not required under FSMA or in the CDFA guidelines, a food safety plan for your farm can help guide your operations with good agricultural practices (GAPS). A food safety plan can outline the content and frequency of the various steps you take to minimize food safety risks, such as worker training, cleaning and sanitizing procedures, record-keeping, and any other policies or standard operating procedures you develop to minimize the risk of contamination on the farm.

Please refer to the Resources section for some guidance on how to write a farm food safety plan (Cornell Produce Safety Alliance 2019).

\section{Step 5: Worker Training}

Worker training is an important part of your food safety operation. Everyone who helps on the farm (employees, staff, volunteers, visitors) should be trained in good health and hygiene and accident and illness prevention, as well as any SOPs they will be involved with or responsible for. Develop a training program that meets the needs of your operation. For regular employees and volunteers, provide training at the beginning of harvest season and do follow-up trainings as needed. For intermittent or new volunteers, do a mini-training or have them read the visitor and volunteer food safety policy (see appendix 2 for a sample). Examples of worker training guidelines are as follows:

\section{Worker and Volunteer Training: Good Health and Hygiene and Accident and IIIness Prevention}

- Proper hand-washing: Hands must be washed before beginning or returning to work and after the following activities: using the restroom, smoking or tobacco use, taking breaks, handling trash containers or disposing of trash, using the telephone, handling money, coughing and sneezing, and handling animals or manure. Hands are washed with liquid soap for 20 seconds, scrubbing fingernails, front and back of hands, and dried with disposable towels. Water is turned off with a disposable towel. Towels are deposited in a covered receptacle. Hands are dried before putting on gloves (if used).

- Personal hygiene: All workers must follow good hygiene and sanitation practices including:

- Wear clean work clothes.
- Have clean and cut nails, tie long hair back, remove dangling strings or jewelry. Take a daily shower.

- Eat and smoke in designated area.

- Avoid eating, chewing gum, tobacco use, spitting, urinating, or defecating while in growing and processing area.

- Use toilet and hand-washing facilities and use them properly. Use only clean, unripped gloves (if using).

- Keep all glass containers away from the field.

- Wear clean, unripped, sanitary gloves (best are nonlatex). Avoid taking gloves into lunchroom or restroom.

- Avoid using product containers for personal use. 
- Accident and illness prevention (workers include anyone helping on the farm, including volunteers):

- To avoid heat exhaustion, drink plenty of water frequently (2 quarts per person per day), especially when hot. Use single-use cups, personal reusable water bottles, or fountains for drinking water.

- Access to shade (umbrella or other shade structure) is provided close by. Take breaks in the shade.

- Workers who show signs of diarrhea, vomiting, fever, jaundice, infected wounds, or other infectious disease should not handle produce.

- Workers who get a cut or have a nosebleed while working must stop immediately, contact their supervisor, and have it treated. The wound is cleaned, disinfected, bandaged, and gloved as soon as possible. Any product that is contaminated with bodily fluids is discarded immediately away from the field. Any container, surface, or tools that are contaminated are cleaned and disinfected as soon as possible.

- All accidents and responses are recorded.

- All workers know the location of the first aid kit and know what steps to take should an injury occur.

- An updated first aid kit should include bandages, antiseptic solution, antibacterial ointment, and nonlatex gloves.

\section{Step 6: Signage}

Consider developing and posting signs that reinforce good agricultural practices, both in the field and in the packing area, such as signs for hand-washing, designated smoking and eating areas, standard operating procedures for cleaning and sanitizing, visitor food safety policies, and a food safety assessment daily checklist (see Appendices 2 and 4).

\section{Step 7: Record-Keeping}

The CDFA guidelines emphasize the importance of record-keeping. Appendix 3 provides a set of record-keeping sheet templates that can be used and adapted for your operation. They include the following kinds of records:

- fertilizer input use

- pesticide use

- toilet and hand-washing maintenance
- preharvest assessment

- cleaning and sanitizing

- worker training and instruction

- marketing and traceback

- pest, rodent, and wildlife control

- injury and illness reporting

- contamination response log

- visitor's log

\section{Step 8: Implement, Review, and Correct}

As you implement your food safety program, you may notice you need to update or modify a practice or procedure to more effectively address the identified risk. Over the course of the season, take time to monitor, evaluate, and adjust your training and procedures accordingly.

\section{REFERENCES}

California Department of Pesticide Regulation (CDPR). 2019. PUE program standards compendium, Volume 1: General administration of the pesticide use enforcement program, Chapter 4: Pesticide use reporting and operator Identification numbers. CDPR website, https://www.cdpr.ca.gov/docs/ enforce/compend/vol_1/chapter_4.pdf.
Cornell Produce Safety Alliance. 2019. Farm food safety plan writing resources. 2019. Cornell Produce Safety Alliance website, https://producesafetyalliance. cornell.edu/resources/farm-food-safety-plan-writingresources.

Lawton, M., A. Kinchla, and L. McKegg. 2015. Produce wash water sanitizers: Chlorine and PAA. UMass Extension website, https://ag.umass. edu/sites/ag.umass.edu/files/fact-sheets/pdf/ pssanitizerlawtonkinchlasept15.pdf. 
Stoeckel, D., C. Fisk, D. Pahl, G. Wall, K. Woods, and E. Bihn. 2018. The water analysis method requirement in the FSMA Produce Safety Rule. Cornell Produce Safety Alliance website, https://producesafetyalliance. cornell.edu/sites/producesafetyalliance.cornell.edu/ files/shared/documents/Water-Analysis.pdf.

Suslow, T. 1997. Postharvest chlorination: Basic properties and key points for effective disinfection. Oakland: University of California Agriculture and Natural Resources Publication 8003.
U. S. Food and Drug Administration (FDA). 2019. FSMA final rule for produce safety: How did the FDA establish requirements for water quality and testing of irrigation water? FDA website, https:// www.fda.gov/Food/GuidanceRegulation/FSMA/ ucm472501.htm 


\section{Section IV. Soils in Urban Agriculture: Testing, Remediation, and Best Management Practices}

(This section adapted with permission from the authors, Surls et al. 2016).

Urban agriculture, including community and school gardens and small farms in cities, has become a popular means of obtaining fresh, local produce. San Francisco, San Diego, Los Angeles, and several other California municipalities have changed policies to facilitate these activities.

Soils are an important consideration for individuals, community groups, and local governments becoming involved in urban agriculture. In many situations, urban soil has been contaminated and degraded by past uses and activity, including industry, unauthorized dumping, construction, heavy traffic, and adjacent buildings where lead-based paint has been applied. In particular, elevated levels of lead are fairly common in urban soils and pose health risks, especially to young children who can ingest soil while playing or helping in gardens. Ongoing exposure to lead can damage the nervous system, interfere with brain development, and create other health problems. Arsenic, cadmium, copper, zinc, and other naturally occurring trace elements in soils, especially heavy metals, can also be elevated to unsafe levels by past land uses.

Although soil degradation and contamination are important concerns and should be addressed, they are not always a problem with urban agriculture sites. A study conducted at several community gardens in the Los Angeles area by University of California researchers found that "in nearly all cases concentrations of trace elements were well within natural ranges" (Hodel and Chang 2002). In contrast, a study conducted in San Francisco found that "a majority of the gardens exceeded the California Human Health Screening Level for arsenic, cadmium, and lead" (Gorospe 2012).

Even where there are elevated levels of lead or other heavy metals or contaminants in soil, relatively little is absorbed by crops, although this depends on soil and other environmental conditions as well as on the plant's characteristics. Accidentally swallowing or inhaling contaminated soil or dust is the most likely way urban farmers will be exposed to unsafe levels of lead or other contaminants. This can happen easily, for example, when people put their fingers in their mouths without thinking.

Beyond heavy metals, other sources of soil contamination and soil hazards might include solvents found at sites with a history of manufacturing use, various petroleum-based chemicals common at former gas stations and other industrial sites, chlorinated pesticides and residual herbicides on former agricultural lands or public landscaped areas, saline soil, and sites where a contaminant may not be harmful to people but may prevent plant growth or production. Physical debris such as lumber, concrete, wire, broken glass, and discarded syringes can also create hazards for the urban farmer. Clearly, there are no easy answers: each site and situation is unique. However, establishing reasonable policies and encouraging sustainable practices will help to ensure that urban farmers and consumers of urban agricultural products are not exposed to unsafe levels of contaminants, including lead and other heavy metals.

This section outlines strategies for urban soil contamination assessment, testing, and remediation; explains best management practices for urban agriculture; and discusses municipal policy concerning safe soils for urban agriculture. This section does not cover soil fertility or other important soil science topics in depth; additional resources on these topics are presented in the Resources section.

\section{SOILS ASSESSMENT FOR URBAN AGRICULTURE}

\section{Site Selection}

Overall soil conditions should be a consideration when selecting a site for urban agriculture. If plants, even weeds, are growing abundantly on the site, it is a good indication that the soil will be able to support crops. If the soil is reasonably easy to dig, it is a positive sign as well. The presence of plant roots and earthworms can indicate soil health. However, these indicators do not guarantee that soil is uncontaminated. When assessing potential sites, be aware that properties with considerable amounts of trash and rubble or obvious dead spots where plants do not 
grow may pose challenges. Heavy herbicide or pesticide use may have even sterilized the soil on a site. A simple test for evaluating soil fertility is to plant bean seeds in soil from the site, perhaps in a pot or biodegradable paper cups, and compare their germination and growth with an equal number of beans grown in purchased potting soil. It is also advisable to dig a hole 1 to 2 feet deep in several places to assess the presence of debris on the site.

\section{Site History}

Learn as much as possible about the history of a proposed site and how it has been used in the past. Walking around the site may provide some clues. Adjacent older homes with peeling paint, paint chips, or evidence of sandblasting (a pitted surface) indicate potential soil lead contamination. Any building built before 1979 that has old or peeling paint may be a hazard due to use of lead-based paint. Proximity to a freeway or a heavily trafficked road is also a source of lead. Although leaded gasoline has not been in use since the 1980s, lead particles in vehicle exhaust may have settled from the air into the soil.

Talking to the property owner and neighbors is a good strategy, as neighbors are often familiar with past uses of the property. It may also be necessary to do some Internet or library research. For example, at some public libraries and online sources, it is possible to access Sanborn maps, which were used by insurance companies to determine the risk involved with insuring individual properties. These maps can provide information about prior uses of a proposed site. Old aerial photographs, which can also be found in local libraries or online, can help identify a site's history as well. The local city hall may have aerial photographs accessible in their archives. There is also a fee-for-service website (Historical Aerials, https:// www.historicaerials.com/), that includes aerial maps of various regions of California that can be used when researching the history of a site. The county tax assessor's office and the local city hall are important sources of tax records and permits that have been obtained for the property, which can help uncover past uses. Sites can also be checked on the California Department of Toxic Substances website, www. envirostor.dtsc.ca.gov/public/, to see whether any documented issues or ongoing cleanup activities are associated with the property.

Examples of sites with prior uses that may have caused soil contamination are parking lots, junkyards, auto repair or painting, carpentry, machine shops, dry cleaners, gas stations, railroad yards, and illegal dumping sites. The history of a site will help to determine the type and extent of soil testing necessary. A site that has been primarily residential or used as green space is generally lower risk. A site that has had past industrial or commercial uses should be more carefully analyzed.

\section{SOIL TESTING}

Laboratory soil testing is always recommended for urban agriculture projects and should be considered a basic cost of starting any project. The cost depends on the size of the proposed site, the number of soil samples needed, and the type of analysis conducted by the lab.

Soil test kits sold at hardware stores or garden centers provide basic estimates of soil fertility but are not suitable for assessing soils at a potential urban agriculture site, as they do not provide information about soil contaminants.

\section{Selecting a Soil Testing Lab}

Finding a university or commercial lab to conduct soil testing is not difficult; searching online for your region or state should yield several choices. Note that in many publications, the University of California Cooperative Extension service is listed as a resource for testing soil. UC Cooperative Extension does not offer soil testing. However, some other state land grant universities accept out-of-state soil sample submissions by mail at very reasonable prices, including the University of Massachusetts at Amherst and Penn State University. When selecting a soil testing lab, consider asking some of the following questions:

1. Do you participate in the North American Proficiency Testing Program (NAPT)? This program assures that soil test analyses are being performed using validated testing methods.

2. Which tests do you recommend for an urban agriculture site with no site history?

3. Do you recommend any specific tests for sites with a history of industrial or commercial use?

4. Do you perform tests for elevated levels of heavy metals and other contaminants, in particular, those listed in the California Code of Regulations Title 22: Inorganic Persistent and Bioaccumulative Toxic Substances? 
5. What costs are involved for testing, given the type of analyses recommended and the anticipated number of samples?

6. What is the recommended procedure for taking soil samples?

7. Is it okay to call the lab for advice and information?

8. Do you provide a narrative with the soil test results? Is there an extra charge for this?

9. Do you provide remediation recommendations with soil tests?

10. What is your turnaround time?

The U.S. Environmental Protection Agency (U.S. EPA) recommends that for urban areas, "at a minimum, the soil test should include $\mathrm{pH}$, percent organic matter, nutrients, micronutrients, and metals, including lead" (U.S. EPA 2011b). This level of testing is adequate for a site that has been residential or green space. Most commercial soil labs can test for the most important heavy metals, including lead, arsenic, cadmium, chromium, and nickel.

More testing may be appropriate for a site with a history of industrial or commercial use, which might include CAM-17 testing. ("CAM-17" refers to the list of seventeen metals specified in the California Administrative Manual: antimony, arsenic, barium, beryllium, cadmium, chromium, cobalt, copper, lead, mercury, molybdenum, nickel, selenium, silver, thallium, vanadium, and zinc). An EPA-recognized laboratory is the best choice for this level of testing.

It is possible that other types of tests may be necessary, such as testing for polynuclear, or polycyclic, aromatic hydrocarbons (PAHs), a class of potentially toxic byproducts of incompletely burned garbage, oil, wood, coal and other organic materials. They can accumulate in soils and become a concern on a site that has been used previously as a car wash, parking lot, road and maintenance depot, or vehicle service station.

Staff members at soils labs can be great sources of information. They are generally willing to talk on the phone about appropriate testing based on site history. However, there are instances where additional support may be necessary.

\section{Resources for Brownfield Soil Assessment}

According to the California Department of Toxic Substance Control (DTSC), brownfields are properties that are contaminated, or thought to be contaminated, and are under-utilized due to perceived remediation costs and liability concerns. In cases involving brownfields that were formerly industrial or manufacturing sites, old gas station sites, and other situations, expert assistance may be necessary: these sites may have cleanup issues beyond what a community project can accomplish without technical expertise and a significant budget. These sites may be too expensive to test and remediate; help may be available, though, through state and local brownfield programs. California DTSC oversees a voluntary cleanup program for brownfield sites. Some cities have brownfield programs that may be able to provide guidance, resources, and perhaps even help in securing funding for cleanup. Although urban agriculture is not yet a common reuse for brownfield sites, it is an area for further exploration. Local offices of the USDA Natural Resources Conservation Service (NRCS) may also be able to provide technical assistance and guidance on a case-by-case basis

\section{TAKING SOIL SAMPLES}

Laboratories generally provide an online instruction sheet on how to sample the soils, prepare the samples, and mail them to the lab. Once you have selected a lab, review its website for instructions or speak to a staff member by phone. Detailed instructions on collecting soil samples are also available in several of the resources listed in the section "Sources of More Information." Review these instructions carefully, since poorly collected or unrepresentative soil samples may not provide accurate information.

Generally, it is essential to approach soil testing with a plan in mind. Making a simple map of a proposed site and noting areas with different characteristics helps you decide how many samples to collect.

\section{Mapping the Sampling Area}

1. Areas where plants are not growing, or the soil is discolored should be sampled separately.

2. An area adjacent to a building with peeling paint should be sampled separately due to the possibility of lead contamination.

3. For each area to be sampled, it is usually appropriate to take five to seven subsamples, then mix them together to create a composite sample. 
4. Take samples from the top 4 to 6 inches of soil.

5. Remove litter, leaves, grass, or anything else covering the soil before sampling. The subsamples can be mixed together thoroughly in a clean bucket to form a composite sample after breaking up any clumps and removing roots, stones, or other materials.

6. Repeat this process for each distinct area of the site.

7. Keep track of the location of each sample. Once results come back, you will need to refer to records that clearly show where on the site samples were taken.

\section{Transporting Samples}

1. Use a resealable, clean plastic bag that holds approximately 2 cups ( 1 to $1 \frac{1}{2} \mathrm{lbs}$ ) of soil to transport the sample.

2. Remove most of the air from a double-bagged sample to prevent spillage.

3. Some labs supply sample jars, which may be free with testing.

4. The soil sample does not need to be refrigerated, but keeping it in the shade or a cool, dry place until it is shipped or delivered to the lab can help achieve accurate test results.

5. Wet samples should not be shipped, as inaccurate testing may result.

6. Soil samples can be dried prior to shipment by keeping the bag open in a dry and wellventilated place or by spreading the soil in a thin layer on clean butcher or waxed paper and allowing it to dry at room temperature.

7. Once sample is adequately dry, mail or bring it to the lab for testing.

\section{Interpreting Soil Test Results}

Some soil labs provide a narrative report with recommendations. Most labs are receptive to questions regarding interpretation of test results. Soil testing will indicate whether plant nutrients are low and need to be raised for best plant growth and whether the soil $\mathrm{pH}$ needs to be adjusted. The soil test can also indicate whether there are higher than acceptable levels of heavy metals or other contaminants, depending on what tests were requested.

Heavy metals are the contaminants most commonly tested for, and there is more guidance available about heavy metals, especially lead, than for many other contaminants. Even so, there is no one standard as to what constitutes safe levels of heavy metals in urban agriculture. Most guidelines that exist are created for residential use scenarios and contact with soil through skin exposure or accidental ingestion, rather than being formulated for gardening or farming. Still, they provide some guidance about what is acceptable.

One standard to consider is the California Human Health Screening Level (HHSL), which is used by the City and County of San Francisco and the City of San Jose in their guidance on lead hazard assessment for urban gardens and farms. For lead, the HHSL is 80 parts per million (ppm).

Anything lower is considered below the level of concern for human health. Another standard is the EPA's Soil Screening Levels (SSLs) for residential use, which consider lead to be a hazard at levels of 400 ppm or more. In 2013, the U.S. EPA Technical Review Workgroup (TRW) for Lead provided a bit of clarification specifically for gardening and deemed soil lead at less than 100 ppm to be low risk for home-grown produce.

The HHSL levels for heavy metals and other potential contaminants are listed in the chart at the California Environmental Protection Agency's (CalEPA) Office of Environmental Health Hazard Assessment (OEHHA) website, oehha.ca.gov/risk/ chhsltable.html; some of the most common are listed in table 5 along with the corresponding SSLs. The U.S. EPA TRW chart with specific, tiered soil lead recommendations for gardening is available in table 6 . These standards are advisory only; check with local municipalities (or school districts for school-based projects) to find out whether more specific requirements have been established.

\section{REMEDIATING SOILS}

If soil testing indicates that levels of lead or other heavy metals are higher than acceptable, consider the following strategies to mitigate the problem.

\section{Working with Existing Soil}

Many urban farmers automatically plan for raised beds to avoid potential soil problems. However, raised beds do have drawbacks, including the cost of materials, obtaining quality "clean" soil to fill them, and the fact that plant roots dry out faster in raised 
Table 5. Advisory levels to guide interpretation of soil test results for heavy metals in parts per million (ppm)*

\begin{tabular}{|l|c|c|}
\hline Inorganic chemicals & California residential HHSLs & U.S. EPA SSLS \\
\hline arsenic ${ }^{\dagger}$ & 0.07 & 0.4 \\
\hline cadmium and compounds & 1.7 & 70 \\
\hline chromium III & 100,000 & 120,000 \\
\hline chromium VI & 17 & 230 \\
\hline lead and lead compounds & 80 & 400 \\
\hline nickel and compounds & 1,600 & 1,600 \\
\hline zinc & 23,000 & 23,000 \\
\hline
\end{tabular}

*These state and federal soil screening level standards are for advisory purposes only. Please refer to the section "Interpreting Soil Test Results" for details. the screening numbers for arsenic are for contamination resulting from human activity. Concentrations of naturally occurring arsenic may be far above the screening number. When levels of arsenic at a site are a concern, consult the agency with authority over remediation decisions.

Table 6. EPA TRW Lead Committee's recommendations for best management practices for gardening in leadcontaminated areas

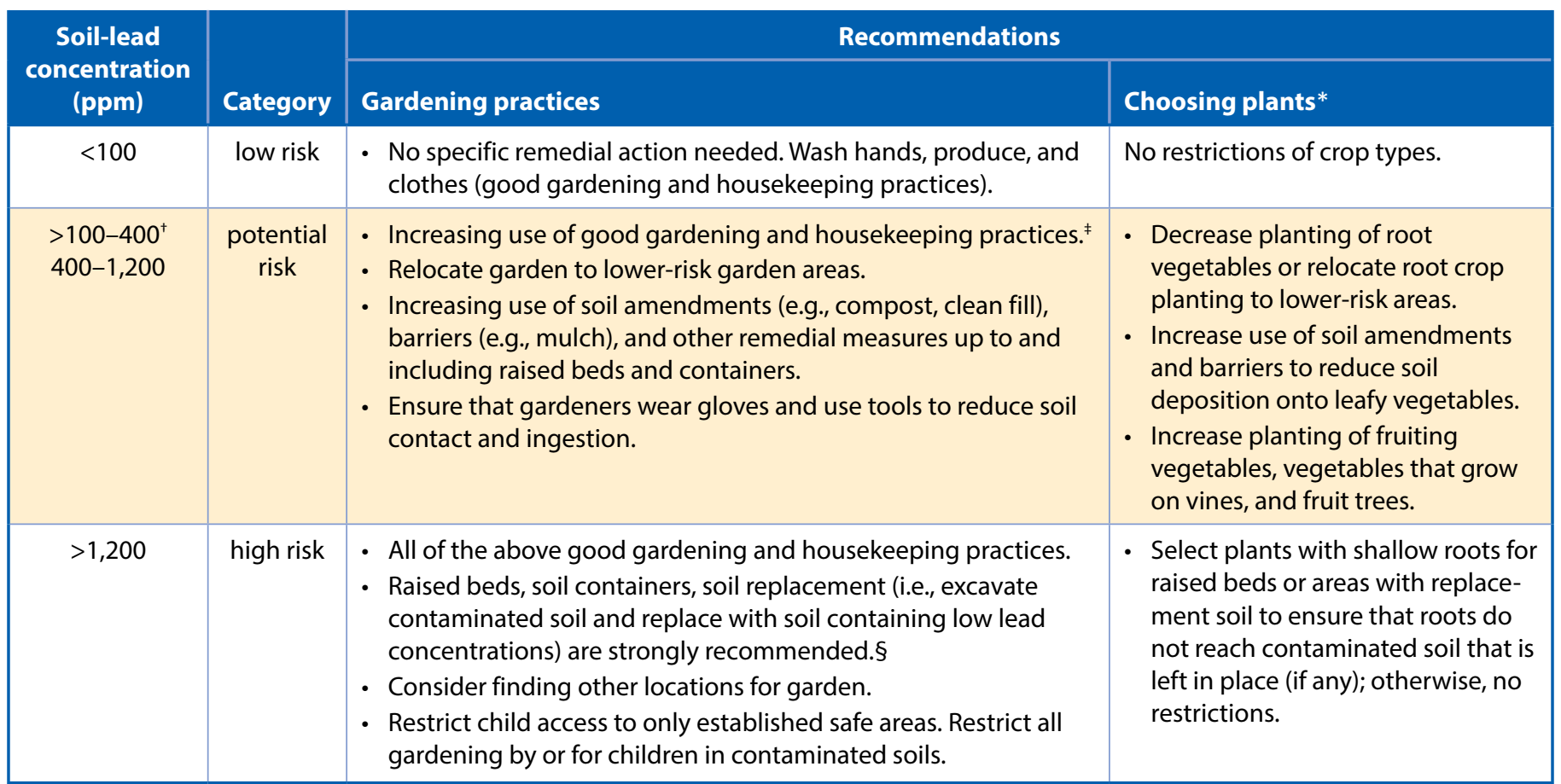

Source: U.S. EPA 2014.

*See U.S. EPA 2014, pp. 20-21.

tWhile 400 ppm lead in soil is considered an appropriate screening level for residential soil lead concentration, the TRW recommends that 100 ppm be used as the low end of the range of soil lead concentrations to mitigate exposure to lead in soil when gardening is an important exposure pathway. Lacking the information to support a quantitative approach for estimating risk for a gardening scenario to support establishing acceptable concentration of lead in garden areas, best professional judgment was used to establish the low end of the range. This soil concentration is below the $400 \mathrm{ppm}$ soil screening level for lead because the gardening exposure pathway includes other sources of lead exposure not sufficiently accounted for in the soil screening level. The basis for the Soil Screening Level (SSL) is children playing in lead-contaminated soil and some other exposures, with the predominant source of exposure from direct soil ingestion or ingestion of soil manifested as house dust. Scientific limitations when it was developed did not allow the SSL for lead to adequately account for consuming home-grown produce. In developing an acceptable concentration of lead in soil for home garden exposures, the same child receptor would be exposed if accompanying the adult in the garden and also exposed through consumption of lead in and on the produce grown in the soil. Hence, the garden-based level is lower than the SSL and reasonable steps to mitigate exposure to lead while gardening in soil-lead concentrations between 100-400 ppm would be appropriate. The TRW acknowledges that background soil-lead concentrations in some communities may exceed the guidance values recommended for garden areas. Mitigation may be necessary for those communities.

\#See U.S. EPA 2014, p. 10.

§Twenty-four (24) inches of clean soil cover is generally considered adequate for gardening; however, site specific conditions should also be considered. A 24-inch barrier normally is necessary to prevent contact of contaminated soil at depth with plant roots, root vegetables, and clean soil that is mixed via deep rototilling. Raised garden beds could cost effectively add 24 inches of clean soil (U.S. EPA 2003). 
beds than in soil, potentially increasing irrigation needs. When possible, it is most economical to plant in the existing soil. If the site has been residential or green space, without a history of industrial use, and soil test results are borderline, it may be possible to work with existing soil by following these best management practices:

1. Turn over the soil deeply and thoroughly.

Contaminants are often concentrated in the top 2 inches of soil and can be diluted through digging and mixing.

2. Maintain the soil $\mathrm{pH}$ at or close to neutral, 6.5 to 7.0. Soil nutrients are most available to plants at this $\mathrm{pH}$, while lead and some other heavy metals are less available.

3. Add organic matter to the soil, and continue to do so with each successive planting. By adding soil amendments and compost, the soil holds water and nutrients more effectively, and heavy metals bind to organic matter and become less available to plants. Organic matter improves soil structure, infiltration, and water-holding capacity, and it also creates a better environment for plant roots by slowly releasing plant nutrients.

Two related products can be considered for use in improving existing garden soil. Biochar is a charcoal product that when mixed with soil adsorbs heavy metals and binds them tightly, making them less available in the soil. It has other potential benefits, including holding water and releasing plant nutrients. The second product, activated charcoal, is sometimes mixed with soil to adsorb contaminants including certain pesticides, herbicides, and petroleum products. Both products can raise soil $\mathrm{pH}$, which could pose a problem if soil is already alkaline. See the section "Sources of More Information" to learn more about these materials before applying them.

\section{Soil Removal}

The most cautious strategy, perhaps most likely to be considered when dealing with a brownfield site, is to remove existing soil from the growing area and replace it with soil that is certified safe. When seeking clean replacement soil, ask vendors for a copy of a soil test report for the product you are considering. However, this expensive procedure is out of the range of what most community groups or individuals can afford. Contaminated soil must be disposed of according to law, which can be expensive, in addition to the costs involved with soil excavation, removal, and replacement

\section{Raised Beds}

A more common approach is to build raised beds and fill them with clean soil. A study of backyard, school, and community garden soils in San Francisco showed that raised bed gardens had significantly lower levels of arsenic, cadmium, and lead than in-ground gardens (Gorospe 2012). Another study, conducted in Chicago, measured significantly less lead in raised bed gardens than in-ground gardens (Witzling et al. 2010).

To create raised beds, urban farmers can build frames of redwood or other lumber, brick, concrete, rocks, or any other sturdy material that will not leach contaminants into the soil. Treated lumber should be avoided since lumber treatments may cause copper or other metals to leach into the soil.

Water-permeable fabrics can be applied as a barrier between the on-site soil and the imported soil used to fill raised beds. Landscape fabric is permeable to liquids and air, unlike black plastic. Landscape fabrics are made from various materials, including nonwoven polypropylene, woven fabric, biodegradable paper mulch, or flexible geotextile fabric.

Once the frame has been lined with landscape fabric, it should be filled with "clean" soil. One way of ensuring that soil is clean is to purchase topsoil or planting mix certified by the Organic Materials Review Institute (OMRI). OMRI performs an independent review of products intended for use in certified organic production, handling, and processing. OMRI reviews producer-submitted products against the National Organic Standards and generates a list of acceptable products. See the OMRI Crop Products list at their website, http://www.omri.org/ sites/default/files/opl_pdf/crops_category.pdf. Some products that are not OMRI-listed may still meet USDA organic rules; the producer may have decided against the expense of being reviewed by OMRI. Local urban farmers or gardeners may have recommendations on potential sources of quality soil. Some vendors may be able to provide documentation that soil has been tested, but, if not, a sample of the soil could be sent to a lab for testing to be sure that it is not contaminated. 


\section{Other Containers}

Other types of containers besides raised beds can be used in urban agriculture. For example, some commercially available growing systems are self-watering, for smaller-scale projects. Others are mesh "socks" that are filled with growing medium and placed on top of the soil. These types of "instant gardens" may be especially appropriate for short-term projects. Although tires are sometimes used as planters, this practice is not recommended, since tires can contaminate soil with leached metals as they degrade over time.

\section{Asphalt Removal}

At some sites, such as schools, open ground is not available, and gardens are constructed over asphalt. In other cases, the asphalt is removed, a process known as depaving, which converts an unused paved area into a garden space. This is a sizeable project to undertake, especially if done manually with the help of volunteers. If a professional company is hired to do the job, though, depaving can be a major expense.

Many sites have created successful urban agriculture projects through depaving. For example, in 2006, volunteers removed 5,000 square feet of asphalt from the grounds of Carthay Center Elementary School in Los Angeles and created a thriving garden for the entire community. To improve the hardened clay soil, tons of soil, mulch, and compost were donated and tilled into the soil by volunteers. The garden consists of raised beds and in-ground beds, as well as a stone fruit orchard, citrus orchard, tropical garden, butterfly garden, and poetry garden.

If a site plan calls for depaving, test for heavy metals and other contaminants prior to removal. To test soil beneath asphalt, cut triangular holes in the asphalt with a hand-held concrete saw to expose the soil. Then remove the asphalt triangles, along with any subgrade debris or stones, and obtain the samples. Replace the pavement triangles and add sand or pea gravel afterward to eliminate a tripping hazard. If soil tests show heavy metals above recommended levels, consider raised beds or large containers rather than removing the asphalt.

\section{Choosing Ornamentals Over Food Crops}

Some sites not appropriate for growing food might still be perfect for ornamental trees and shrubs or a wildflower meadow. Not every site needs to be for food production; sites can serve other purposes in the community, such as green space and beautification.

\section{BEST MANAGEMENT PRACTICES}

Several gardening practices, such as the following, make sense in many urban agriculture settings, whether gardening in the soil, raised beds, or other containers, even where soil testing does not indicate problems:

- Remove any debris from the site, such as trash, metal, wood, and tires. Use care in removal and disposal of these materials, being aware of and following any pertinent regulations.

- Cover the soil wherever possible. Do not leave soil in open areas uncovered, especially if the soil is known to be contaminated. Plant open areas with a ground cover or mulch them. Mulch paths and walkways between planting beds. Mulch not only keeps weeds in check and conserves water, it also helps prevent dust that may contain lead or other contaminants from getting on crops or other surfaces that participants may touch. Install landscape fabric under mulch to prevent erosion, evaporation, airborne dust, and weeds.

- Wear gloves while working on the site.

- Facilitate hand-washing. Incorporate a hand-washing station into the urban farm and train participants to use it frequently. Washing hands immediately after working in the urban farm is an important practice to prevent exposure to harmful materials that may be in the soil. Hand-washing is even more important for children, who tend to put their fingers in their mouths and are more vulnerable to relatively smaller amounts of harmful materials.

- Thoroughly wash produce from the site before storing, cooking, and eating. If desired, rinsing in a vinegar solution (1 part vinegar to 100 parts water) can help ensure that tiny particles of soil are washed off. Remove older, outer leaves of lettuce or leafy greens before eating. Peel root vegetables before eating.

- Wear closed-toe footwear while working on the urban farm. If possible, remove shoes worn while at the farm before entering the home. Consider rinsing gardening items that may also have soil on them. 


\section{REFERENCES}

City and County of San Francisco Department of Public Health, Occupational and Environmental Health. 2010. Guidance for San Francisco residents and public agencies: Lead hazard risk assessment and management of urban gardens and farms. San Francisco: Children's Environmental Health Promotion.

Craigmill, A., and A. Harivandi. 2010. Home gardens and lead: What you should know about growing plants in lead-contaminated soil. Oakland: University of California Agriculture and Natural Resources Publication 8424. ANR catalog website, http:// anrcatalog.ucanr.edu/Details.aspx? item $\mathrm{No}=8424$.

Depave. 2012. How to depave: The guide to freeing your soil. Portland, OR: Parking Lots to Paradise Productions.

Goodwin, E. 2011. Dilmun Hill Cornell Student Farm soil best management practices project report. Ithaca, NY: Cornell University.

Gorospe, J. 2012. Growing greens and soiled soil: Trends in heavy metal contamination in vegetable gardens of San Francisco. San Jose, CA: San Jose State University Master's Thesis 4131.

Hodel, D. R., and A. C. Chang. 2002. Trace elements and urban gardens. University of California Cooperative Extension, Los Angeles County website, http://celosangeles.ucanr.edu/ Environmental_ Horticulture/Trace_Elements_and_Urban_ Gardens_568/.

Hodgson, K., M. Caton Campbell, and M. Bailkey. 2011. Urban agriculture: Growing healthy, sustainable places. Chicago: American Planning Association.

Kessler, R. 2013. Urban gardening: Managing the risks of contaminated soil. Environmental Health Perspectives 121:11-12.

Peryea, F. L. 1999. Gardening on lead and arsenic contaminated soils. Pullman: Washington State University Extension Publication EB1884.

Shayler, H., M. McBride, and E. Harrison. 2009. Guide to soil testing and interpreting results. Ithaca, NY: Cornell Waste Management Institute.
Surls, R., V. Borel, and A. Biscaro. 2016. Soils in urban agriculture: Testing, remediation, and best management practices. Oakland: University of California Agriculture and Natural Resources Publication 8552. ANR catalog website, https:// anrcatalog.ucanr.edu/Details.aspx?itemNo=8552.

U.S. Department of Housing and Urban Development (HUD). 1995. Report on the national survey of lead-based paint in housing. HUD Contract NO. HC-5848.

U.S. Environmental Protection Agency (U.S. EPA). 2003. Recommendations of the Technical Review Workgroup for Lead for an approach to assessing risks associated with adult exposures to lead in soil. Washington, DC: U.S. EPA Publication EPA540-R-03-001.

___ 2007. The use of soil amendments for remediation, revitalization, and reuse. Washington, DC: U.S. EPA Publication 542-R-07-013.

___ 2011a. Brownfields and urban agriculture: Interim guidelines for safe gardening practices. U.S. EPA Publication 560-S-11-001.

___ 2011b. Evaluation of urban soils: Suitability for green infrastructure or urban agriculture. U.S. EPA Publication 905-R-11-03.

___ 2014. Technical review workgroup recommendations regarding gardening and reducing exposure to lead-contaminated soils. U.S. EPA Office of Solid Waste and Emergency Response Publication OSWER 9200.2-142. U.S. EPA website, http://www. epa.gov/superfund/lead/products/ FINAL\%20 TRW\%20Lead\%20Committee\%20Gardening\%20 Recommendations_06\%6003\% 602014.pdf.

U.S. Geological Survey (USGS). 2013. Polynuclear aromatic hydrocarbons definition page. USGS website, http://toxics.usgs.gov/definitions/pah.html.

Walker-Scott, L. 2009. The myths of rubberized landscapes. Puyallup, WA: Washington State University.

Witzling, L., M. Wander, and E. Phillips. 2010. Testing and educating on urban soil lead: A case of Chicago community gardens. Journal of Agriculture, Food Systems, and Community Development 1(2): 167185. 


\section{Section V. Food Safety Guidelines for Urban Animal Production}

\section{FOOD SAFETY GUIDELINES FOR RAISING SMALL RUMINANTS IN URBAN SETTINGS}

Small ruminants can be a great addition to backyard or other urban agricultural production operations. Sheep and goats are versatile, easy to handle, require relatively small space, and can produce meat, milk, fiber, and fertilizer while acting as a companion animal for the owner. Before starting an urban or backyard farm with livestock, become familiar with city zoning laws and municipal ordinances. Raising livestock in urban or peri-urban areas can create challenges, such as the animals living in close proximity to neighbors, disturbance due to noises and odors, restrictive municipal ordinances, and space limitations. To protect your health and the health of those consuming products from your livestock, it is important to keep a healthy herd or flock as well as practice good sanitation (clean and sanitized tools and equipment) and hygiene practices (clean hands, clothes, and personal protective equipment). For diversified farm operations (raising animals and growing fruits or vegetables) it is also important to follow Good Agricultural Practices (GAPs) and Good Handling Practices (GHPs) to minimize the risk of cross-contamination, particularly in relation to the management, storage, and application of animal manure or compost on the farm, as well as the practice of on-farm sanitation protocols.

\section{Sourcing Healthy Small Ruminants}

You want to begin with a healthy herd. Start by purchasing animals from a healthy herd or flock that has a well-documented herd health program free of diseases. Healthy small ruminants eat regularly, chew their cud, have shiny hair and wool coats, strong legs and feet, are alert and sociable, and have bright and clear eyes. To prevent health problems, develop a herd health program that includes good husbandry practices, proper nutrition, a clean and well-ventilated environment, and preventive measures such as vaccination and deworming. Build a Veterinary-Client-Patient-Relationship (VCPR) with your local veterinarian. In other words, develop a relationship with the veterinarian so he or she can develop a herd health program for you, prescribe medications, and assist you with other questions or issues as they arise. Animal health is closely related to profitability, since healthy animals are more productive and produce animal products free of diseases that could impact public health. The implementation of a system of practices designed to reduce the risk of introducing diseases to a herd or flock and prevent the spread of disease among animals is called biosecurity. Ideally you should work with a veterinarian to develop practical and cost-effective biosecurity measures. Good biosecurity practices include proper handling of new animals; quarantine and isolation of new and sick animals; regular veterinary consultations; limiting contact with visitors, outside animals, and wildlife; use of animal identification; knowledge of interspecies disease transmission; and control of pests and rodents.

The following steps can be taken to develop a herd health program and biosecurity protocols for your farm. Please note that this is not an exhaustive list.

\section{Develop a set of herd health protocols in} consultation with your veterinarian

- vaccination protocols

- deworming protocols

- kidding or lambing protocols

- treatment protocols

- culling plans

- nutrition practices (ration formulation, body score assessment, available feed sources, etc.)

- record keeping of new additions, disease events, feed provided, reproduction and production, body condition scores, laboratory testing results, etc.

\section{Housing}

- Assess available space for pasture and shelter (barn or shed).

- Provide well-ventilated shelters.

- Provide clean feeding and watering areas.

- Provide protection from predators (e.g., fencing).

- Regularly clean and sanitize housing.

- Separate animals by age, if possible. 


\section{Biosecurity Practices (or Standard Operating Procedures)}

\section{Purchasing new animals}

- Check the health status of the source herd or flock.

- Quarantine new animals for at least 2 weeks (ideally 30 days).

- Vaccinate and deworm new animals.

- Separate animals by age.

Traffic control (movement of people, animals, and equipment)

- Restrict visitor access to barns, pastures, kidding or lambing areas.

- Wear personal protective equipment (PPE) when handling animals, cleaning barns, or removing bedding.

- Examples of PPE include gloves, coveralls, and dedicated boots.

- Clean, scrub, and sanitize boots after using in dirty environments (contaminated with animal manure or bedding).

- Provide PPE to visitors.

- Avoid sharing equipment or tools with neighbors to prevent cross-contamination.

- Clean and disinfect your vehicle or trailer after transporting animals (e.g., from fairs, shows, etc.).

\section{Pest control: rodents (rats and mice)}

- Remove food, water, and shelter areas of rodents, and seal entryways (in feed storage facilities and barns).

- Feed pets only the amount of food they will eat at a single feeding or bring food inside at night.

- Keep garbage, trash, and garden debris in receptacles with tight-fitting lids.

- Habitat control: Thin dense vegetation (shrubs, climbing hedges, tree limbs).

- Seal all cracks and openings (e.g., house, barns, coops, etc.).

- Place traps or bait stations (keeping them away from pets and children) every 25 to 50 feet around the perimeter of the house.

- Place traps along beams, walls, and ceiling routes and doors.

- Monitor all traps regularly, and dispose of dead rodents immediately.
Sanitation and cleaning of barn and equipment

- Remove all grossly visible debris. The presence of contaminated organic material, especially feces, will inactivate most disinfectants.

- Wash the area or item with water and detergent.

- Thoroughly rinse the cleaned area to remove any detergent residue. Some disinfectants may be inactivated by detergents. Therefore, it is very important to rinse well after washing the area or item.

- Allow the area or item to dry completely.

- Select and apply an appropriate, effective disinfectant. There are many disinfectants and the efficacy will depend on the use of the right disinfectant for the targeted virus or bacteria, adequate concentration (more is not better), contact time, and consistency. [See Center for Food Security and Public Health (2014) table on characteristics of selected disinfectants.]

- Always read the entire product label and follow dilution instructions explicitly to ensure that the safest, most effective concentration is applied. Contact time may vary depending on the disinfectant selected, but is usually at least 10 minutes.

- Low concentrations of bleach or sodium hypochlorite $(\mathrm{NaOCl})$ (2 to $500 \mathrm{ppm}$ ) are active against vegetative bacteria, fungi, and most viruses. (Note: Household bleach contains $6 \%$ sodium hypochlorite.) See table 7 for bleach dilutions. Higher concentrations (2,500 ppm and above) are highly corrosive, and they are irritating to the mucous membranes, eyes, and skin, so they should be limited in use and must be used with extreme caution. Other disinfectants commonly used in livestock facilities are oxidizing agents (e.g., Virkon-S), phenols (e.g., Tek-Tol), and quaternary ammonium compounds (D 256). Note: Bleach should never be mixed with acids or ammonia, as this will result in the release of toxic chlorine gas.

- Thoroughly rinse away any residual disinfectant and allow the area or item to dry.

\section{Minimizing the Risk of Cross-Contamination on the Farm}

Zoonoses are diseases transmitted directly or indirectly between animals and humans. Foodborne illness is the most frequently observed preventable disease of zoonotic origin, usually caused by ingesting contaminated and improperly handled meat, 
Table 7. Bleach dilutions

\begin{tabular}{|c|c|c|c|c|}
\hline $\begin{array}{c}\text { Sodium } \\
\text { hypochlorite\% }\end{array}$ & Bleach solution ratio & Bleach dilution & $\begin{array}{c}\text { Ppm } \\
\text { (available chlorine) }\end{array}$ & $\begin{array}{l}\text { Comments } \\
\text { always use on } \\
\text { cleaned surfaces }\end{array}$ \\
\hline $0.025 \%$ & $1: 200$ & $\begin{array}{l}11 / 2 \text { Tbsp ( } 0.6 \mathrm{oz} \text { ) bleach } \\
\text { to } 1 \mathrm{gal} \text { water }\end{array}$ & 250 ppm & $\begin{array}{l}\text { common household } \\
\text { use }\end{array}$ \\
\hline $0.1 \%$ & $1: 50$ & $\begin{array}{l}1 / 8 \text { cup ( } 1 \text { oz) bleach to } \\
1 \mathrm{gal} \text { water }\end{array}$ & 1,000 ppm & commonly used \\
\hline $0.16 \%$ & $1: 32$ & $\begin{array}{l}1 / 2 \text { cup ( } 4 \text { oz) bleach to } \\
1 \text { gal water }\end{array}$ & $1,562.5 \mathrm{ppm}$ & commonly used \\
\hline $0.5 \%$ & $1: 10$ & $\begin{array}{l}1 \frac{1 / 2}{2} \text { cups ( } 12 \mathrm{oz} \text { ) bleach } \\
\text { to } 1 \mathrm{gal} \text { water }\end{array}$ & $5,000 \mathrm{ppm}$ & $\begin{array}{l}\text { This is a very strong } \\
\text { solution and should be } \\
\text { used on a limited basis. }\end{array}$ \\
\hline
\end{tabular}

Source: Adapted from Devorak et al. 2008.

milk, or vegetables. Foodborne pathogens can be bacteria (e.g., Campylobacter, Salmonella, E. coli O157:H7), viruses (hepatitis E virus), or parasites (e.g., Cryptosporidium). Many of these pathogens are harbored in the gastrointestinal tract of healthy domestic animals and wildlife. The introduction of foodborne pathogens to vegetable crops may occur through different routes, such as wildlife intrusions (e.g., deer, rodents), contaminated water, domestic animals (i.e., livestock, poultry, and pets), application of untreated manure, contaminated equipment or vehicles, and through farm workers.

Livestock are considered reservoirs for certain pathogens, and there are many factors that affect the shedding of these pathogens, such as age, husbandry practices, diet, season, and environmental conditions. Small ruminants are carriers of some of these pathogens, including Campylobacter, Salmonella, and Shiga toxin-producing Escherichia coli (STEC). Raising healthy small ruminants by following good husbandry practices will reduce the risk of transmission and shedding of these pathogens through the feces. Because pathogens can be present in manure, there is an increased risk of pathogen spread via food products (i.e., vegetables, fruits, and nuts) when uncomposted or raw manure is applied to crop fields or indirectly contaminates the soil or water. Creating and maintaining adequate separation from animals on adjacent fields or from sources on your own farm is essential. Your vegetable crop fields should be located at a safe distance from sources of animal contamination, such as barns, manure, bedding, compost storage, and other potential runoff sites. When planning to bring animals to your backyard, consider potential runoff issues and wind directions that can blow dust onto your crops.

\section{Guidelines for Producing Safe Milk}

Healthy animals are less likely to carry zoonotic diseases (those that are transmitted from animals to humans) and foodborne pathogens (transmitted through food). There are several zoonotic diseases transmitted through milk (e.g., Brucella, Listeria, tuberculosis, and Coxiella burnetii).

Other zoonotic illnesses are a result of direct or indirect fecal contamination (e.g., Salmonella, Campylobacter, E. coli O157:H7). Animals carrying zoonotic pathogens appear healthy and normal. The consumption of raw milk (unpasteurized milk) has been linked to several foodborne outbreaks in the United States. Minimize microbial contamination and growth in milk by milking clean and healthy animals in a clean environment and by assuring that the milking system, storage, and processing equipment are properly cleaned, sanitized, and maintained. Home pasteurization and heat treatment (heating at $145^{\circ} \mathrm{F}$ for 30 minutes or at $165^{\circ} \mathrm{F}$ for 15 seconds) will destroy disease-producing bacteria and reduce the number of bacteria in milk that can produce off-flavors or spoil milk. Several tools and pieces of equipment can be used for home pasteurization, such as a pasteurizer, double boiler, or glass jars placed in a heated water bath. In order to sell milk or milk products for human consumption, a farm must be licensed and meet the local and state requirements regarding milk quality and safety. If you are in California, please contact CDFA, https://www.cdfa. ca.gov/dairy/, for more information. 
FOOD SAFETY GUIDELINES FOR URBAN POULTRY

There are a number of important food safety considerations when raising chickens in urban environments. Chickens can add tremendous value to an urban farm as a source of protein in the form of eggs and meat, as a pest control measure to help control slugs and other garden pests, and as a reliable source of fertilizer, revenue, and educational opportunities for garden visitors. Yet there are important steps that every urban farmer should take to ensure the maintenance of a healthy flock and minimize the risk of cross-contamination and transmission of diseases between animals and humans.

This section will discuss the importance of biosecurity, namely a set of management practices designed to help reduce the introduction and spread of disease-causing organisms onto and between farms. It will also discuss the importance of good soil practices, as well as good hygiene practices that minimize the risk of human infection or consumption of heavy metals from backyard or urban poultry production. Key topics include good husbandry practices, including obtaining healthy chicks from a reliable source, ensuring good nutrition, and preventive health measures through clean and well-maintained housing, sanitation, water, soils, and ongoing management.

Good Handling Practices (GHPs) including washing and sanitizing surfaces, good health and hygiene practices associated with washing hands after handling poultry, and cleaning and sanitizing personal protective equipment utilized in poultry production are also important to minimize human risk of exposure to possible pathogens and contaminants.

Before planning a backyard or commercial flock, it is also important to be aware of your city ordinances. Be sure to determine if keeping chickens in the city is legal and if there are any other restrictions such as the number of hens that can be kept, the size or location of the coop, and whether slaughter is allowed, etc. If producing eggs for sale, make sure to follow California laws pertaining to egg handling for sale (see Food Safety Laws for Egg Producers in Section II of this guide). For more general information on raising chickens in the city, please refer to our Resources section.

\section{Biosecurity Measures to Keep Carriers of Disease Away}

In most circumstances, chickens pose a relatively low risk of giving disease to humans; however, there are a few diseases that can be transmitted back and forth. Proper care and handling of eggs and processing of poultry carcasses are critical to avoid problems. Appropriate disposal of dead birds and used litter are also important (Frame 2009).

Some of the diseases that affect poultry can cause illness and death in the poultry (e.g., Marek's disease virus) but have no effect on human health. Other diseases (Salmonella enteritidis, Campylobacter) do not affect poultry health but can adversely affect human health. In either case, it is important to protect both poultry and humans from risk of exposure to harmful pathogens.

There is some concern that the upsurge in number of small backyard flocks, particularly if not properly managed, might significantly increase the probability of disease exposure to the commercial industry. As such, it is important to follow best practices to minimize the risk of disease in your flock, using the following strategies (Cadena 2015):

- Source chicks from a reliable hatchery that participates in the National Poultry Improvement Plan (NPIP) ("U.S. Salmonella enteritidis Monitored Program") and that are vaccinated against Marek's disease.

- Minimize exposure to wildlife (e.g., birds, mammals), pests (e.g., rodents, mice), and domestic animals that may be carriers of diseases harmful to chicken health. Waterfowl in particular are a reservoir for avian influenza, but other animals can carry or spread the virus.

- Build shade and shelter structures, as well as chicken runs, that are enclosed with hardware cloth that prevent exposure to other animals. Hardware cloth is recommended because it is strong and has small holes that wildlife (e.g., mice, rats, raccoons, skunks, opossums) can't break through. The thicker and closer together the squares are, the better.

- All chicken coops should have a solid floor with litter or slatted floor to prevent pests from entering.

- If you observe a large presence of birds or wildlife predators near your chickens, consider hanging predator repellent tape (shiny tape that can scare birds and other predators). 
Housing: Your chickens will need a dry spot to lay eggs, roost, and generally feel safe when they are not out scratching and hunting for bugs. Chickens need a nest box (one box per five birds) to lay eggs and a perch to rest on (at least 6 inches of perch space per bird is needed). Chicken coops can fall into two basic categories: mobile and permanent. A mobile pen is light enough to be moved around the yard or garden and allows for a controlled movement of the chickens and their litter. A permanent pen restricts the chickens to one area. Hens can be released from both pens during the day to roam the yard, and easily trained to return to roost at night. Many times, permanent pens include a "run," an area outside of the coop where hens can scratch and dust bathe while still being confined within a perimeter fence (ATTRA 2015). However, it is important to minimize risk of exposure to other wildlife as mentioned above.

Outside runs: It is recommended that outside runs be covered with good quality hardware cloth and roofing that will keep out wild birds and keep the chickens inside. Some may find this inconvenient, but it is important. Wild birds can carry diseases that can kill chickens or set up a reservoir of infection that could get into the area's commercial poultry industry with devastating consequences (Frame 2009).

Pest control: Rats and mice like to nest near food and shelter, and they thrive in areas where chicken feed is improperly stored and excessive spillage occurs. Clean up any spilled feed. Rats could become a problem in excessively wet areas or where water leaks occur. Feed should never be sprinkled into the litter or floor of poultry houses. This only encourages rodents to hang around the coops. Feed should be properly dispensed in hanging hoppers that limit access to rodents. Also, unused feed should be stored in closed containers in a cool area. A rodent control program of bait feeding or trapping should be mandatory in addition to all other precautions. Look for signs of mice or rat infestation (i.e., feces, chewing marks, burrows, fur, tracks). Install, monitor, and dispose of traps on a regular basis. Install fences to deter wildlife such as coyotes, foxes, raccoons, or opossums. Rats and rodents can carry many pathogens that are harmful to both humans and poultry, such as E. coli (University of British Columbia 2016). As such, it is important to take precautionary measures to minimize the intrusion of rats and rodents into the chicken coop.
Keep a clean coop: Remove all feathers and dander to reduce viral load in the environment, then use a "dry cleaning" method; use a rag and wipe down all the surfaces. Avoid using water in cleaning because it can promote bacteria and viruses. Keep environment dry. Ensure that the feed you provide your birds is medicated to keep Coccidia levels low. Coccidia is deadly to chickens, but not harmful to humans. Change the litter regularly.

\section{Minimize Risk of Lead Contamination}

To minimize the risk of lead contamination, evaluate the farm or garden site history and adjacent land use to determine if there are any known sites on or adjacent to the farm that may have a risk of prior contamination (such as former dumpsites, old homesteads, barn sites, or other industrial use). If there is evidence of possible risk, take the following measures to minimize the exposure of chickens to contaminated soils (Cornell Waste Management Institute 2013; Shayler 2012; Spliethoff 2013):

- Have your soil tested by a certified lab and work with UC Cooperative Extension to evaluate results. If risk is elevated, consider having eggs tested by a diagnostic lab or chicken's blood tested by a veterinarian.

- Locate the coop or chicken run away from any known potential or historical contaminants (consider risk of drift from adjacent land use as well).

- Add clean soil and clean cover material to the area of concern.

- Discourage flock from eating soil. Provide flock regular feed, grit, and calcium supplements in feeders, instead of scattering food, to reduce ingestion of soil. Calcium may reduce uptake of lead $(\mathrm{Pb})$ into eggs.

- Avoid feeding chickens unwashed plant material, especially from contaminated garden, farm, or yard areas. Best to use reliable source of clean table scraps and feed.

- Keep the coop and run clean at all times. Apply clean straw or mulch to the chicken run and change on a regular basis to reduce exposure to the soil.

- Limit open foraging to reduce exposure to soil contaminants and wildlife that may be carriers of harmful pathogens. 


\section{How to Test for Salmonella enteritidis (SE) in Your Urban Farm}

Salmonella is type of bacteria commonly found in poultry. However, Salmonella enteritidis (SE) is a specific serotype of Salmonella that can cause foodborne illness in humans while typically showing no signs of disease in poultry. Commercial poultry farms in the United States with more than 3,000 laying hens are required by law to test the environment that their birds are raised in for the presence of SE. While not all chickens are carriers of Salmonella enteritidis, for the health and well-being of you, your family, and those who may come in contact with your chickens, you might consider testing for Salmonella enteritidis. Testing one or two times per year will give you some indication of any risk associated with SE in your laying hens. UC Cooperative Extension provides guidelines for procedures on how to test for SE in your flock at their following website, http://ucanr. edu/sites/poultry/files/243638.pdf.

\section{Minimize Risk of Exposure to Salmonella enteritidis (SE) and Other Pathogens Carried by Poultry}

In addition to SE, poultry can also be carriers of Campylobacter. To minimize risk of exposure to pathogens carried by poultry, wash hands with soap and warm water (for at least 20 seconds), scrubbing nails and between fingers after handling birds and baby chicks and after coming into contact with chicken feces (in the coop or back yard). Use disposable hand towels. Do not rely on antibacterial gel or wipes. Consider dedicating a pair of boots solely for use in the chicken coop. Avoid wearing shoes in the house that have come into contact with chicken feces in the yard, on the farm, or in the coop. Do not wash feeders, waterers, or other equipment in the kitchen sink.

The Centers for Disease Control and Prevention (CDC) recommends cooking all poultry and eggs thoroughly. Do not eat or drink foods containing raw eggs. Wash hands, kitchen work surfaces, and utensils with soap and water immediately after they have been in contact with raw meat, poultry, or eggs. Be particularly careful with foods prepared for infants, the elderly, and the immunocompromised.

\section{Avoid Risk of Pathogen Exposure from Use of Chicken Manure as Fertilizer}

Because poultry may carry foodborne pathogens, such as E. coli, Salmonella, or Campylobacter, in their gastrointestinal tract, there is an increased risk of pathogen spread via food products (e.g., vegetables, fruits, and nuts) when manure is applied to crop fields. Some pathogens can persist for long periods in the soil. Salmonella can persist in the litter applied to fields for more than 6 months. Campylobacter can persist for about 25 days. Factors affecting the survival in the soil (and compost) include livestock species, pathogen, manure type, composition (e.g., humidity, dry matter), soil type, environmental conditions (e.g., season, ambient temperature, rainfall, sunlight, etc.). To minimize the risk of exposure to enteric pathogens, compost the manure following industry standards including appropriate turning, duration, and at the right temperatures. For more details, see the "Manure and Compost Management" section.

\section{Food Safety in Egg Production and Storage}

The following are some general recommendations on effective egg handling practices, or standard operating procedures (SOPs), to minimize food safety risks to consumers of eggs. For more information, see the Resources section of this guide (PEPA 2019).

\section{Egg Collection}

- Keep fresh, clean bedding in front of nests.

- Make rollout options available.

- Collect eggs at least twice daily, more often if extremely hot or cold weather.

- Use clean baskets, plastic or paper flats, cartons.

- Discard excessively dirty, cracked, or misshapen eggs.

\section{Washing Eggs}

\section{For backyard owners}

- It is typically recommended not to wash eggs. Washing eggs, if done incorrectly, can result in pathogenic bacteria getting to the inside of the egg and potentially proliferating. Rather, collect eggs daily; remove dust, soil, manure, and feathers from eggshells, and refrigerate immediately. Try to reduce floor eggs.

\section{For commercial egg handlers}

- It is best to wash eggs as soon as you collect them. 
This helps limit contamination and loss of interior quality. Wash water must be potable.

- All processing facilities and equipment must be kept clean and in good repair and shall be completely washed at the end of each day's operation.

- Lighting and equipment should be adequate to properly identify egg defects in the candling booth and the processing area.

- Potable water with less than 2 ppm of iron shall be used.

- Wash water shall be maintained at $90^{\circ} \mathrm{F}$ or higher and at least $20^{\circ} \mathrm{F}$ higher than the temperature of the eggs to be washed in order to prevent the absorption of water and bacteria through the membrane into the egg. Never let eggs sit in water.

- A USDA-approved cleaning compound shall be used in the wash water.

- Wash water shall be added continuously and replaced every 4 hours.

- Washed eggs shall be spray rinsed with warm water and a USDA-approved sanitizer.

- If eggs are to be oiled, follow USDA guidelines.

\section{Storage}

\section{For commercial egg handlers}

- Eggs should be placed in a cooler or refrigerator immediately after gathering and stored at $45^{\circ} \mathrm{F}$. Do not store eggs with foods or products that give off strong odors since eggs may absorb the odors.

- Store (and package) eggs with the small end down.

- Eggs stored at room temperature $\left(75^{\circ} \mathrm{F}\right)$ can drop as much as one grade per day. Holding fertile eggs at a temperature above $85^{\circ} \mathrm{F}$ for more than a few hours can allow the embryo to start developing.

- Store only clean, dry eggs with unbroken shells.

- Label egg cartons according to applicable federal, state, or local laws and avoid reusing them.

For more detailed information on best practices for raising small ruminants and poultry on an urban farm, including how to construct safe housing, manage and compost manure, create a food safety checklist for egg handlers, etc., please consult the Resources section.

\section{REFERENCES}

Appropriate Technology Transfer for Rural Areas (ATTRA). 2015. Urban Poultry. Butte, MT: National Center for Appropriate Technology. ATTRA website, https://attra.ncat.org/urban-poultry/.

Cadena, M. 2015. Biosecurity on pasture poultry farms. PowerPoint. UC Davis, UC Cooperative Extension website, https://ucanr.edu/sites/poultry/files/265801. pdf.

Center for Food Security and Public Health (CFSPH). 2014. Selected characteristics of disinfectants. Ames: Iowa State University. CFSPH website, http://www.cfsph.iastate.edu/Disinfection/Assets/ CharacteristicsSelectedDisinfectants.pdf.

Cornell Waste Management Institute. 2013. What gardeners can do: Tips for urban chicken keepers. Ithaca, NY: Cornell University Press. Cornell University Library eCommons website, https://ecommons.cornell.edu/bitstream/ handle/1813/48155/What-Gardeners-Can-DoChickens-English.pdf? sequence=2\&isAllowed $=\mathrm{y}$.

Dvorak, G. 2008. Disinfection 101. The Center for food security and public health. Ames: Iowa State University.
Frame, D. 2009. Considerations in raising small backyard flocks of poultry in population-dense communities. Utah State Cooperative Extension website, https://ucanr.edu/sites/poultry/files/186897. pdf.

PEPA (Pacific Egg and Poultry Association). 2019. California egg quality assurance plan. Sacramento, CA PEPA website, http://www.pacificegg.org/ceqap. html.

Shayler, H. 2012. Understanding your test results: Lead in chicken run soils and chicken eggs. Ithaca, NY: Cornell University Cooperative Extension website, http://cwmi.css.cornell.edu/ UnderstandingTestResultsLeadSoilsEggs.pdf.

Spliethoff, H .M., R. G. Mitchell, L. N. Ribaudo, O. Taylor, H. A. Shayler, V. Greene, and D. Oglesby. 2014. Lead in New York City community garden chicken eggs: Influential factors and health implications. Environmental Geochemistry and Health 36, 633-649.

University of British Columbia. 2016. Rats pose health threat to poultry, humans. ScienceDaily website, www.sciencedaily.com/ releases/2016/01/160114121740.htm. 


\section{Section VI. Manure and Compost Management}

Produce growers may use animal manure to improve soil fertility and quality. Manure and compost applications can improve soil health, as well as nutrient availability, water retention, drainage, aeration, and structure. However, organic farmers must follow certain safety restrictions between application and harvest. The prevention of microbial contamination of crops is based on time-interval criteria between application of raw manure and crop harvest. The United States Department of Agriculture (USDA) National Organic Program (NOP) rule requires a 120-day interval between incorporating raw manure into the soil and harvest for crops that have edible portions in direct contact with the soil surface and 90 days for crops that have edible portions not in direct contact with the soil (Rittenhouse 2015).

Manure is of particular importance to organic farmers because they are prohibited from using synthetic fertilizers. But uncomposted manure may be a source of pathogens. The direct and indirect use of manure in crops increases the potential for exposure to foodborne pathogens and consequently can become a food safety hazard. Proper manure and compost processing and application practices are necessary for the reduction of pathogen load. Controlled composting processes (based on temperature and pile turning) have been demonstrated to adequately reduce the microbial load of foodborne pathogens. For turned pile composting, the temperature of the pile should be maintained at $131^{\circ} \mathrm{F}$ or higher for 15 days or longer, and the pile should be turned a minimum of five times. For aerated static composting, the temperature of the pile should be maintained at $131^{\circ} \mathrm{F}$ or higher for 3 consecutive days. Monitoring the pile with thermometers is the only effective way to verify that required temperatures have been reached. Turning times and temperature should be documented. Aged manure piles without turning or controlling temperature may not reach the required temperatures and time for pathogen reduction. There are many factors affecting the survival of pathogens, including the C:N ratio (organic source), temperature, humidity, oxygen, bedding (e.g., straw, rice hulls, wood shavings, etc.), turning, and time (NRCS 2000).

Composting in small-scale urban and peri-urban settings may be challenging. Work with your local farm advisor or extension educator to develop a composting protocol customized to your needs and resources to reduce pathogens.

Integration of sustainable practices such as the use of small ruminants for grazing in fields destined for vegetable cultivation may introduce additional food safety risks. Raw manure deposited in production fields by grazing animals may introduce foodborne pathogens to the growing environment and lead to increased contamination of produce, especially highrisk crops (eaten raw), such as lettuce, tomatoes, or spinach. Limited science-based data exists to define the microbial risk or adequate waiting period after animals graze a produce field prior to harvest.

Organic farmers in the United States follow the National Organic Program (NOP) standards, which require 90 or 120 days between incorporating raw manure into the soil and harvest. Although not specifically addressed in NOP, farmers using grazing within production fields may also use this standard (Pires 2015).

The following SOP provides the key elements for safe and effective manure and compost management and application in urban farms.

\section{SOP: Manure and Compost Application in Urban Farms or Home Gardens (Graham et al. 2015)}

- Keep manure storage areas physically isolated from vegetable handling facilities, home garden fields, equipment, and open water sources.

- Use covers or barriers to minimize the risk of leaching, runoff, or spreading by wind.

- Properly compost animal manure following industry standards.

- Avoid recontamination by separating piles, minimizing leaching or runoff, and reducing the risk of introduction of wild or domestic animals.

- Practice good personal hygiene when handling manure or compost. Use proper personal protective equipment (PPE) and sanitation. Wash hands after handling manure or compost. Wear a mask, or mist the compost if it is dusty.

- Maximize the time between application of raw animal manure to garden areas and harvest of vegetable crops. 
- Application of manure and harvesting interval (time between application and crop harvest) follow the NOP rules described above.

- Apply untreated manure only in crops with a lower risk (e.g., crops normally cooked or produce not in direct contact with the soil).

- Minimize the contact between produce and applied manure (e.g., plastic mulch).

- Untreated or uncomposted manure should not be used as a side-dress or top dress for crops; always incorporate raw manure into the soil.

- Consider using cover crops to minimize manure nutrient leaching or runoff from fallow fields.
- Keep records of the type of manure being applied (age, treatment, source, etc.), composting method (turning times, temperature, feedstocks used, etc.), date of application, rate (quantity applied), method of application, and what crops will be grown.

- During growing and harvest seasons, keep domestic and wild animals and pets out of areas with vegetable crops.

For more detailed instructions for on-farm composting and best practices to ensure on-farm food safety with the use of manures and compost, please consult the Resources section of this guide.

\section{REFERENCES}

Graham, C., A. Adhikari, F. Malekian, K. Fontenot, and M. L. Lewis Ivey. 2015. Manure use: Best practices to ensure on-farm food safety. Factsheet by LSU AgCenter and Southern University Agricultural Research and Extension Centers. Baton Rouge: Louisiana State University website, https:// www.lsu.edu/agriculture/plant/extension/hcplpublications/14_Pub.3463-ManureUse.pdf.

Natural Resources Conservation Service (NRCS). 2000. Composting. Environmental Engineering National Engineering Handbook, Chapter 2, Part 637. Washington, D.C.: USDA. NRCS website, https:// www.nrcs.usda.gov/Internet/FSE_DOCUMENTS/ nrcs143_022229.pdf.
Pires, A. 2015. Mixed species and crops considerations, pastured poultry workshop PowerPoint. Davis, CA: UC Davis Veterinary School. UC ANR website, http://ucanr.edu/sites/poultry/files/265805.pdf.

Rittenhouse, T. 2015. Tipsheet: Manure in organic production systems. NCAT, ATTRA. Butte, MT: National Center for Appropriate Technology. NCAT website, https://www.ams.usda.gov/sites/default/files/ media/Manure\%20in\%20Organic\%20Production\%20 Systems_FINAL.pdf. 


\section{ORGANIZATIONAL RESOURCES}

The following organizations provide free or low-cost informational resources for small farms on food safety, regulations, and other topics. Some of these organizations periodically organize in-person trainings and other events.

- Community Alliance with Family Farmers /the Farmers' Guild, http://www.caff.org/programs/ foodsafety/

- Cornell College of Agriculture and Life Sciences National Good Agricultural Practices Program, https://gaps.cornell.edu

- National Sustainable Agriculture Coalition, http:// sustainableagriculture.net/publications/

- Sustainable Economies Law Center, http://www. theselc.org/food_resources

- UC Agriculture and Natural Resources, http:// ucanr.edu/sites/UrbanAg/

- UC Cooperative Extension Small Farm Program, http://sfp.ucdavis.edu/food_safety/

\section{Food Safety Laws for Urban Agriculture (pertinent to Section II)}

- California Department of Food and Agriculture (CDFA), https://www.cdfa.ca.gov/ahfss/Animal_ Health/Food_Safety.html

- CDFA Small Farm Food Safety Guidelines (multiple languages), https://www.cdfa.ca.gov/is/i_\&_c/ sffsg.html

- Community Alliance with Family Farmers' Guild, http://www.caff.org/programs/foodsafety/

- Food and Drug Administration Fact Sheets on FSMA, https://www.fda.gov/Food/GuidanceRegulation/FSMA/ucm247546.htm

- Sustainable Economies Law Center, http://www. theselc.org/food_resources

- University of California Agriculture and Natural Resources Urban Ag, https://ucanr.edu/sites/UrbanAg/ Food_Safety_Handling_and_Processing_/

\section{Developing a Food Safety Program for Your Urban Farm (pertinent to Section III)}

\section{General Food Safety Tips}

Cornell University's Produce Safety Alliance, Farm Food Safety Plan Writing Resources, https:// producesafetyalliance.cornell.edu/resources/farmfood-safety-plan-writing-resources/

Dahlquist-Willard, R. 2016. To learn how to make an inexpensive hand-washing station, watch "Making Your Own Handwashing Station." UCCE video: https:// www.youtube.com/watch?v=0XCXVcTVQMc

Suslow, T. 2003. Key points of control and management for microbial food safety: Edible landscape plants and home garden produce. Oakland: University of California Agriculture and Natural Resources Publication 8101. ANR catalog website, http:// anrcatalog.ucanr.edu/pdf/8101.pdf

Washington State Department of Agriculture, "Bridging the GAPS, Farm Guide Good Agricultural Practices and On-Farm Food Safety for Small, Mid-Sized and Diversified Fruit and Vegetable Farms": https://agr.wa.gov/ departments/business-and-marketing-support/ gapghp

University of Vermont Sustainable Agriculture Program's Standard Operating Procedures Needed for GAPs and How to Write Them: https://ucanr.edu/ sites/UrbanAg/files/285022.pdf

USDA Food Safety Tips for School Gardens Memo. 2009. https://fns-prod.azureedge.net/sites/default/ files/foodsafety_schoolgardens.pdf

USDA Food and Nutrition Services, "Implementing Farm to School Activities. Food Safety: https:// www.fns.usda.gov/cfs/implementing-farm-schoolactivities-food-safety

\section{Disinfection and Sanitizing}

Center for Food Security and Public Health, Iowa State, on Disinfection: http:// www.cfsph.iastate.edu/ Disinfection/

Center for Public Safety and Environmental Health. Downloadable sign titled "Cleaning and Disinfection Protocol." Ames: IA: Iowa State University. http:// www.cfsph.iastate.edu/Maddies_Textbook/Resources/ CleaningDisinfection/SignCleaningDisinfectProtocol. pdf

Contra Costa Health Services Department. Fact Sheet 
on well disinfection procedures. Contra Costa County, California. https://cchealth.org/eh/smallwater/pdf/ well_disinfection_procedures.pdf

Cornell National GAPs Program Cleaning and Sanitizing Guide: https://gaps.cornell.edu/ educational-materials/decision-trees/sanitation-andpostharvest-handling/

Dvorak, G. 2008. Disinfection 101. The Center for Food Security and Public Health. Ames, IA: Iowa State. http://www.cfsph.iastate.edu/Disinfection/ Assets/Disinfection101.pdf (This guide is geared for disinfection in livestock operations.)

Strohbehn, C., and P. A. Domato. 2011. On-farm food safety: Cleaning and sanitizing guide. Publication 1974c. Ames, IA: Iowa State University Extension.

University of Massachusetts Extension. Fact Sheet on produce wash water sanitizers: Chlorine and PAA. https://ag.umass.edu/sites/ag.umass.edu/files/factsheets/pdf/pssanitizerlawtonkinchlasept15.pdf

\section{Soils in Urban Agriculture: Testing, Remediation, and Best Management Practices (pertinent to Section IV)}

\section{Soils and Soil Testing}

Basic Soil Science. The University of California’s Master Gardener Program has a "Garden Web" that offers a helpful list of common questions and answers on basic soil science, including soil texture, structure, $\mathrm{pH}$, salinity, nutrients, and fertilizers. ucanr.org/sites/ gardenweb/Vegetables/? uid $=26 \& \mathrm{ds}=462$

UC Davis Soil Web. The UC Davis Soil Web is a useful online tool that can give clues to past disturbances, soil removal, fill dirt additions, etc., in many areas of California. casoilresource.lawr.ucdavis.edu/soilweb/

\section{Brownfields Reuse}

Although urban agriculture is not yet a common reuse, the California Department of Toxic Substances Control (DTSC) offers helpful information about brownfields and California's voluntary cleanup program on their website, https://dtsc.ca.gov/ brownfields/

"Re-Use: Creating Community-Based Brownfield Redevelopment Strategies" is an American Planning Association resource that provides details on the reuse of brownfield sites, including agricultural use of remediated brownfields, and is also a helpful guide to community engagement, funding, site assessment, and cleanup of contaminated sites. The guidebook includes a case study of a brownfield site converted to a successful urban farm. https:// planning-org-uploaded-media.s3.amazonaws. com/legacy_resources/research/brownfields/pdf/ brownfieldsguide.pdf

\section{Soil Quality/Soil Health}

The USDA Natural Resources Conservation Service has a very useful website with a variety of resources, including assessment cards to use to evaluate soil. http://www.nrcs.usda.gov/wps/portal/nrcs/site/soils/ home/

\section{Soil Testing and Remediation for Urban Agriculture}

"Activated Charcoal" is a University of Florida Extension web page that includes information on the various uses of activated charcoal in soil remediation. http:// solutionsforyourlife.ufl.edu/ hot_topics/sustainable_ living/activated_charcoal.shtml

"Biochar: A Home Gardener's Primer" is a Washington State University Extension fact sheet that provides a quick overview of what biochar is, the science behind its manufacture and use, and how it affects soil, plants, and the environment. http://cru.cahe.wsu. edu/CEPublications/FS147E/ FS147E.pdf

Cornell University's Waste Management Institute has extensive information on soil testing and remediation. http://cwmi.css.cornell.edu/soilquality. htm

"Heavy Metals and Gardens," created by Jennifer Gorospe at San Jose State University, offers multilingual resources for urban California residents on soil testing, interpreting results, and remediation. https://sites.google.com/site/healthygardeners/home

The Organic Materials Review Institute (OMRI) provides lists of certified organic soil and soil amendment sources that can help identify possible sources of certified clean soils and amendments. http://www.omri.org/omri-lists

\section{Policy-Related Resources on Urban Agriculture and Soil}

"Dig, Eat, and Be Healthy: A Guide to Growing Food on Public Property" is a guidebook from ChangeLab Solutions that offers strategies for negotiating the use of public land for growing food, including types of agreements and specific suggestions on how to handle the issue of soil testing in such agreements, and it includes a helpful section on school gardens. changelabsolutions.org/sites/default/files/Dig_Eat_ and_Be_Happy_FINAL_20130610_0.pdf

"Seeding the City: Land Use Policies to Promote Urban Agriculture" is a downloadable toolkit from ChangeLab Solutions that focuses on best practices for urban agriculture, with 
helpful model comprehensive plan language on various aspects of farming in cities, including soil testing. changelabsolutions.org/sites/ default/files/Urban_Ag_SeedingTheCity_ FINAL_\%28CLS_20120530\%29_20111021_0.pdf

\section{Food Safety Guidelines for Animal Production in Urban Farms (pertinent to Section V)}

\section{Small Ruminants}

An Illustrated Guide to Sheep and Goat Production: https://attra.ncat.org/attra-pub/summaries/ summary.php?pub=218

Biosecurity for Sheep and Goat Producers. USDA Animal and Plant Health Inspection Department. https://www.aphis.usda.gov/aphis/ourfocus/ animalhealth/animal-disease-information/sheepand-goat-health/ct_biosecurity

California Department of Food and Agriculture (CDFA). 2015. Regulatory requirements for distribution of milk for raw consumption in California. Sacramento, CA: CDFA. www.cdfa. ca.gov/ahfss/Milk_and_Dairy_Food_Safety/pdfs/ RawMilkRequirementsSummary.pdf

eXtension Materials-Goats: http://articles.extension. org/goat

Coffey, L. 2017. Sheep and goats: Frequently asked questions. Butte, MT: National Center for Appropriate Technology. https:// attra.ncat.org/attrapub/viewhtml.php?id=579

Coffey, L., M. Hale, and H. Lewis. 2010. Small ruminant resources. Butte, MT: National Center for Appropriate Technology. https://attra.ncat.org/attrapub/viewhtml.php?id=221

Goat Vegetation Management: http://articles.extension. org/pages/19563/goat-vegetation-management

Hale, M., L. Coffey, T. Spencer, and A. Pressman. 2011. Small-scale livestock production. Butte, MT: National Center for Appropriate Technology. https://attra.ncat. org/attra-pub/summaries/summary.php?pub=371

Keeping Your Goats Healthy: http://articles.extension. org/pages/64562/keeping-your-goats-healthy

Managing Internal Parasites in Sheep and Goats: https:// attra.ncat.org/attra-pub/summaries/ summary. php?pub=215

Schoenian, S. Maryland small ruminants. University of Maryland Extension. https://www.sheepandgoat.com
Shepherd, H. 2014. An introduction to animal husbandry and nutrition. Ames, IA: Iowa State Extension. https://store.extension.iastate.edu/ Product/An- Introduction-to-Animal-Husbandryand-Nutrition

\section{Poultry and Eggs}

Baier, A. 2013. Laying hen organic and food safety checklist. ATTRA, Butte, MT: National Center for Appropriate Technology. https://ucanr.edu/sites/ UrbanAg/files/271496.pdf

California Department of Food and Agriculture Egg Safety and Quality Management Program. http:// www.cdfa.ca.gov/ahfss/mpes/esqm.html

California Department of Public Health webpage. California Retail Food Code. Excerpt from California Health and Safety Code Part 7. www.cdph.ca.gov/ services/Documents/fdbRFC.pdf

Cornell Waste Management Institute. 2012. Healthy Soils, Healthy Communities Project. Understanding your test results: Lead in soil and chicken eggs, Ithaca, NY: Cornell Waste Management Institute. https://ecommons.cornell.edu/handle/1813/48152

Cornell Waste Management Institute; Healthy Soils, Healthy Communities Project. 2013. What gardeners can do: Tips for urban chicken keepers. Ithaca, NY: Cornell Waste Management Institute. https:// ecommons.cornell.edu/handle/1813/48155

Egg Grading Manual, United States Department of Agriculture, Agricultural Marketing Service, Agricultural Handbook, Number 75, http://www.ams.usda.gov/AMSv1.0/ getfile?dDocName=STELDEV3004502. (See Shell Egg Processing Plant checklist above.)

Egg Products Inspection Act. Washington D.C.: Food Safety Inspection Service. https://www.fsis.usda.gov/ wps/portal/fsis/topics/rulemaking/egg-productsinspection-act/EPIA

Ernst, R. A. 2004. Hatching egg sanitation: The key step in successful storage and production. Oakland, University of California Agriculture and Natural Resources Publication 8120. http://anrcatalog.ucanr. edu/pdf/8120.pdf

Frame, D. D. 2009. Considerations in raising small backyard flocks of poultry in population-dense communities. Utah Cooperative Extension. http:// ucanr.edu/sites/poultry/files/186897.pdf

PEPA (Pacific Egg and Poultry Association). 2019. California egg quality assurance plan. Sacramento, CA. http://www.pacificegg.org/ceqap.html 
Pires, A. 2015. Mixed species and crops considerations. Pastured Poultry Workshop PowerPoint. Oakland, University of California Agriculture and Natural Resources. http://ucanr.edu/sites/poultry/ files/265805.pdf

Pitesky, M. 2016. Root simple podcast: 76 Keeping your poultry healthy with Dr. Maurice Pitesky. https:// www.rootsimple.com/2016/02/076-keeping-yourpoultry-healthy-with-dr-maurice- pitesky/

USDA Factsheets. Shell eggs from farm to table. Food Safety Inspection Service website, USDA. https:// www.fsis.usda.gov/wps/portal/fsis/topics/food-safetyeducation/get-answers/food-safety-fact-sheets/eggproducts-preparation/shell-eggs-from-farm-to-table/ CT_Index

\section{Manures and Compost Management (pertinent to Section VI)}

\section{Composting}

Erickson, M., F. Critzer, and M. Doyle. 2010.

Composting criteria for animal manure. Issue brief by the Produce Safety Project, Pew Charitable Trusts. http://www.pewtrusts.org/ /media/assets/2009/ psp20issue20brief20seriespdf.pdf?la=en

Frankenfield, A. 2017. Compost: How to make it and how much to use. Factsheet by Pennsylvania State University Extension. http://extension.psu.edu/ business/start-farming/soils-and-soil- management/ compost-how-to-make-it-and-how-much-to-use.

Graham, C., A. Adhikari, F. Malekian, K. Fontenot, M. L. Lewis Ivey. 2015. On-farm composting: Best practices to ensure on-farm food safety. Fact sheet by LSU Ag Center and Southern University Agricultural Research and Extension Centers. http://edit.lsuagcenter.com/ /media/system/6/7/c/ 1/67c15464da8a3e23b85e6edf7035331f/15_pub3460_ onfarmcomposting_finalpdf.pdf

\section{Manure Management and Storage}

Anonymous. 2013. Handling and storage options for manure. Series of factsheets, videos, and webcasts hosted by eXtension. http://articles.extension.org/ pages/8638/handling-and-storage-options-formanure.

Bradley, A. L. 2018. Manure management for small and hobby farms. Fact sheet by Northeast Recycling Council. https://nerc.org/documents/manure management/ manure_management_handbook.pdf
Graham, C., A. Adhikari, F. Malekian, K. Fontenot, and M. L. Lewis Ivey. 2015. Manure use: Best practices to ensure on-farm food safety. Fact sheet by LSU Ag Center and Southern University Agricultural Research and Extension Centers. http://edit.lsuagcenter.com/ /media/system/6/7/c/ 1/67c15464da8a3e23b85e6edf7035331f/14_pub3463_ manureuse_finalpdf.pdf

\section{Manure and Compost Management and Food Safety Risks}

City of San Jose Gardening and composting. https:// www.sanjoseca.gov/your-government/environment/ homes-green-tips-resources/gardening-composting

Central Vermont Solid Waste Management. Building your own composting bin: Designs for your community. http://www.cvswmd.org/ uploads/6/1/2/6/6126179/variety_of_bin_plans.pdf

Compost bulking materials, Cornell Waste Management Institute.https://ecommons.cornell.edu/bitstream/ handle/1813/2314/compostfs5.pdf;sequence $=4 \backslash$

Cornell National Good Agricultural Practices Program. Soil amendments. http://gaps.cornell. edu/educational-materials/decision-trees/soilamendments

Rishell, E. Making compost from yard waste. Virginia Cooperative Extension Prince William County Office. https://www.pubs.ext.vt.edu/content/dam/ pubs_ext_vt_edu/426/426-703/426-703_pdf.pdf

Rittenhouse, T. 2015. Tip Sheet: Manure in organic production systems. Butte, MT: National Center for Appropriate Technology. https://www.ams.usda. gov/sites/default/files/media/Manure\%20in\%20 Organic\%20Production\%20Systems_FINAL.pdf media/Manure\%20in\%20Organic\%20Production\%20 Systems_FINAL.pdf

University of Minnesota Extension. Using manure and compost as nutrient sources and vegetable crops. https://www.extension.umn.edu/garden/fruitvegetable/using-manure-and-compost/

Urban Agriculture Tool Kit from USDA. https://www. usda.gov/sites/default/files/documents/urbanagriculture-toolkit.pdf 


\section{APPENDIX 1. ON-FARM FOOD SAFETY ASSESSMENT FOR CALIFORNIA URBAN FARMS}

(Prepared by Jennifer Sowerwine, UC Cooperative Extension, and UC Berkeley, 2018.)

This form is designed to help urban farmers assess and record any food safety risks on their farm, and identify and monitor what corrective actions, if necessary, should be taken to ensure the farm is following good agricultural practices, good animal husbandry practices, and good handling practices to minimize the risk of on-farm contamination. The materials herein are adapted from the USDA

\section{Instructions on How to Use This Form}

1. Review the document in advance. Determine when and how to do an on-farm risk assessment. For example, choose a time immediately after the rains to evaluate any risk of water runoff onto your crops. To evaluate whether workers are following good health and hygiene practices and implementing standard operating procedures, be sure to assess the farm during harvest season.

2. For each question, record "Yes" (it is already being done), "No" (if it still needs to be done), or "N/A" if it is not applicable to your farm operation. In the notes section, record any notes or corrective actions that may be needed.

3. The column labeled "Doc" indicates the type of documentation that may be required to show
Good Agricultural Practices and Good Handling Practices Audit Verification Checklist and User's Guide, https://www.ams.usda.gov/sites/default/ files/media/GAPGHP_Audit_Program_User\%27s_ Guide\%5B1\%5D.pdf, and the CDFA Food Safety Guidelines, which focus on fresh produce safety, https://www.cdfa.ca.gov/is/i_\&_c/pdfs/SFFSGbooklet-English.pdf. For more detailed information on how to assess good husbandry practices for small ruminants and poultry, please refer to Section V of this guidebook and the Resources section.

conformance to that question. For example, it might include documented standard operating procedures (SOPs) posted on the wall for workers to follow or outlined in your food safety manual (FSM). Or it might include a record-keeping sheet $(R)$ showing an action was taken. A " $\mathrm{P}$ " indicates that a policy or standard operating procedure is included in the Food Safety Manual to show conformance with the question.

4. As noted above, in some instances, observation of the practice is necessary to assess conformance with the question. This may involve making observations at the farm during harvest season to observe behavior of volunteers, workers, and helpers. 


\section{General Farm Information}

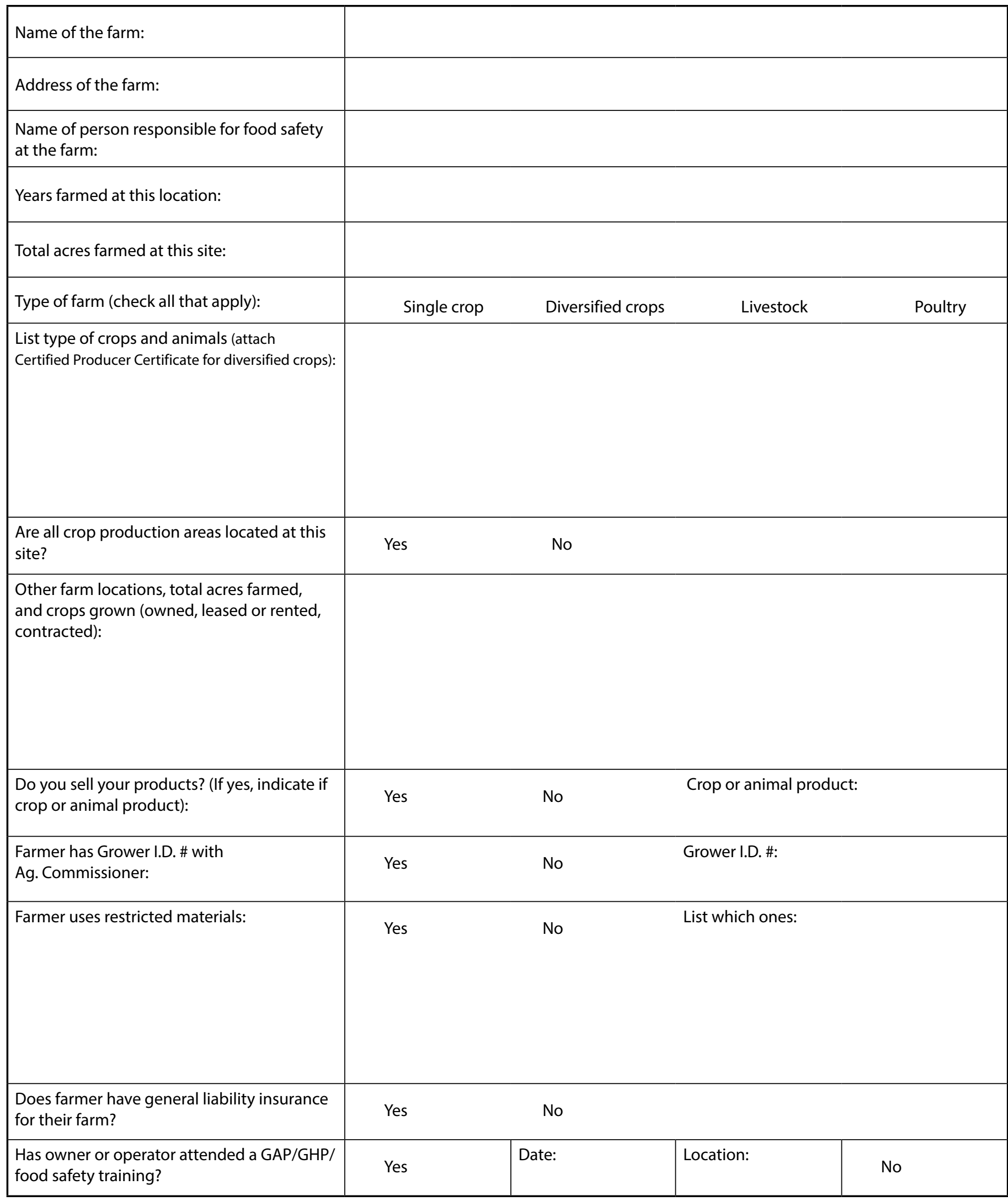




\section{Implementation of a Food Safety Program}

\begin{tabular}{|c|c|c|c|c|c|}
\hline Questions & Yes & No & N/A & Doc & Notes (describe) \\
\hline $\begin{array}{l}\text { 1. A documented food safety program that } \\
\text { incorporates GAPs and GHP has been } \\
\text { implemented. }\end{array}$ & $\square$ & $\square$ & & D: FSM & \\
\hline $\begin{array}{l}\text { 2. A map exists that accurately represents the } \\
\text { farm. }\end{array}$ & $\square$ & $\square$ & $\square$ & Map & \\
\hline $\begin{array}{l}\text { 3. The farm owner has designated someone to } \\
\text { implement and oversee an established food } \\
\text { safety program. }\end{array}$ & $\square$ & $\Gamma$ & 7 & D: FSM & \\
\hline $\begin{array}{l}\text { 4. The person responsible for food safety has } \\
\text { taken a food safety training course. }\end{array}$ & $\square$ & 1 & $\square$ & & \\
\hline
\end{tabular}




\section{Traceability}

\begin{tabular}{|c|c|c|c|c|c|}
\hline Questions & Yes & No & N/A & Doc & Notes (describe) \\
\hline $\begin{array}{l}\text { 5. If distributing produce at a farm stand } \\
\text { where the food is grown, a sign with farm } \\
\text { name and address is displayed on-site. }\end{array}$ & & & & D: Sign R & \\
\hline $\begin{array}{l}\text { 6. When selling or donating produce off-site } \\
\text { in a package, all produce is labeled with the } \\
\text { farm name and address. }\end{array}$ & & & & & \\
\hline $\begin{array}{l}\text { 7. When selling directly to the public (rather } \\
\text { than through a food facility such as a store } \\
\text { or restaurant), records of the type of food } \\
\text { sold and the date are kept for } 30 \text { days. }\end{array}$ & & & & & \\
\hline
\end{tabular}




\section{Pesticide Use Reporting Requirements}

\begin{tabular}{|c|c|c|c|c|c|c|}
\hline \multicolumn{2}{|c|}{ Questions } & Yes & No & $\frac{\text { N/A }}{\square}$ & $\frac{\text { Doc }}{D-R}$ & Notes \\
\hline 9. & $\begin{array}{l}\text { Grower records and submits pesticide } \\
\text { use reports by the 10th day of the } \\
\text { month following the month when } \\
\text { pesticide application was completed. }\end{array}$ & & & & & \\
\hline & $\begin{array}{l}\text { Grower keeps pesticide use records for } \\
\text { current year and } 2 \text { years prior. }\end{array}$ & 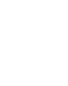 & & 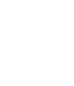 & $D-R$ & \\
\hline
\end{tabular}




\section{Water Quality}

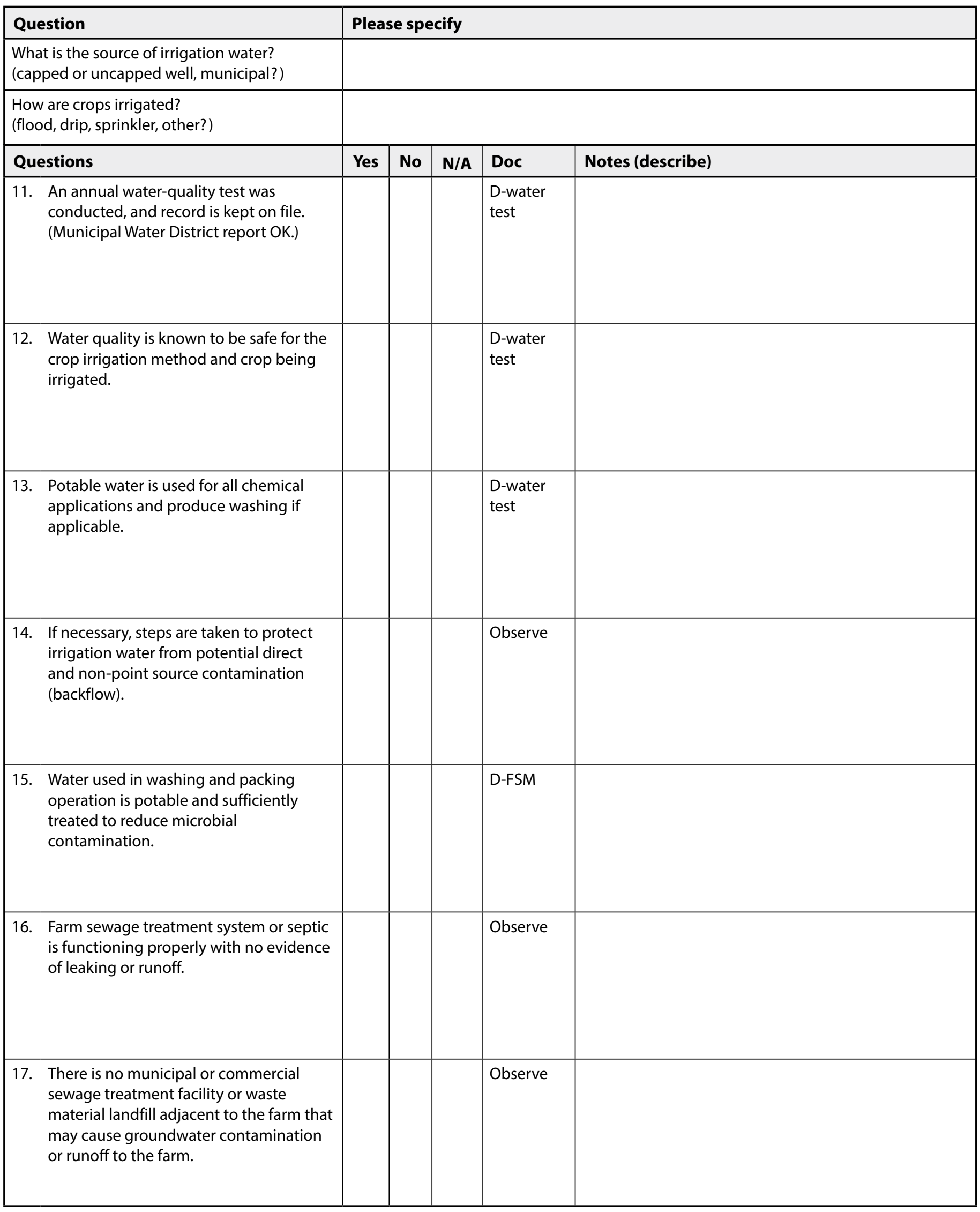




\section{Animals/Wildlife/Livestock/Poultry/Pest Control}

\begin{tabular}{|c|c|c|c|c|c|c|}
\hline \multicolumn{2}{|c|}{ Questions } & \multirow{2}{*}{\begin{tabular}{|c|} 
Yes \\
$\square$
\end{tabular}} & \multirow{2}{*}{$\frac{\text { No }}{\square}$} & \multirow{2}{*}{$\frac{\text { N/A }}{\square}$} & \multirow{2}{*}{\begin{tabular}{|l|} 
Doc \\
Observe
\end{tabular}} & \multirow[t]{2}{*}{ Notes (describe) } \\
\hline 18. & $\begin{array}{l}\text { Crop production areas are not located } \\
\text { near or adjacent to dairy, livestock, or } \\
\text { fowl production facilities unless adequate } \\
\text { barriers exist. }\end{array}$ & & & & & \\
\hline 19. & $\begin{array}{l}\text { Measures are taken to prevent runoff } \\
\text { from adjacent land use (e.g., livestock, } \\
\text { dump, or poultry operations) from } \\
\text { contaminating crop production areas, } \\
\text { using furrows and ditches. }\end{array}$ & $\square$ & 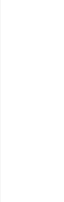 & $\square$ & Observe & \\
\hline 20. & $\begin{array}{l}\text { Crop production area has a 3-year buffer } \\
\text { period if previously used for concentrated } \\
\text { animal husbandry. }\end{array}$ & $\Gamma$ & 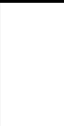 & & & \\
\hline 21. & $\begin{array}{l}\text { Crop production areas are monitored } \\
\text { for presence or signs of wild or domestic } \\
\text { animals entering the land, and this is } \\
\text { documented. }\end{array}$ & $\square$ & $\Gamma$ & 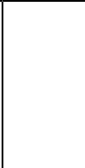 & \begin{tabular}{|l|} 
D-R \\
Observe
\end{tabular} & \\
\hline 22. & $\begin{array}{l}\text { Measures are taken to reduce the } \\
\text { opportunity for wild and domestic } \\
\text { animals to enter crop production areas, } \\
\text { including fences. }\end{array}$ & $\square$ & & & \begin{tabular}{|l|} 
D-R \\
Observe
\end{tabular} & \\
\hline 23. & $\begin{array}{l}\text { Good husbandry practices are followed } \\
\text { in small ruminant and poultry operations } \\
\text { (see Urban Ag Food Safety Guide for } \\
\text { guidelines). }\end{array}$ & $\square$ & & $\Gamma$ & D-FSM & \\
\hline 24. & $\begin{array}{l}\text { Measures are taken to exclude animals or } \\
\text { pests from packing and storage facilities } \\
\text { (traps, mouse barriers, fly paper, enclosed } \\
\text { packing area). }\end{array}$ & $\square$ & ᄃ & $\Gamma$ & Observe & \\
\hline 25. & $\begin{array}{l}\text { There is an established pest and rodent } \\
\text { control program for the facility if } \\
\text { necessary and records are kept. }\end{array}$ & $\square$ & $\square$ & $\square$ & P-FSM R & \\
\hline
\end{tabular}




\section{Soils}

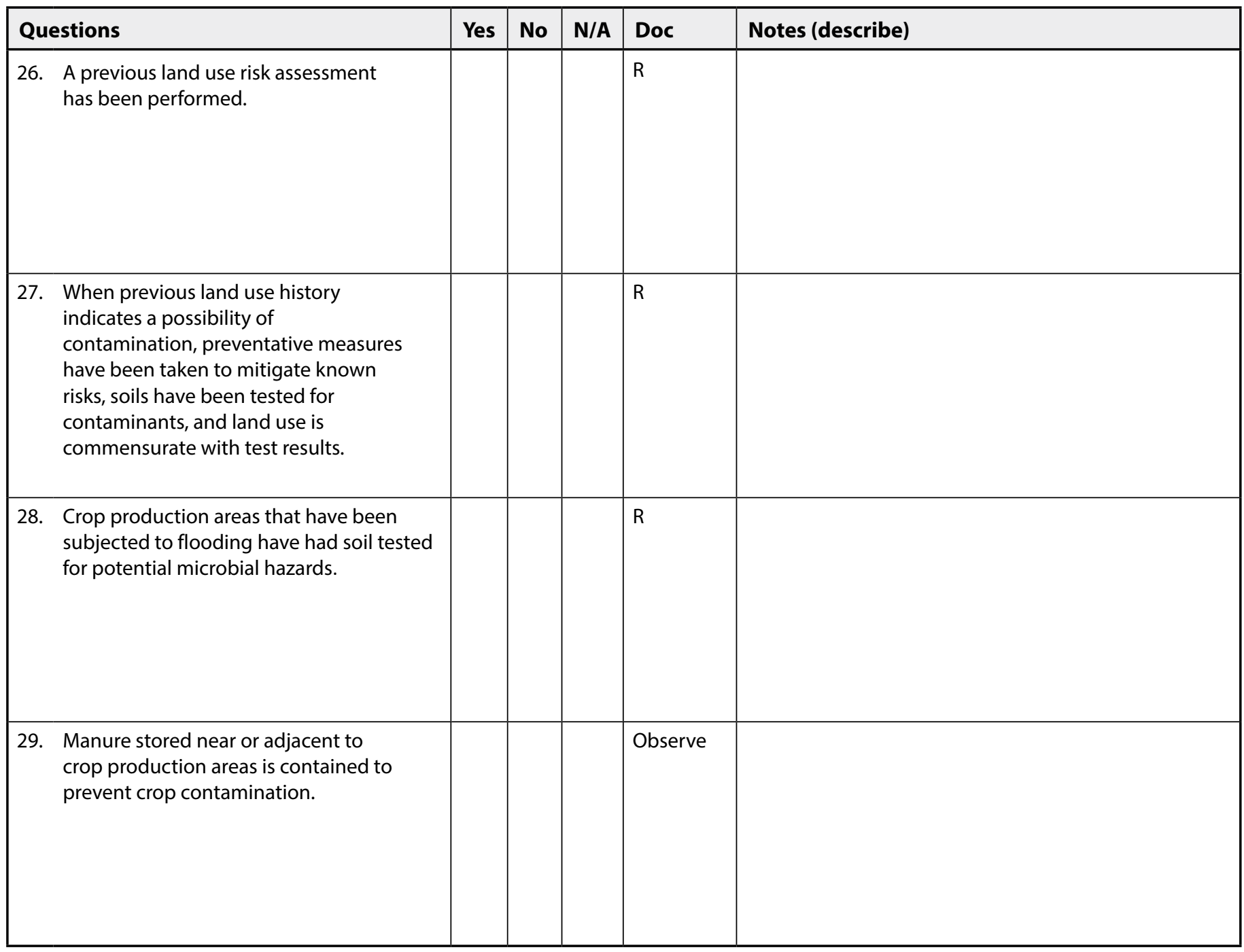




\section{Manure and Compost}

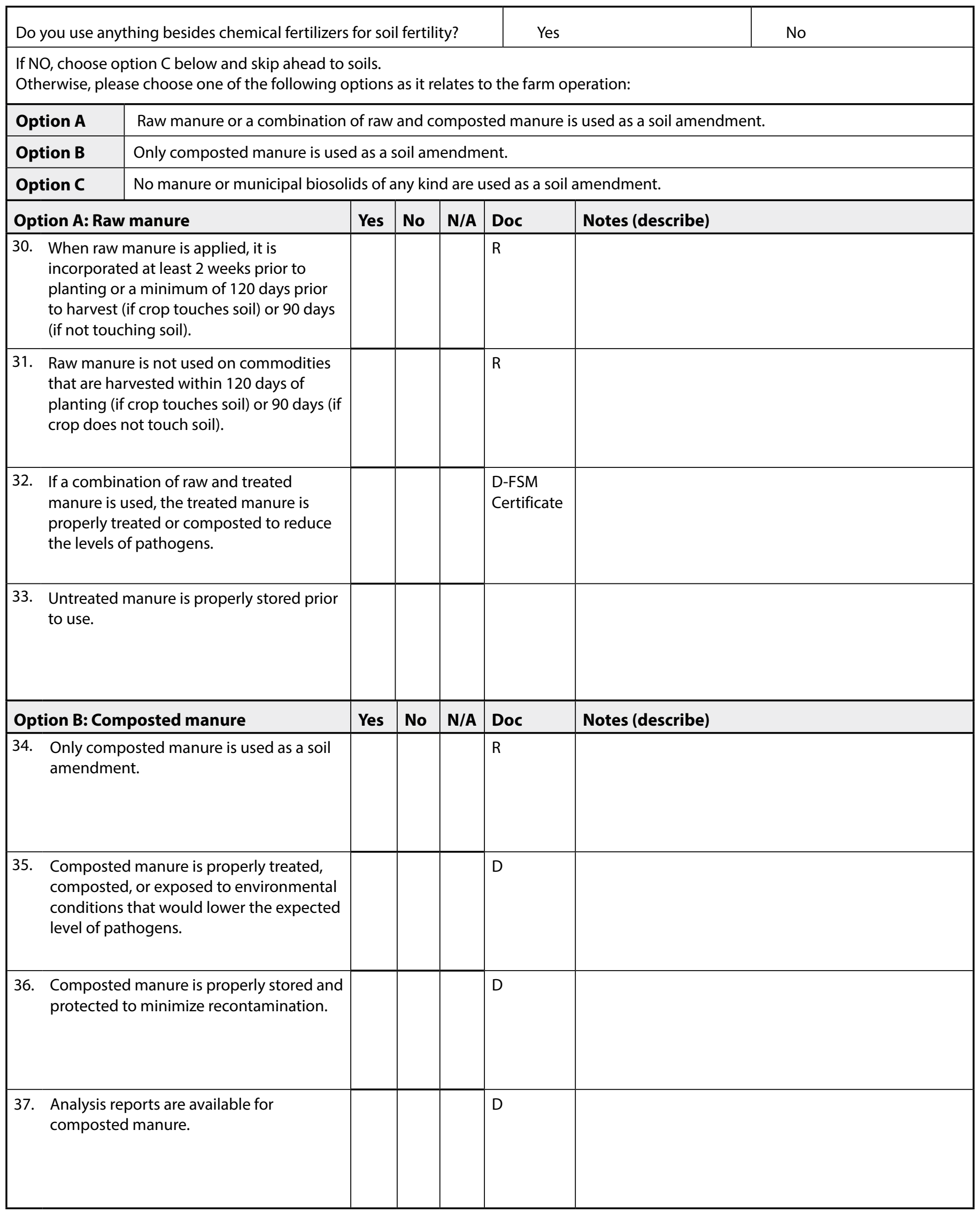




\section{Field Harvesting}

\begin{tabular}{|c|c|c|c|c|c|}
\hline Questions & Yes & No & N/A & Doc & Notes (describe) \\
\hline $\begin{array}{l}\text { 38. All harvest containers are single use or } \\
\text { are cleaned and sanitized on a daily basis, } \\
\text { prior to use. }\end{array}$ & $\square$ & $\square$ & $\square$ & D-FSM & \\
\hline $\begin{array}{l}\text { 39. All harvest tools (machetes, knives) are } \\
\text { kept as clean as possible and disinfected } \\
\text { on a regular basis. }\end{array}$ & $\square$ & 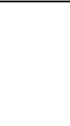 & $\square$ & & \\
\hline $\begin{array}{l}\text { 40. Damaged containers are properly } \\
\text { disposed of or repaired. }\end{array}$ & $\square$ & 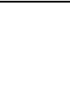 & 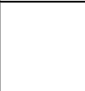 & & \\
\hline $\begin{array}{l}\text { 41. Standard operating procedures or } \\
\text { guidelines exist on what measures } \\
\text { should be taken in the case of product } \\
\text { contamination by chemicals, petroleum, } \\
\text { glass breakage, pesticides, or other } \\
\text { contaminating factors. }\end{array}$ & $\square$ & $\square$ & $\square$ & P-FSM & \\
\hline $\begin{array}{l}\text { 42. Measures are taken during harvest to } \\
\text { inspect the field for and remove foreign } \\
\text { objects such as glass, metal, rocks, dead } \\
\text { animals, or other dangerous and toxic } \\
\text { items that can contaminate the product. }\end{array}$ & $\square$ & $\square$ & $\square$ & P-FSM & \\
\hline $\begin{array}{l}\text { 43. Harvesting containers are not used for } \\
\text { carrying or storing nonproduce items } \\
\text { during harvest season. }\end{array}$ & $\square$ & $\square$ & 7 & D-FSM & \\
\hline $\begin{array}{l}\text { 44. Efforts (such as not stacking buckets) } \\
\text { have been made to remove excessive dirt } \\
\text { and mud from product and containers } \\
\text { during harvest. }\end{array}$ & $\square$ & $\square$ & $\square$ & & \\
\hline $\begin{array}{l}\text { 45. Remove or prevent the harvest of any } \\
\text { potentially contaminated produce if } \\
\text { signs of animal intrusion are detected } \\
\text { (e.g., droppings, chew marks). }\end{array}$ & $\square$ & $\square$ & $\square$ & & \\
\hline
\end{tabular}




\section{Washing and Packing}

\begin{tabular}{|c|c|c|c|c|c|}
\hline Questions & Yes & No & N/A & Doc & Notes (describe) \\
\hline $\begin{array}{l}\text { 46. All harvested product is stored } \\
\text { and handled to reduce possible } \\
\text { contamination. }\end{array}$ & L & $\square$ & $\square$ & & \\
\hline $\begin{array}{l}\text { 47. Source water used in packing operation } \\
\text { is potable. }\end{array}$ & $\square$ & $\square$ & $\square$ & & \\
\hline $\begin{array}{l}\text { 48. Produce wash water is sufficiently } \\
\text { treated to reduce microbial } \\
\text { contamination and, when necessary, } \mathrm{pH} \\
\text { and strength levels monitored. }\end{array}$ & $\Gamma$ & $\square$ & $\square$ & & \\
\hline $\begin{array}{l}\text { 49. Wash tanks are cleaned and sanitized on } \\
\text { a scheduled basis. }\end{array}$ & $\square$ & $\square$ & $a$ & $D \& R$ & \\
\hline $\begin{array}{l}\text { 50. Food contact surfaces are clean, } \\
\text { sanitized, and in good condition, and } \\
\text { cleaning logs are maintained. }\end{array}$ & $\square$ & $\square$ & $\square$ & D-FSM R & \\
\hline $\begin{array}{l}\text { 51. Any water used for cooling or ice is } \\
\text { potable, and ice is manufactured, } \\
\text { transported, and stored under sanitary } \\
\text { conditions. }\end{array}$ & $\square$ & $\square$ & $\square$ & $R$ & \\
\hline
\end{tabular}




\section{General Housekeeping in Packing House/Farm Stand/Storage Facility}

\begin{tabular}{|c|c|c|c|c|c|}
\hline Questions & Yes & No & N/A & Doc & Notes (describe) \\
\hline $\begin{array}{l}\text { 52. All facilities, equipment, and food } \\
\text { contact surfaces are thoroughly cleaned } \\
\text { and then sanitized prior to first use and } \\
\text { then once a day during use or more } \\
\text { often if needed. }\end{array}$ & $\square$ & $\square$ & $\square$ & & \\
\hline $\begin{array}{l}\text { 53. Chemicals (pesticides, paints, oil, } \\
\text { gasoline) not approved for use on } \\
\text { product are stored separately from } \\
\text { packing area. }\end{array}$ & $\square$ & $\square$ & 7 & $\begin{array}{l}\text { D-FSM } \\
\text { Observe }\end{array}$ & \\
\hline $\begin{array}{l}\text { 54. Area near packing facility is reasonably } \\
\text { free of litter and debris. }\end{array}$ & $\square$ & 1 & & Observe & \\
\hline $\begin{array}{l}\text { 55. Area near packing facility is reasonably } \\
\text { free of standing water. }\end{array}$ & $\square$ & $\square$ & 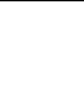 & Observe & \\
\hline $\begin{array}{l}\text { 56. Shoes or boots worn in animal } \\
\text { production areas are not worn } \\
\text { in packing house to avoid cross- } \\
\text { contamination. }\end{array}$ & $\square$ & 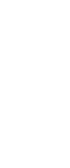 & $\square$ & & \\
\hline $\begin{array}{l}\text { 57. Outside garbage cans and dumpsters } \\
\text { are closed or located away from packing } \\
\text { facility entrances, and area around such } \\
\text { sites is reasonably clean. }\end{array}$ & $\square$ & $\square$ & & Observe & \\
\hline $\begin{array}{l}\text { 58. Packing facility interior is clean and } \\
\text { maintained in an orderly manner, } \\
\text { especially objects above food handling } \\
\text { area (fans, pipes, ducts, beams). }\end{array}$ & $\square$ & 7 & 1 & Observe & \\
\hline $\begin{array}{l}\text { 59. Wastewater is disposed of away from } \\
\text { food handling area by use of barriers, } \\
\text { drains, or sufficient distance. }\end{array}$ & $\square$ & 7 & 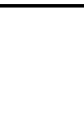 & & \\
\hline $\begin{array}{l}\text { 60. Product that is spilled or comes into } \\
\text { contact with the floor is disposed of } \\
\text { immediately. }\end{array}$ & $\square$ & $\square$ & $\square$ & P-FSM & \\
\hline
\end{tabular}




\section{Product Containers and Storage}

\begin{tabular}{|c|c|c|c|c|c|}
\hline Questions & Yes & No & N/A & Doc & Notes (describe) \\
\hline $\begin{array}{l}\text { 61. Only new, clean, or sanitized containers } \\
\text { are used for packing product. }\end{array}$ & $\square$ & $\square$ & $\square$ & & \\
\hline $\begin{array}{l}\text { 62. Empty packing containers (trays, } \\
\text { baskets, boxes) are properly stored off } \\
\text { the ground, covered, and sufficiently } \\
\text { sealed to be protected from } \\
\text { contamination (birds, rodents, and } \\
\text { other pests, etc.). }\end{array}$ & $\square$ & $\square$ & $\square$ & D-FSM & \\
\hline $\begin{array}{l}\text { 63. Containers, pallets, boxes, bins, bags, } \\
\text { and all storage areas are cleaned before } \\
\text { use and in good condition. Damaged } \\
\text { containers are discarded. }\end{array}$ & $\Gamma$ & $\square$ & $\square$ & & \\
\hline $\begin{array}{l}\text { 64. Ensure refrigeration equipment is } \\
\text { working properly. Measure and record } \\
\text { temperature at least once daily. }\end{array}$ & $\square$ & 1 & $\square$ & & \\
\hline $\begin{array}{l}\text { 65. Storage facilities including coolers } \\
\text { and farm stand are inspected (for } \\
\text { leaking air conditioner, nests) and } \\
\text { cleaned prior to loading with product. } \\
\text { (no litter, standing water, evidence of } \\
\text { pests, etc.). Records are maintained. }\end{array}$ & $\square$ & 1 & $\square$ & D-R & \\
\hline
\end{tabular}




\section{Transportation and Loading}

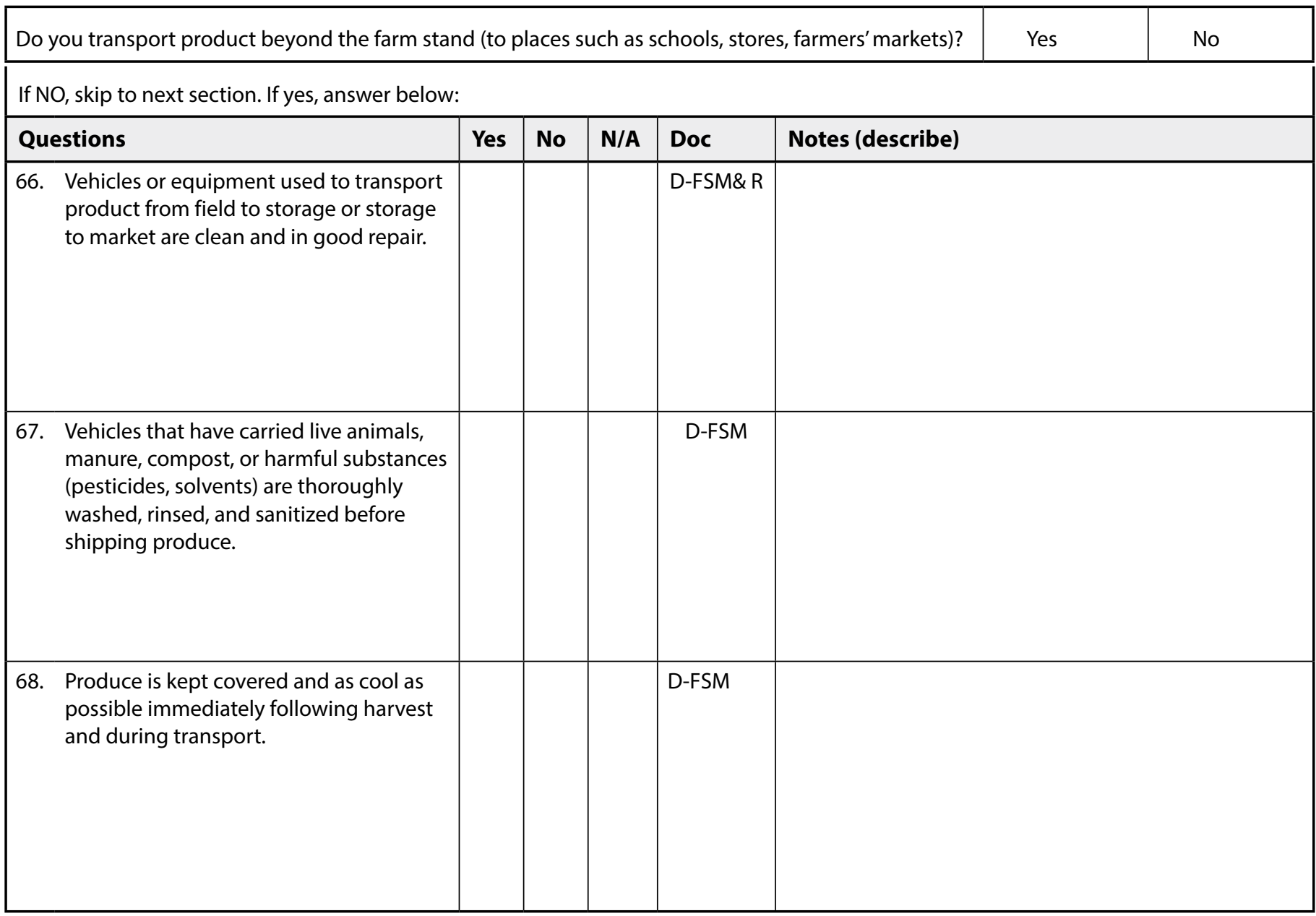




\section{Health and Hygiene}

\begin{tabular}{|c|c|c|c|c|}
\hline Questions & \multirow{2}{*}{$\frac{\text { Yes }}{\square}$} & \multirow{2}{*}{$\frac{\text { No }}{\square}$} & \multirow{2}{*}{$\frac{\text { Doc }}{R}$} & \multirow[t]{2}{*}{ Notes (describe) } \\
\hline $\begin{array}{l}\text { 69. Potable water is available to all workers } \\
\text { (fresh daily, covered). }\end{array}$ & & & & \\
\hline $\begin{array}{l}\text { 70. Training in proper sanitation, hygiene, } \\
\text { and heat illness prevention is provided } \\
\text { to all workers and is documented. }\end{array}$ & $\square$ & $\square$ & D-FSM \& R & \\
\hline $\begin{array}{l}\text { 71. Culturally appropriate and easily } \\
\text { understood signs are posted, instructing } \\
\text { employees to wash hands before } \\
\text { beginning or returning to work. }\end{array}$ & & & D-Sign & \\
\hline $\begin{array}{l}\text { 72. Employees and visitors are required } \\
\text { to follow good hygiene practices and } \\
\text { wash their hands before beginning or } \\
\text { returning to work and before applying } \\
\text { gloves (if used). }\end{array}$ & 5 & $\square$ & P-FSM & \\
\hline $\begin{array}{l}\text { 73. Workers and visitors are following good } \\
\text { hygiene and sanitation practices and } \\
\text { washing their hands before returning to } \\
\text { work. }\end{array}$ & $\square$ & 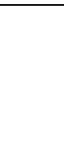 & Observe & \\
\hline $\begin{array}{l}\text { 74. A clean toilet with toilet paper and a } \\
\text { trash bin is available for all workers and } \\
\text { visitors. }\end{array}$ & $\Gamma$ & E & Observe & \\
\hline $\begin{array}{l}\text { 75. All toilet facilities are clean and serviced } \\
\text { on a scheduled basis, and cleaning is } \\
\text { documented. }\end{array}$ & $\square$ & 7 & D-FSM \& R & \\
\hline $\begin{array}{l}\text { 76. A hand-washing station (with potable } \\
\text { water, soap, single-use towels, and trash } \\
\text { bin) is clean and located near toilet. }\end{array}$ & 5 & $\square$ & Observe & \\
\hline $\begin{array}{l}\text { 77. Disposal of wastes from hand-washing } \\
\text { station does not cause unsanitary } \\
\text { conditions or contamination. }\end{array}$ & 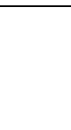 & $\square$ & & \\
\hline
\end{tabular}


Health and Hygiene, continued

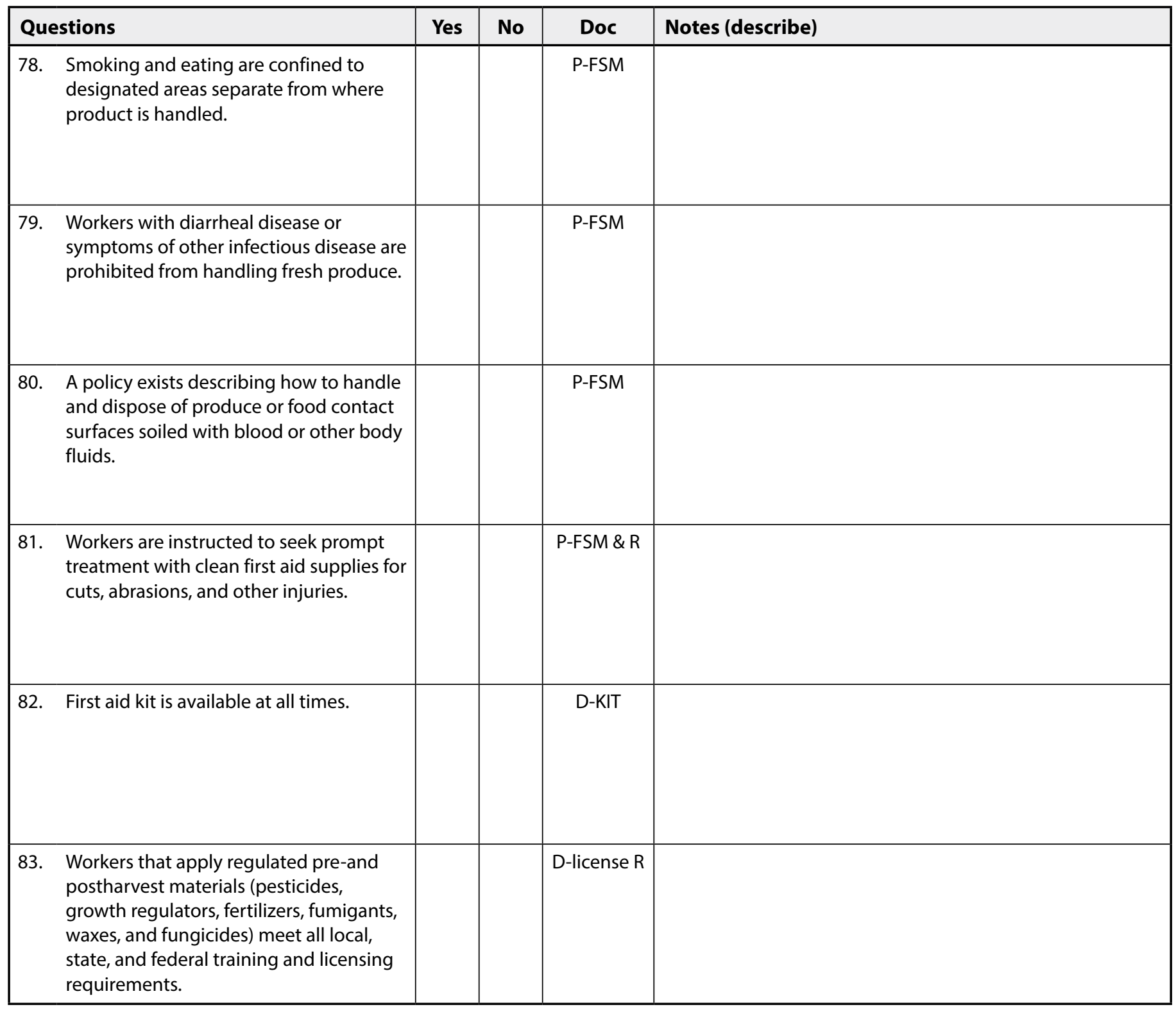




\section{Record-Keeping}

The following records are kept (as outlined in CDFA Small Farm Food Safety Guidelines):

\begin{tabular}{|c|c|c|c|c|}
\hline Questions & Yes & No & Doc & Notes (describe) \\
\hline $\begin{array}{l}\text { 84. Planting and harvest dates. Varieties, } \\
\text { suppliers, etc. }\end{array}$ & $\square$ & 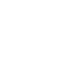 & $\mathrm{R}$ & \\
\hline $\begin{array}{l}\text { 85. Applications of fertilizer, pesticides, or } \\
\text { any other inputs. }\end{array}$ & - & 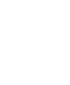 & $\mathrm{R}$ & \\
\hline 86. Water testing dates and results. & & $\square$ & $\mathrm{R}$ & \\
\hline $\begin{array}{l}\text { 87. Employee training: Type of training } \\
\text { (general safety, food safety, etc.), dates, } \\
\text { who was trained, follow-up training. }\end{array}$ & 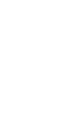 & 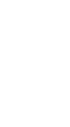 & $\mathrm{R}$ & \\
\hline $\begin{array}{l}\text { 88. Animal entry: Dates when checked or } \\
\text { observed, type(s) of animal signs, what } \\
\text { action(s) you took to try to solve or } \\
\text { mitigate the problem. }\end{array}$ & 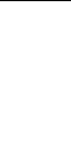 & $\Gamma$ & $\mathrm{R}$ & \\
\hline $\begin{array}{l}\text { 89. Equipment maintenance: Dates, type of } \\
\text { maintenance, which piece of equipment } \\
\text { (including refrigeration and temperature } \\
\text { of storage rooms), cleaning schedule. }\end{array}$ & & 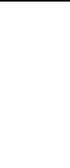 & $\mathrm{R}$ & \\
\hline $\begin{array}{l}\text { 90. Sanitation schedule of harvest } \\
\text { implements and harvest containers. }\end{array}$ & 2 & 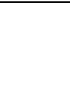 & $R$ & \\
\hline $\begin{array}{l}\text { 91. Cleaning schedule for processing and } \\
\text { storage facilities. }\end{array}$ & & 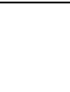 & $\mathrm{R}$ & \\
\hline $\begin{array}{l}\text { 92. Pest control program in processing and } \\
\text { storage facilities: Who does the program, } \\
\text { treatment or trapping, and dates. }\end{array}$ & $\square$ & $\square$ & $R$ & \\
\hline $\begin{array}{l}\text { 93. Marketing: Dates of farmers' markets or } \\
\text { other marketing options. }\end{array}$ & 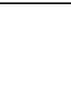 & 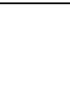 & $\mathrm{R}$ & \\
\hline $\begin{array}{l}\text { 94. Labeling: Package identification } \\
\text { according to requirements outlined for } \\
\text { your scale of operation. }\end{array}$ & $\square$ & $\square$ & $\mathrm{R}$ & \\
\hline
\end{tabular}




\section{APPENDIX 2. FOOD SAFETY POLICY}

\section{Hand-washing and hygiene}

- Have clean and cut nails.

- Hands must be washed before beginning or returning to work and after the following activities: using the restroom, smoking or tobacco use, taking breaks, eating, handling trash containers, handling money, coughing and sneezing, shoveling manure or compost, and after applying sunscreen.

- Hands are washed with soap and water for $20 \mathrm{sec}$ onds and dried with disposable towels.

\section{Field hygiene}

- Never spit, eat, smoke, drink, or chew gum in the field or packing area.

- Use garbage cans for trash.

- Always use designated toilet facilities and wash hands afterward.

- Tie hair back and keep all glass containers away from field.

- Avoid using product containers (harvest bins) for personal use.

- Return tools after use.

\section{Hydration}

- To avoid heat exhaustion, drink lots of water frequently (2 quarts per person per day, especially when hot).

- Take breaks in the shade when necessary.

\section{IIIness and injury prevention}

- Know where the first aid kit is located.

- Anyone suffering from a contagious disease or temporary illness (diarrhea, nausea, vomiting, excessive sneezing, or runny nose) is advised to stay at home.
- Anyone who gets a cut or has a nosebleed while working must stop immediately; contact your supervisor, and have it treated.

- Wounds are immediately cleaned, treated, bandaged, and covered with rubber glove(s) as soon as possible.

- Discard any product that is contaminated with bodily fluids, and disinfect any tools, surfaces, or containers immediately.

- Report and record all accidents, illnesses, or injuries immediately.

\section{Glove use}

- If using gloves, wash hands for 20 seconds with water and dry thoroughly before and after gloves are removed; replace gloves when ripped or worn out.

\section{Designated areas}

- Only eat, smoke, drink, and chew gum in areas designated for these activities.

- Put all personal belongings in designated area.

\section{Good agricultural practices}

- Follow all standard operating procedures outlined in the farm manual related to pre- and postharvest checklists related to cleaning and sanitizing, good hygienic practices, and avoidance of cross-contamination.

\section{Security}

- Report any strange or suspicious activity or chemicals in or around the facility. 


\section{APPENDIX 3. FOOD SAFETY RECORD-KEEPING FORMS}

\section{UC Berkeley/UCCE Food Safety for Small Farms Program}

\section{Monthly Pesticide Use Record}

Name of operation:

Each time you apply a pesticide, please record it on the pesticide use report available online at: https://www.cdpr.ca.gov/docs/pur/forms/ dpr-pml-183.pdf. (A copy is included in the Food Safety binder.)

\section{Fertilizer Input Use Record}

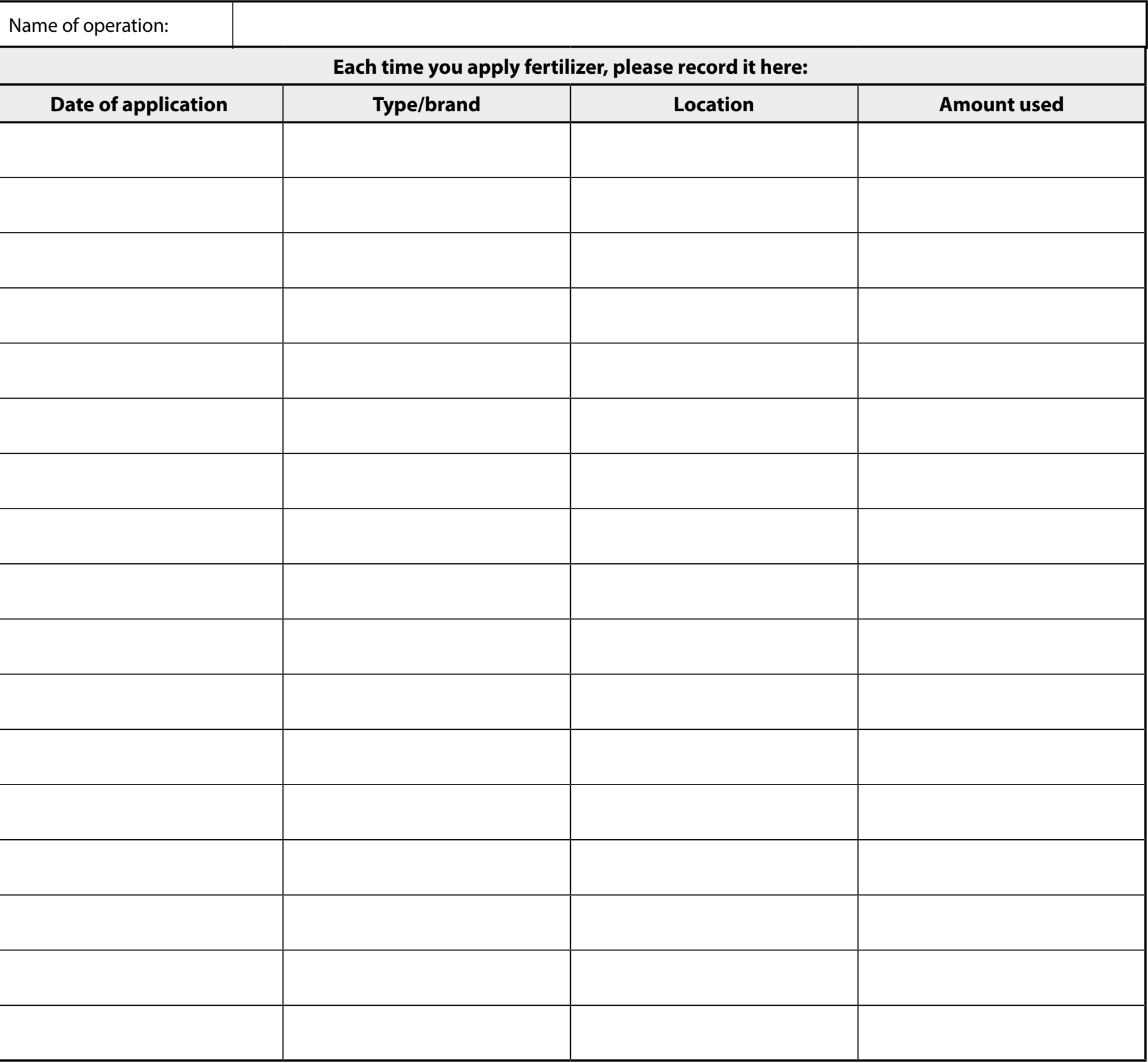


Toilet and Hand-Washing Maintenance Record

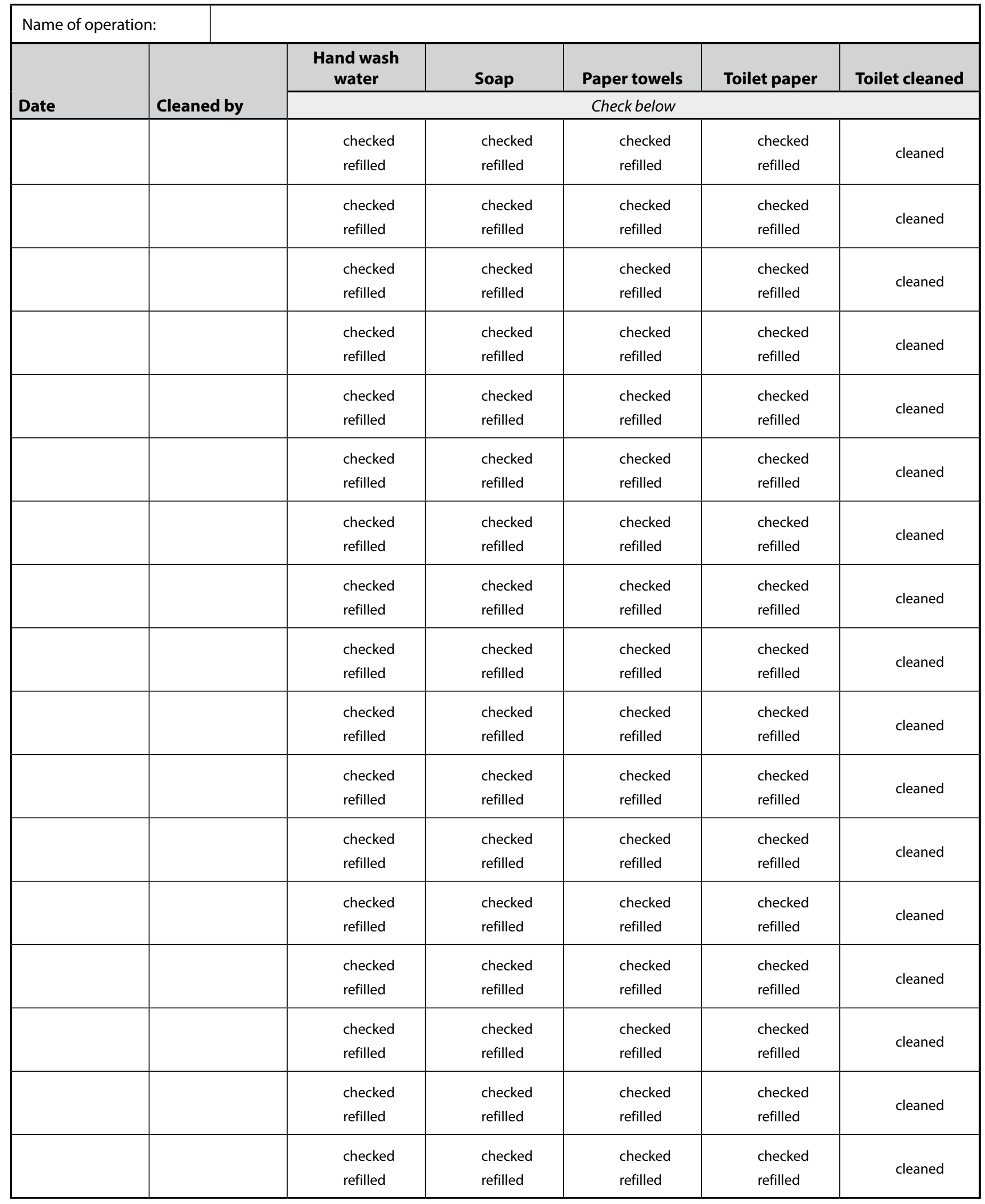


Preharvest Assessment and Farm Cleaning Record

\begin{tabular}{|c|c|c|c|c|c|c|}
\hline & & $\begin{array}{l}\text { Preharvest } \\
\text { assessment }\end{array}$ & $\begin{array}{l}\text { Harvest } \\
\text { container }\end{array}$ & Washing bin & $\begin{array}{c}\text { Storage/ } \\
\text { packing shed }\end{array}$ & Truck \\
\hline Date & Cleaned by & \multicolumn{5}{|c|}{ Mark with X } \\
\hline & & & & & & \\
\hline & & & & & & \\
\hline & & & & & & \\
\hline & & & & & & \\
\hline & & & & & & \\
\hline & & & & & & \\
\hline & & & & & & \\
\hline & & & & & & \\
\hline & & & & & & \\
\hline & & & & & & \\
\hline & & & & & & \\
\hline & & & & & & \\
\hline & & & & & & \\
\hline & & & & & & \\
\hline & & & & & & \\
\hline & & & & & & \\
\hline & & & & & & \\
\hline & & & & & & \\
\hline & & & & & & \\
\hline & & & & & & \\
\hline & & & & & & \\
\hline & & & & & & \\
\hline
\end{tabular}




\section{Worker Training and Instruction Record}

Name of farm:

Training material (please see Food Safety Manual for content of worker training).

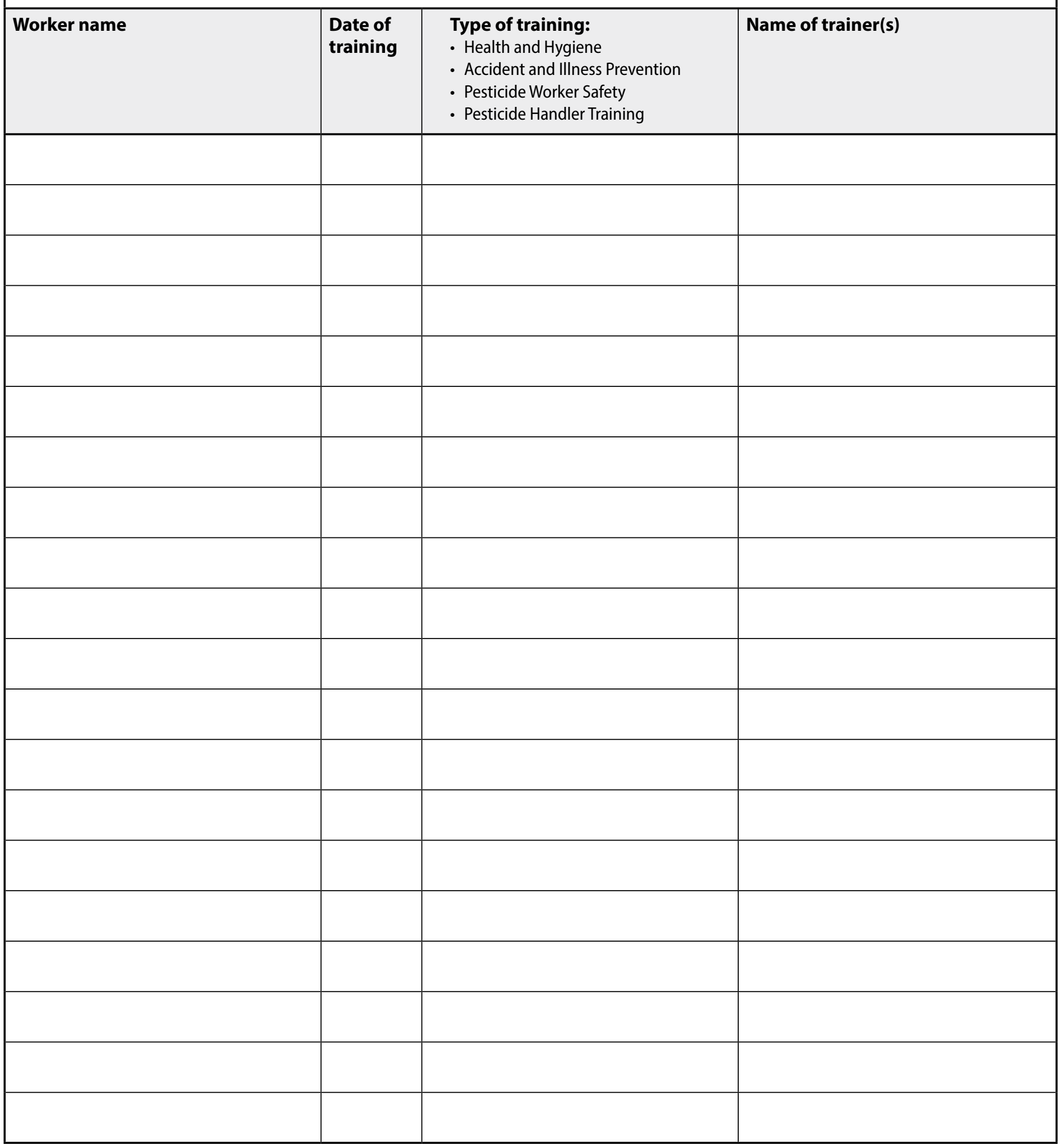




\section{Traceback Record}

Name of operation:

Record any crop you sell at and beyond your farm stand here*

\begin{tabular}{|c|c|c|c|c|c|c|c|}
\hline $\begin{array}{c}\text { Date } \\
\text { harvested }\end{array}$ & $\begin{array}{c}\text { Date } \\
\text { shipped }\end{array}$ & Crop & $\begin{array}{c}\text { Production } \\
\text { area/field }\end{array}$ & \# Boxes & $\begin{array}{l}\text { Picked up/ } \\
\text { delivered by }\end{array}$ & Sent to & Total price \\
\hline & & & & & & & \\
\hline & & & & & & & \\
\hline & & & & & & & \\
\hline & & & & & & & \\
\hline & & & & & & & \\
\hline & & & & & & & \\
\hline & & & & & & & \\
\hline & & & & & & & \\
\hline & & & & & & & \\
\hline & & & & & & & \\
\hline & & & & & & & \\
\hline & & & & & & & \\
\hline & & & & & & & \\
\hline & & & & & & & \\
\hline & & & & & & & \\
\hline & & & & & & & \\
\hline & & & & & & & \\
\hline & & & & & & & \\
\hline & & & & & & & \\
\hline & & & & & & & \\
\hline & & & & & & & \\
\hline
\end{tabular}




\section{Pest/Rodent/Wildlife Control Board}

Name of operation:

Monitor and record all signs of pests at the farm, actions taken, and results.

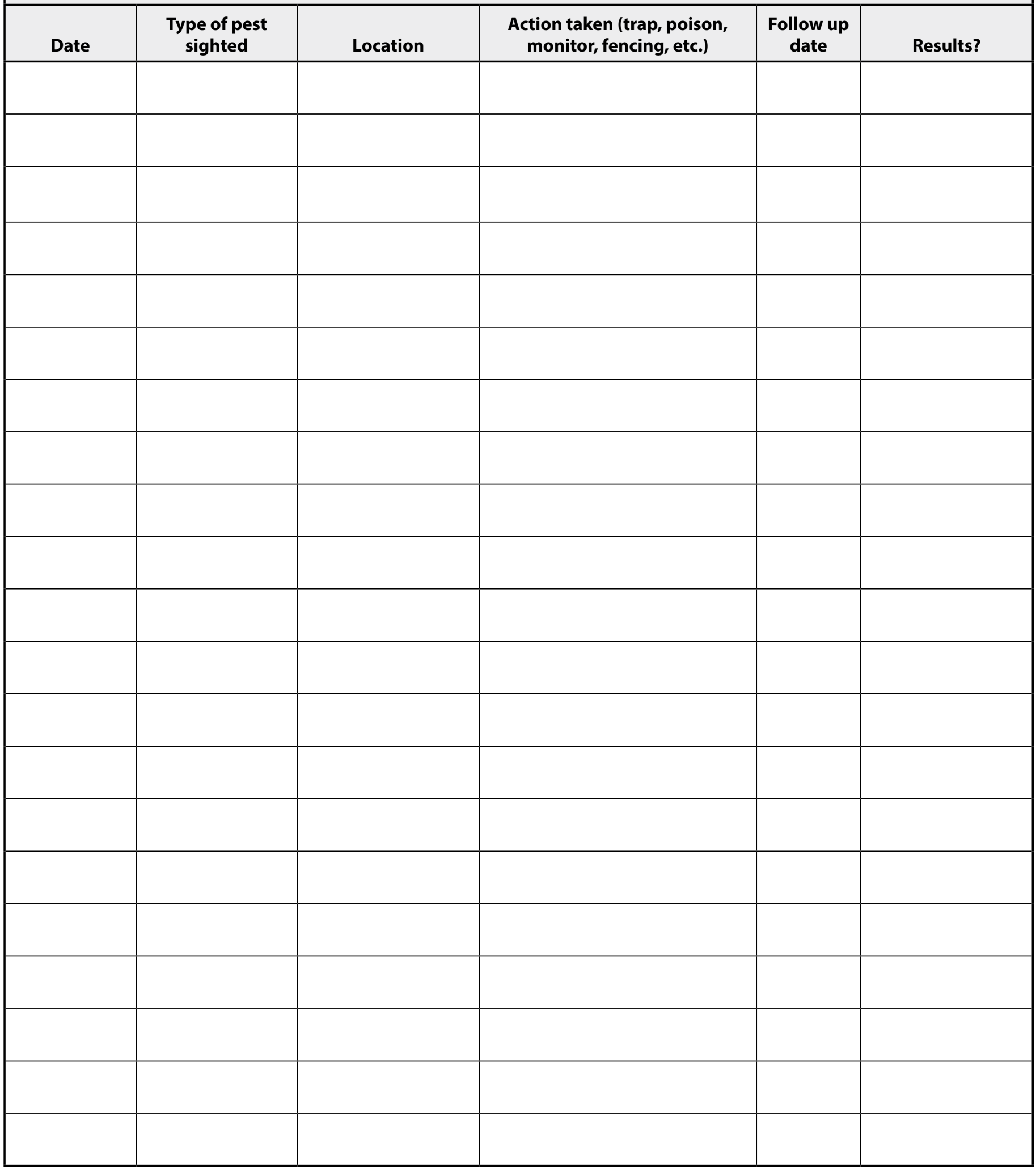




\section{Injury and IIIness Reporting Record}

Name of operation:

Record any occurrence of illness/injury at the farm and action taken.

Discard any soiled produce and sanitize tools and equipment.

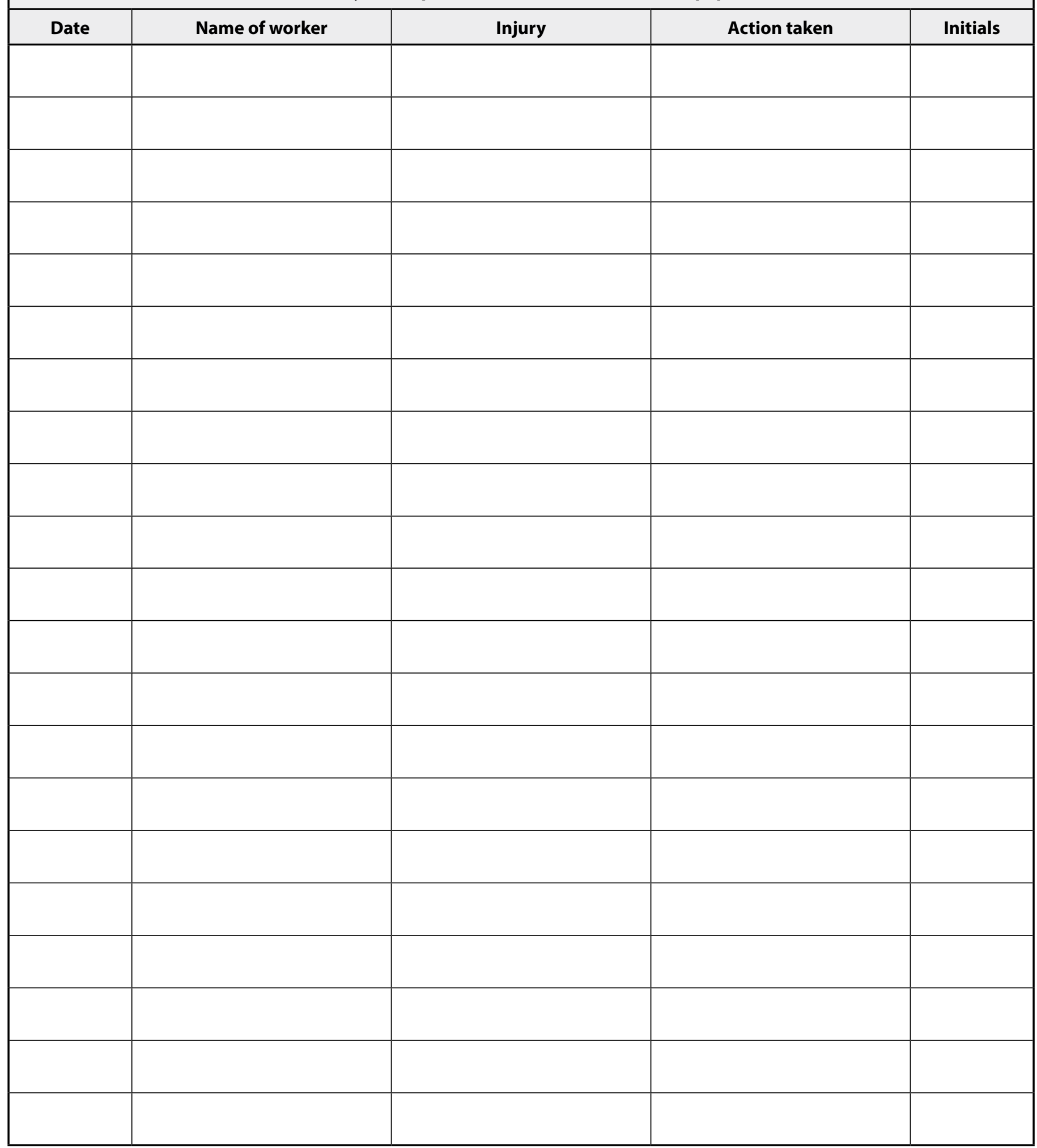




\section{Contamination Response Record}

Name of operation:

In the event of a chemical spill or runoff, document the type of contamination and action taken.

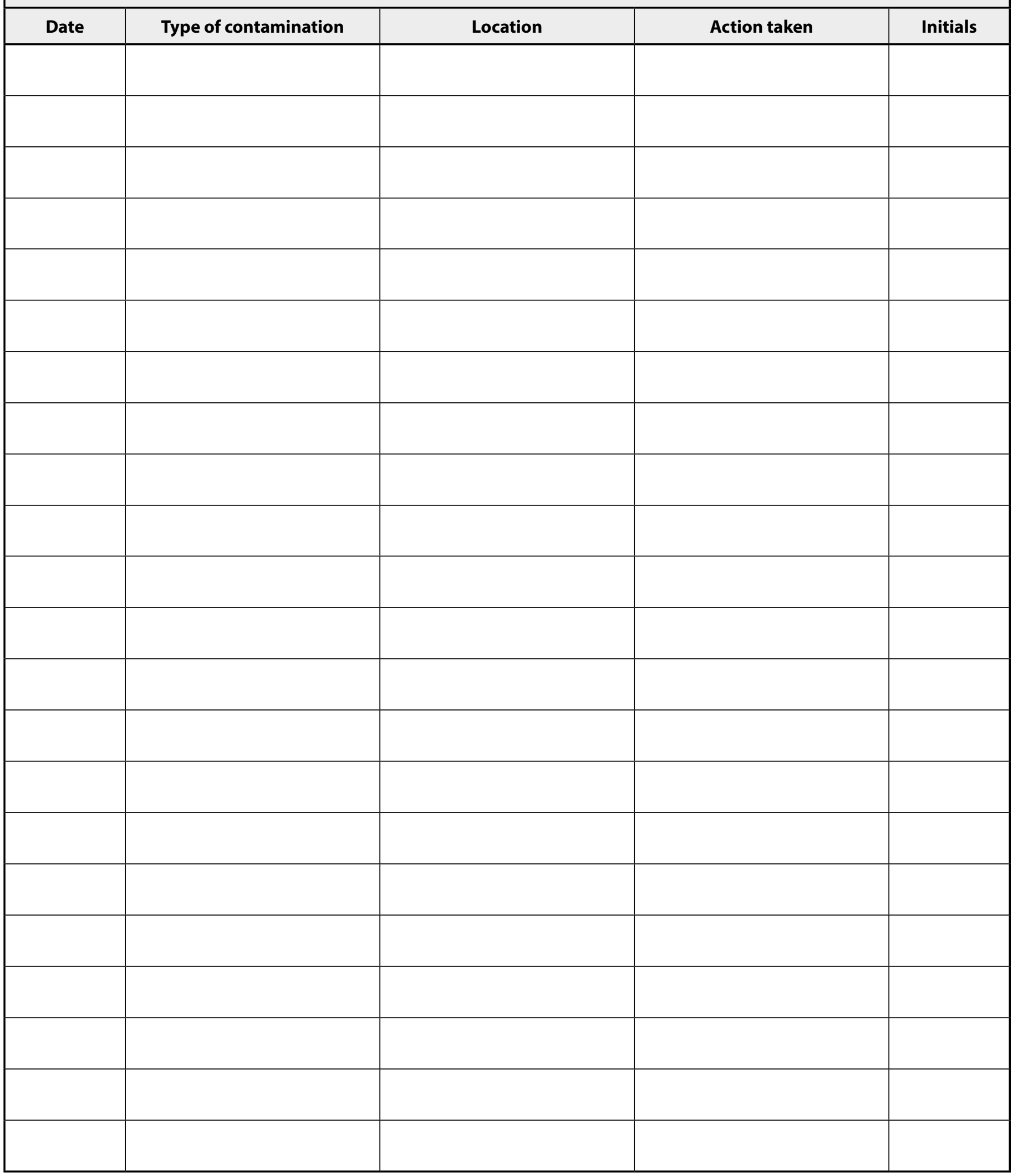




\section{Visitor Log}

\begin{tabular}{|c|c|c|c|c|c|}
\hline Name of o & & & & & \\
\hline All vi & are requ & d to compl & Safety policies. Please re & icy, and sigr & below. \\
\hline Date & $\begin{array}{l}\text { Enter } \\
\text { time }\end{array}$ & Exit time & Visitor name/company & $\begin{array}{l}\text { Employee } \\
\text { initials }\end{array}$ & $\begin{array}{c}\text { Reviewed } \\
\text { hygiene } \\
\text { policy }(\sqrt{ })\end{array}$ \\
\hline & & & & & \\
\hline & & & & & \\
\hline & & & & & \\
\hline & & & & & \\
\hline & & & & & \\
\hline & & & & & \\
\hline & & & & & \\
\hline & & & & & \\
\hline & & & & & \\
\hline & & & & & \\
\hline & & & & & \\
\hline & & & & & \\
\hline & & & & & \\
\hline & & & & & \\
\hline & & & & & \\
\hline & & & & & \\
\hline & & & & & \\
\hline & & & & & \\
\hline & & & & & \\
\hline & & & & & 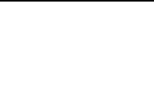 \\
\hline & & & & & 7 \\
\hline & & & & & 7 \\
\hline
\end{tabular}




\section{APPENDIX 4. ON-FARM FOOD SAFETY ASSESSMENT}

\section{Daily Check List}

Preharvest

1. Are toilet and wash facilities properly located, clean, and stocked with toilet paper, wash water, soap, and paper towels?

2. Is drinking water and shade available to all workers?

3. Are harvest containers available, clean, well located, and protected?

4. Is harvest, washing and packing equipment, and area clean, sanitized, and in good condition?

5. Are shade or other precool measures in place?

6. Is there evidence of animal feces, dead animals, animal crop damage, or other physical contamination in the crop area that needs to be isolated for "no harvest"?

7. Are there other notable sources of contamination such as dump sites, fuels or chemicals, manure, burning debris, or water runoff that may affect food safety?

8. Is transportation equipment clean and available with protective covering?

9. Are all signs posted to a) instruct workers and visitors to wash hands before and after handling food, harvesting, eating, and smoking and $b$ ) indicate that wash water is not potable?

10. Have all new workers and visitors been trained in proper hygiene practices and their training been recorded?

11. Have all traps or pest control measures been checked and any animals disposed?

\section{End of day}

12. Are harvest buckets and washing bins cleaned and sanitized?

13. Has the drinking water container been cleaned and sanitized?

14. Is the packing area cleaned, sanitized, and free of debris?

15. Is all packaging stored in a safe and secure location?

16. Are all chemicals stored in a safe, locked storage cabinet away from the packing area?

17. Has all personal protective equipment (PPE) been cleaned?

18. Have all garbage cans been emptied?

19. Do any supplies need to be restocked (hand gloves, cleansers, sanitizers, toilet or handwashing supplies, first aid kit, record-keeping sheets, signage)?

20. Have all activities been recorded in the food safety record-keeping forms? 


\section{ACKNOWLEDGMENTS}

Special thanks to Maurice Pitesky (University of California Cooperative Extension Specialist in Poultry Health and Food Safety Epidemiology), Eunice Kwon (Director of Community Engagement), and Yassi Eskandari (Policy Director) at the Sustainable Economies Law Center for their helpful contributions.

This publication was supported by the Beginning Farmer and Rancher Grant of the USDA-NIFA program, titled Growing Roots: Deepening Support for Diverse New Farmers and Ranchers in California, Grant \# 2015-70017-22868.

\section{FOR FURTHER INFORMATION}

To order or obtain ANR publications and other products, visit the ANR Communication Services online catalog at http://anrcatalog.ucanr.edu/ or phone 1-800-994-8849. Direct inquiries to

University of California

Agriculture and Natural Resources

Communication Services

2801 Second Street

Davis, CA 95618

Telephone 1-800-994-8849

E-mail: anrcatalog@ucanr.edu

(C)2020 The Regents of the University of California. This work is licensed under the Creative Commons Attribution-NonCommercialNoDerivatives 4.0 International License. To view a copy of this license, visit http://creativecommons.org/licenses/by-nc-nd/4.0/ or send a letter to Creative Commons, PO Box 1866, Mountain View, CA 94042, USA.

Publication 8660

ISBN-13: 978-1-62711-119-5

The University of California, Division of Agriculture and Natural Resources (UC ANR) prohibits discrimination against or harassment of any person in any of its programs or activities on the basis of race, color, national origin, religion, sex, gender, gender expression, gender identity, pregnancy (which includes pregnancy, childbirth, and medical conditions related to pregnancy or childbirth), physical or mental disability, medical condition (cancer-related or genetic characteristics), genetic information (including family medical history), ancestry, marital status, age, sexual orientation, citizenship, status as a protected veteran or service in the uniformed services (as defined by the Uniformed Services Employment and Reemployment Rights Act of 1994 [USERRA]), as well as state military and naval service.

UC ANR policy prohibits retaliation against any employee or person in any of its programs or activities for bringing a complaint of discrimination or harassment. UC ANR policy also prohibits retaliation against a person who assists someone with a complaint of discrimination or harassment, or participates in any manner in an investigation or resolution of a complaint of discrimination or harassment. Retaliation includes threats, intimidation, reprisals, and/or adverse actions related to any of its programs or activities.

UC ANR is an Equal Opportunity/Affirmative Action Employer. All qualified applicants will receive consideration for employment and/or participation in any of its programs or activities without regard to race, color, religion, sex, national origin, disability, age or protected veteran status.

University policy is intended to be consistent with the provisions of applicable State and Federal laws.

Inquiries regarding the University's equal employment opportunity policies may be directed to: Affirmative Action Contact and Title IX Officer, University of California, Agriculture and Natural Resources, 2801 Second Street, Davis, CA 95618, (530) 750-1397. Email: titleixdiscrimination@ucanr.edu. Website: http://ucanr.edu/sites/ anrstaff/Diversity/Affirmative_Action/.

To simplify information, trade names of products have been used. No endorsement of named or illustrated products is intended, nor is criticism implied of similar products that are not mentioned or illustrated.

An electronic copy of this publication can be found at the ANR Communication Services catalog website, http://anrcatalog.ucanr.edu/.

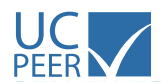

This publication has been anonymously peer reviewed for technical accuracy by University of California

REVIEWED scientists and other qualified professionals. This review process was managed by ANR Associate Editor for Food and Nutrition Karina Diaz-Rios.

web-12/20-LR/SO 